IZA DP No. 7098

Cross-Border Spillover:

U.S. Gun Laws and Violence in Mexico

Arindrajit Dube

Oeindrila Dube

Omar García-Ponce

December 2012 


\title{
Cross-Border Spillover: U.S. Gun Laws and Violence in Mexico
}

\author{
Arindrajit Dube \\ University of Massachusetts Amherst \\ and IZA
}

Oeindrila Dube

New York University

Omar García-Ponce

New York University

\section{Discussion Paper No. 7098 \\ December 2012}

\author{
IZA \\ P.O. Box 7240 \\ 53072 Bonn \\ Germany \\ Phone: +49-228-3894-0 \\ Fax: +49-228-3894-180 \\ E-mail: iza@iza.org
}

Any opinions expressed here are those of the author(s) and not those of IZA. Research published in this series may include views on policy, but the institute itself takes no institutional policy positions. The IZA research network is committed to the IZA Guiding Principles of Research Integrity.

The Institute for the Study of Labor (IZA) in Bonn is a local and virtual international research center and a place of communication between science, politics and business. IZA is an independent nonprofit organization supported by Deutsche Post Foundation. The center is associated with the University of Bonn and offers a stimulating research environment through its international network, workshops and conferences, data service, project support, research visits and doctoral program. IZA engages in (i) original and internationally competitive research in all fields of labor economics, (ii) development of policy concepts, and (iii) dissemination of research results and concepts to the interested public.

IZA Discussion Papers often represent preliminary work and are circulated to encourage discussion. Citation of such a paper should account for its provisional character. A revised version may be available directly from the author. 


\section{ABSTRACT}

\section{Cross-Border Spillover: U.S. Gun Laws and Violence in Mexico*}

To what extent, and under what conditions, does access to arms fuel violent crime? To answer this question, we exploit a unique natural experiment: the 2004 expiration of the U.S. Federal Assault Weapons Ban exerted a spillover on gun supply in Mexican municipios near Texas, Arizona and New Mexico, but not near California, which retained a pre-existing statelevel ban. We find first that Mexican municipios located closer to the non-California border states experienced differential increases in homicides, gun-related homicides and crime gun seizures in the post-2004 period. Second, the magnitude of this effect is contingent on political factors related to Mexico's democratic transition. Killings increased substantially more in municipios where local elections had become more competitive prior to 2004, with the largest differentials emerging in high narco-trafficking areas. Our findings are consistent with the notion that political competition undermined informal agreements between drug cartels and entrenched local governments, highlighting the role of political instability in mediating the gun-crime relationship.

JEL Classification: K14, D72, D73

Keywords: gun control, violence, informal employment, cross-border spillover, cartels

Corresponding author:

Arindrajit Dube

Department of Economics

University of Massachusetts Amherst

1030 Thompson Hall

Amherst, MA 01003

USA

E-mail: adube@econs.umass.edu

\footnotetext{
* We are especially grateful to Sanford Gordon for numerous discussions and suggestions, and also thank Joshua Angrist, Eli Berman, Michael Clemens, William Easterly, Jon Eguia, Macartan Humphreys, Brian Knight, David Laitin, John Lott, Jens Ludwig, Sendhil Mullainathan, Emily Owens, Debraj Ray, Peter Rosendorff, Alexandra Scacco, Jake Shapiro and David Stasavage as well as seminar participants at the Stanford Conference on Mexican Security, NBER Crime Working Group, Columbia CSDS, IAE Conflict Concentration, ESOP Political Economy of Conflict Conference, LACEACrime, NYU, Universidad Javeriana, and El Colegio de México CEE for providing useful comments.
} 


\section{Introduction}

Does access to arms promote violent crime? And if so, under what conditions? Previous work has addressed the first question, predominantly by analyzing how local gun laws affect homicide rates in jurisdictions within the United States. Yet, this approach faces the shortcoming that regulations may be passed in response to local criminality, instead of causing changes in crime. Moreover, the literature has ignored the idea that gun supply may induce larger effects on violence depending on the degree of political instability, which affects the organizational structure of criminal syndicates and their incentives to use weapons. Thus, past studies face flaws in their design and have been narrow in scope for neglecting the role of political conditions.

This paper addresses both the methodological and substantive gaps within the literature. We do this by exploiting a unique natural experiment that enables us to examine how an exogenous change in access to arms affected violent crime in Mexico over 2002-2006. We focus specifically on the 2004 expiration of the U.S. Federal Assault Weapons Ban (FAWB), which lifted the prohibition on domestic sales of military-style firearms in America, and use the resultant cross-border spillover on gun supply to identify effects on homicides in Mexico.

We posit that the FAWB expiration served as an important shock to the supply of assault weapons in Mexico, given the extent of gun trafficking across these two nations. ${ }^{1}$ Two additional features of the legislation enable us to develop a credible empirical strategy. The timing of the expiration was pre-determined by a 10-year sunset provision in the original 1994 law banning assault weapons, which ensures that it did not arise in response to violence in Mexico. In addition, the policy did not affect all U.S. states equally: some -including California (CA) - retained their own state-level bans on assault weapons, while others - including Texas (TX), Arizona (AZ) and New Mexico (NM) — had no equivalent state-level laws. The lifting of the federal ban thus made it plausibly easier to obtain assault weapons in Mexican locations closer to ports of entry into this latter group of states, providing geographic variation across municipios in resultant arms flows.

Given these features, in the first part of the paper, we use a difference-in-differences type strategy to examine whether violence increased disproportionately in Mexican municipios located closer to entry ports in AZ, NM and TX, versus closer to CA, after 2004. We find substantial increases in homicides as well as homicides tied specifically to guns. Our estimates indicate that homicides rose by $60 \%$ more in municipios at the non-California entry ports, as compared to municipios 100 miles away, suggesting that the policy change induced at least 238 additional deaths annually in the area located within 100 miles of the border ports. It is not obvious that the policy change should have exerted such substantial effects on killings, since, in principle, alternative weapons markets could have been used to satisfy the un-met demand

\footnotetext{
${ }^{1}$ As of 2006, over $90 \%$ of crime guns seized in Mexico were traced back to the United States (GAO, 2009).
} 
for assault weapons in the period prior to the policy change. ${ }^{2}$

In addition, we document increases in crime guns seized by the Mexican military, specifically for the gun category that includes assault weapons, but not handguns, providing evidence that the FAWB expiration increased violence through its effect on assault weapons supply. We consider and rule out a number of alternative explanations, including an intensification of the drug trade, the deterioration of economic conditions, and changes in legal enforcement, by incorporating related time-varying controls on drug seizures, income, and enforcement patterns on both sides of the border.

Beyond this average effect, we also expect the consequence of gun supply increases to be more pronounced in areas with marked instability. Therefore, in the second part of the paper, we explore the political antecedents of the relationship between weapons availability and crime. Mexico is an important context for examining political mechanisms through which arms escalate violence, given the interaction of drug trafficking and electoral politics in shaping violence dynamics. Although a substantial amount of narco-trafficking has been present in the country since the mid 1980s, it has been marked by a dramatic intensification in violence over the last ten years, contributing to a near doubling of the homicide rate over this period (INEGI, 2011). ${ }^{3}$ Over this period, the nation also underwent a notable democratic transition which unleashed competition in local elections during the 1990s, culminating in the 2000 loss of the presidency by the Institutional Revolutionary Party (PRI), which had dominated Mexico's elections since 1929.

Extant academic work and journalistic accounts have both drawn a connection between this increase in electoral competition, drug-trafficking, and resultant violence. A common conjecture asserts that rising competition reduced the ability of drug cartels to bribe PRI mayors in exchange for selective enforcement (Astorga, 2005; Escalante, 2011). The breakdown in these informal agreements is thought to have fueled fighting among rival cartels, and between cartels and the state. Osorio (2012) develops a theoretical model of this account and empirically shows that competitive municipios experienced more drug-war related violence in the post-2006 period. Dell (2011) provides complementary evidence by documenting that violence increased after mayors from the conservative National Action Party (PAN) were elected to office. Villarreal (2002) also contends that the democratic transition disrupted patronage networks, thereby promoting violence as challengers contested PRI strongmen with diminished power.

We conjecture that in a political environment where bribes and informal agreements help

\footnotetext{
${ }^{2}$ Although most crime guns seized in Mexico are traced back to the U.S., and enter the country through the U.S.-Mexico border, some have also been traced back to countries in Central America (GAO, 2009), and enter Mexico through this southern route (PGR, 2008).

${ }^{3}$ Mexico experienced 139,000 homicides over the past decade. Estimates of deaths that are explicitly drugwar related vary across sources and are not available from one consistent time series. However, a combination of data from the National Human Rights Commission and the Office of the President presented in Ríos and Shirk (2011) indicate the figure may be as large as approximately 43,400 for the 2001-2010 period.
} 
maintain order, an influx of arms is most likely to increase violence in the presence of greater electoral competition - competitiveness undermines the pre-existing system of exchange, and guns are particularly valuable given underlying instability. We present several pieces of evidence to support this hypothesis. First, we undertake a period-based falsification: we show that the original passage of the FAWB in 1994 led to no decreases in homicides south of the border. This supports the idea that assault weapons access affects crime disproportionately in environments marked by political and cartel instability, as was the case for Mexico in the 2000s, but not in the 1990 s.

However, these two periods may differ along other political economy dimensions, and there may be asymmetric effects from the enactment versus expiration of gun control. As a more direct test, we show that the 2004 FAWB expiration led to a differential rise in homicides in municipios that were more electorally competitive prior to the 2004 policy change, as measured by the effective number of political parties contesting local elections. These differential effects were also larger in areas with more drug trafficking, which is consistent with competition mattering due to its effect on implicit arrangements between local authorities and drug traffickers. While other studies have examined the relationship between competition and violence in Mexico, these results are the first to highlight the interaction of political competition and access to arms in determining violence.

Most closely related to our analysis is a recent working paper by Chicoine $(2011)^{4}$ which also attempts to assess how the FAWB expiration affects violence in Mexico, but by comparing homicides across states with and without drug cartels, with annual data over 1995-2008. However, this approach is problematic since homicide differences across cartel vs. non-cartel states cannot be attributed solely to changes in U.S. gun policy. ${ }^{5}$ In contrast, we utilize finer-grained municipal variation in proximity to particular border states, which corresponds more closely to arms flows. Moreover, we focus our analysis tightly around the law change, over 2002-2006, prior to an intensification of the drug war marked by numerous government military operations. As an additional check on our annual results, we also look specifically at the quarters before and after the law change, which enables even cleaner identification of the effect, and shows that homicides rose almost immediately — within a quarter of the ban's expiration - and persisted thereafter. In addition, Chicoine (2011) does not examine political or other institutional mechanisms in his account.

The vast majority of previous gun-crime studies have examined the effect of U.S. gun laws on U.S. crime rates. Analyses of the original 1994 FAWB enactment tend to find either small

\footnotetext{
${ }^{4}$ Our papers were written independently.

${ }^{5}$ In addition, Chicoine (2011) designates states as cartel states if the leadership of a major cartel was based there before 2004. But this classification can turn out to be quite coarse, as states such as Baja California Sur, Nayarit and Durango do not include a leadership base but experienced extensive drug-trafficking even prior to 2004, which we discuss further in the data section.
} 
crime-reducing effects (Koper and Roth, 2001), or mixed results (Lott, 1998) in the American context. However, these studies utilize pre-enactment variation in state-level assault weapons bans, which may be correlated with changes in local crime rates, potentially confounding the estimates. Other studies have also reported small crime-reducing effects of legislation requiring background checks on handgun purchases (Ludwig and Cook, 2000), and mixed results around the impact of laws that give individuals the right to carry concealed weapons (CCW). ${ }^{6}$ Relatedly, Duggan et al. (forthcoming) finds that gun shows - which allow vendors to sell firearms without background checks in some states - exert no significant effects on homicides within three weeks in or near the zip code where the show takes place. In contrast, we analyze effects when weapons are transported away from sale locations, at both the quarterly and annual level, as guns are durable goods and may promote mortality over a longer window.

Overall, the relatively small or mixed effects observed in the U.S. context suggest that access to weapons may exert larger effects in environments displaying greater instability in the industrial organization of violence, as with current cartel in-fighting in Mexico, which has been fueled in part by the changing nature of electoral politics. Previous failure to examine the role of political conditions may reflect the literature's singular focus on the United States, as democratic stability reduces the likelihood of electoral dynamics determining criminality (Villarreal, 2002).

The proximity-based effects we document are also consistent with the idea that there are substantial costs associated with weapons smuggling. Evidence of such costs have also been shown in Knight (2011) for crime gun movements across U.S. states. In part, these costs reflect the risk of detection entailed in transporting illegal weapons. In Mexico, smuggling costs also arise from the spatial segmentation of the drug-trafficking organizations (DTOs): particular cartels control certain ports of entry, which makes it costly to obtain weapons via border areas in rival cartel territory. Finally, while the results in our paper highlight the conflict-related consequences of arms trafficking, DellaVigna and La Ferrara (2010) shows its profitability, pointing to the economic benefits accruing to weapons-making companies.

In the political science literature, most previous work on arms have focused on their potential effects on civil wars, with the country as the unit of analysis. For example, conflicts in neighboring countries have been held to increase risk of insurgency due to the greater availability and lower price of weapons (Gleditsch, 2007). ${ }^{7}$ Our focus is not on civil war violence, but on

\footnotetext{
${ }^{6}$ Lott and Mustard (1997) and Moody (2001) found that these CCW laws reduced crime rates, but these results were subsequently challenged by Ayres and Donohue (1999 and 2003), and Black and Nagin (1998). Other studies have also suggested that CCW laws do not reduce criminality, based on empirical analyses (Ludwig, 1998 and Duggan, 2003), and theoretical models (Donohue and Levitt, 1998).

${ }^{7}$ Contagion effects of civil war (as discussed in Gleditsch, 2002; Gleditsch and Salehyan, 2007; Gleditsch, Salehyan and Schultz, 2008; and Salehyan, 2009) —arising from either spillovers in weapons (Collier et al., 2003) or other factors such as refugee movements (Salehyan and Gleditsch, 2006; Salehyan, 2008) and direct intervention by third parties (Gleditsch and Beardsley, 2004) — call into question the "closed polity" model of
} 
criminal homicides, many of which are connected to the drug trade. ${ }^{8}$ Thus our analysis sheds light on the determinants of a new and growing form of violence around the globe - non-state actors using insurgent tactics to fight for profits in illegal markets rather than political power. ${ }^{9}$ The socioeconomic consequences of this type of criminality have been documented extensively in the Mexican context, as manifest in the pervasiveness of drug gangs and their inter-links with civil society (Díaz-Cayeros et al., 2011); the role of drug money in spurring businesses and promoting a new type of consumer culture (McDonald, 2005); and drug war violence exerting negative effects on female labor force participation and the informal sector (Dell, 2011).

Although violence of this form doesn't aim to overthrow the state, it has arguably become more politically targeted, as reflected in the rising homicide of politicians and journalists in the post-2000 period (Ríos and Shirk, 2011). More generally, it has been posited that state destabilization resulting from large-scale homicides represents a blurring of lines between criminal violence and civil war in Latin America (Killebrew and Bernal, 2010), although there is a debate about the extent to which such criminality represents a threat to democracy in the region. ${ }^{10}$ The review by Blattman and Miguel (2010) suggests that common factors such as access to illicit drugs, state weakness and poverty influence both criminality and conflict. ${ }^{11}$

The remainder of the paper is structured as follows. Section 2 details the institutional context. Sections 3 and 4 describe the data and empirical strategy, respectively. Section 5 presents the main results on violence, while Section 6 explores potential mechanisms through which access to assault weapons affects violence. Section 7 concludes.

\section{Institutional Context}

In this section we describe the institutional context within which the FAWB expiration took place and increased access to firearms. We first discuss the interlocking roles of political

intra-state conflict, in which each state is treated as an isolated unit (Gleditsch, 2007). However, by presenting a case in which a stable, advanced nation exerts a weapons-related externality on a country experiencing instability, our analysis counters the presumption embodied in several of these studies that the weak states experiencing conflict serve as the primary source of weapons spillovers.

${ }^{8}$ Data on killings linked specifically to the drug war are only available after 2006, when our sample period ends. However, over 2007-2008, the earliest years these data are available, drug-war homicides represented $70 \%$ of total homicides in Mexico.

${ }^{9}$ Besides the drug market, human trafficking and the illegal smuggling of natural resources including precious metals and timber have also contributed to this rising form of violence (UNODC, 2010).

${ }^{10}$ For example, Bergman and Whitehead (2009) suggest that crime poses a direct challenge to the consolidation of rule of law in Latin America though others including Arias and Goldstein (2010) contend that this form of violence need not represent regime failure.

${ }^{11}$ For example, Collier and Hoeffler (1998 and 2004) find that higher income reduces risk of civil war, and interpret the effect as arising from lower opportunity costs or earnings foregone from joining a rebellion. In contrast, Fearon and Laitin (2003) posit that higher income reduces conflict risk by reducing state capacity. Miguel et al. (2004) establish that this negative relationship is robust to instrumenting economic growth with rainfall shocks. 
competition and the drug trade in Mexico. We then provide an overview of the federal and state-level bans on assault weapons in the U.S., and how the sunsetting of the FAWB led to differential access to assault weapons in different parts of the U.S.-Mexico border.

\subsection{Electoral Competition, the Drug Trade and Violence in Mexico}

Mexico's electoral arena was dominated by the PRI for close to seven decades. ${ }^{12}$ Starting in 1929, the PRI consolidated a hegemonic party system (Sartori, 1976), which succeeded in carefully balancing "legitimacy" and authoritarianism by allowing the creation of minor parties and holding elections (Molinar, 1991a). However, beginning in the late 1980s, and peaking in the mid-1990s, the country experienced a process of growing electoral competition that nurtured the development of democracy (Merino, 2003). A distinctive characteristic of Mexico's democratic transition was its centripetal nature, with subnational opening of the party system preceding the arrival of democracy at the national level (Hiskey and Bowler, 2005). Opposition victories first took place at the municipality level, then at the state level, and ultimately at the presidential level in 2000, when Vicente Fox of the PAN party defeated the PRI presidential candidate.

Figure I shows the rise in political competition at the municipal level during the 1990s and 2000s. We measure the effective number of political parties contesting mayoral elections using the well known Laakso-Taagepera index, which is defined as $N_{L T}=\frac{1}{\sum_{i} s_{i}^{2}}$, where $s_{i}$ is party $i$ 's vote share (Laakso and Taagepera, 1979). ${ }^{13}$

Scholars have noted that this marked rise in political competition had the inadvertent consequence of escalating violence, via its interaction with Mexico's drug trade. According to Astorga (2005), the dispersion of political power resulting from the democratic transition weakened the state's mechanisms of control and coercion over the drug cartels, which were born under an authoritarian regime that controlled, protected or tolerated them. ${ }^{14}$

Although the origins of drug trafficking in Mexico stretch back to the turn of twentieth century, the drug trade picked up during the 1960s and 1970s with growing U.S. demand for marijuana, and escalated further during the 1980s as Mexican and Colombian traffickers began operating together to meet the rising demand for cocaine (Astorga, 2005; Toro, 1995). However, the degree of violence remained relatively restrained during these decades as compared to the 2000s, owing in part to the long-standing agreements between traffickers and the PRI,

\footnotetext{
${ }^{12}$ In its inception, in 1929, the PRI was created as the National Revolutionary Party (Partido Nacional Revolucionario, or PNR).

${ }^{13} \mathrm{~A}$ higher value of this index indicates greater competitiveness. We provide greater detail on this and other related measures used in our analysis in Section 3.

${ }^{14}$ The relationship between drug trafficking organizations and local politics since the origins of Mexico's drug trade has been extensively documented by Astorga (1999, 2005). For instance, Félix Gallardo, a drug lord who became the leading cocaine trafficker in Mexico in the mid-1970s, lived as a respectable entrepreneur for many years, apparently protected by Sinaloa's ex-governor Leopoldo Sánchez Celis (see Astorga, 1999).
} 
which served to restrain cartel violence. These agreements were embodied in patron-client relationships between drug traffickers and various political authorities, including the Ministry of the Interior, the police, and local elected officials (O'Neil, 2009).

The entry and victory of other political parties in local elections undermined the implicit agreements between DTOs and the political establishment, encouraging territorial contestation by rival cartels, while increasing incentives of politicians to step up enforcement against the syndicates (Astorga and Shirk, 2010; Bartra, 2012; O'Neil, 2009; Osorio 2012). We posit that more guns are more likely to unleash violence precisely in areas that display greater underlying instability generated by the rise in competition since these are the very locations where cartels have the incentive to secure weapons and violently contest both their rivals and the state.

Besides the increase in electoral competition, other factors have been hypothesized as contributing to cartel de-stabilization over the 1990s. The North American Free Trade Agreement (NAFTA) may have facilitated the trafficking of illegal goods by promoting greater trade openness, thereby increasing profits and gains from in-fighting (Friman and Andreas, 1999; Naím, 2006). In addition, a reorganization of Mexico's police agencies and greater political decentralization altered the channels of intermediation between local authorities and criminal organizations (Astorga and Shirk, 2010; Snyder and Duran-Martinez, 2009).

The cartel de-stabilization resulting from these other factors as well as political competition all led to more drug-related violence, which skyrocketed in the 2000s. Two major turning points within this decade are worth noting. First, in 2001, the leader of the Sinaloa cartel, Joaquín "El Chapo" Guzmán, escaped from prison and attempted to take over important drug routes along the Texas and California borders. Violence subsequently increased in drug production areas and crossing points along the U.S.-Mexico border (Wall Street Journal, 2009). Second, in December 2006, President Felipe Calderón launched an aggressive military campaign against the drug cartels. These operations were phased-in geographically, and resulted in dramatic and haphazard violence increases throughout the country. ${ }^{15}$ Thus, we exclude all years after 2006 from our sample, since violence increases triggered by the campaign may confound our distance-based empirical strategy. We also avoid comparing across the pre and post 2001 period by limiting attention to the years between 2002 and 2006, which constitutes a relatively homogenous phase of the Mexican drug war.

\footnotetext{
${ }^{15}$ The military campaign started in Michoacán and Baja California in December 2006; extended to Chihuaha, Durango, Sinaloa, Nuevo León and Tamaulipas in 2007; and was initiated in Jalisco and Guerrero in 2008. According to data from the Instituto Nacional de Estadística y Geografía (INEGI), homicide rates increased nearly four-fold in 2008 in municipios within 100 miles of the border.
} 


\subsection{Assault Weapons Ban in the U.S.}

On September 13, 1994, the United States Congress passed the Violent Crime Control and Law Enforcement Act, which placed a first time restriction on the manufacture, transfer and possession of semi-automatic weapons. The law focused on a group of firearms considered particularly dangerous for their capacity to rapidly fire multiple shots, which makes them useful for criminal applications. ${ }^{16}$ The act was signed into law by then President Clinton for 10 years. However, as a consequence of a sunset provision, it was set to -and did-expire in September 2004. ${ }^{17}$ During the decade the law was in place, a handful of U.S. states had their own restrictions on assault weapons. This included California, which already had an assault weapons ban prior to 1994 that remained in place after the federal law sunsetted. ${ }^{18}$ Thus, while other states bordering Mexico experienced a change in the assault weapons control regime, the same was not true for California.

We can assess the extent to which CA gun control laws were binding, and the degree to which the FAWB affected the gun control regime in TX, AZ and NM by evaluating gun sales and production data. ${ }^{19}$ Panel A of Figure II shows that there was approximately a $15 \%$ increase in combined gun sales in AZ, TX and NM as compared to a 5\% rise in CA after 2004. The divergence is larger when we are able to look specifically at rifles, the gun category that includes assault weapons. For example, firearms production data from the U.S. Bureau of Alcohol, Tobacco and Firearms (BATF) is displayed in Panel B, and shows that rifles production more than doubled after 2004 in the non-California states, while remaining unchanged in California. While we cannot attribute increases in TX, AZ and NM entirely to the policy change, the differential increase compared to $\mathrm{CA}$ indicates that the FAWB expiration had an impact on gun sales and production.

\subsection{Gun Flows to Mexico}

The combination of tough gun laws in Mexico, weak gun laws in the United States, and proximity across the border makes it optimal for Mexican drug cartels and crime syndicates to source their firearms to the U.S. In contrast to the United States, Mexico has highly restrictive gun

\footnotetext{
${ }^{16}$ In particular, it barred 19 specific semi-automatic firearms deemed "assault weapons" (including the Automat Kalashnikov or AK-series and the Colt AR-15 series), as well as any semi-automatic rifle, pistol or shotgun capable of accepting a detachable magazine, which also had two or more of the following features: telescoping or folding stock, pistol grip, flash suppressor, bayonet lug, or grenade launcher. Notably, the act also banned magazines that could hold more than 10 rounds, which affected an even wider group of assault weapons.

${ }^{17}$ Overall, the U.S. has one of the least restrictive gun regimes globally, and ranked second in the world (after Yemen) according to the 2011 Gun Rights Index.

${ }^{18}$ We provide greater detail on California's ban and gun control laws in an Online Appendix.

${ }^{19}$ Gun sales are tracked in the National Instant Criminal Background Check System (NICS), for purchases that take place in federally licensed firearms dealers. A limitation of this data is that private sellers, including those at gun shows, are not included, and the numbers are not disaggregated by gun type.
} 
laws. Possession of high-caliber guns is essentially prohibited for citizens. ${ }^{20}$ In addition, there is only one legally authorized retail outlet for firearms in Mexico, which is operated by the Ministry of National Defense. As a comparison, there were 7,240 federally licensed firearms outlets in California, Arizona, New Mexico and Texas in 2010, the earliest year for which this data is available (BATF, 2010). The number of outlets by ZIP code in these four border states is mapped in Panel A of Figure III.

Indeed, the vast majority of crime guns seized in Mexico originate from the United States. As of 2006, around $90 \%$ of the weapons confiscated in Mexico and submitted to BATF's eTrace program could be linked back to the U.S. (GAO, 2009). ${ }^{21}$ The fraction traced to the U.S. also rose between 2004 and 2006, suggesting increased U.S. sourcing over this period. While traced gun data would be ideal for examining how gun flow patterns respond to policy changes, they do not exist for the pre-2004 period, and neither the BATF nor the Mexican authorities have released the data for the post-2004 period. Given these constraints, we instead utilize publicly available statistics from eTrace and other sources to examine spatial patterns and likely changes in gun trafficking over this period.

Most of the guns traced to the U.S. come from the border states, and to a greater degree from the non-California states. As indicated by Online Appendix Figure A.I., between 2004 and 2008, $49 \%$ of guns traced to the U.S. originated from either Texas or Arizona. In contrast, $20 \%$ were traced to California. If we normalize these flows by population, the "export rate" of the other two states are nearly three times as large as that of California. ${ }^{22}$ A Hearst newspaper survey of guns trafficked to Mexico from 44 court cases filed in the U.S. also found similar patterns: of 1,600 guns, $50 \%$ came from Texas, $29 \%$ came from Arizona, while 3\% came from California (Freedman, 2011a). The article reporting on these figures notes that California's strict gun laws appear to have "had the unintended consequence of making California gun stores unattractive to purchasers buying weapons for the Mexican drug cartels (ibid)."

While we do not have information about exports by state going back to the pre-2004 years, the combination of larger sales in the non-California states after 2004, along with the pattern of aggregate flows to Mexico suggests that there was a sizable increase in gun flows owing to the FAWB expiration. Our analysis examines this hypothesis directly, by assessing effects of the gun law change on both violence and gun seizures in Mexico.

\footnotetext{
${ }^{20}$ Articles 9 and 10 of the Mexican Federal Law of Firearms allow possession and carrying of pistols of only calibers $.380(9 \mathrm{~mm})$ or less, and revolvers of calibers .38 special or less.

${ }^{21}$ Since 2004, the Mexican government has sent about a quarter of its seized guns to eTrace to trace the origin of these weapons (GAO, 2009).

${ }^{22}$ The flows from New Mexico are relatively low as it is a small state. The data from BATF (used to generate Panel A of Figure III) reveals that the number of guns shops in border counties normalized by population is actually higher in NM (3.6) relative to either TX (2.0) or AZ (3.3).
} 


\subsection{Why Proximity Matters: Drug Cartels, Entry Ports and Lim- ited Arbitrage}

Our empirical strategy tests for differential effects of gun access on violence, based on the variation in geographic proximity to non-CA entry ports across Mexican municipios. A key part of this argument is that gun price differentials across municipios are not fully arbitraged away through the transport of illicit weapons. In this subsection we detail why this might be the case. We focus on the nature of the demand, the trafficking networks, the smuggling technology, and the spatial control of various segments of the border by various cartels.

First, Mexican DTOs are heavily involved in gun smuggling across the U.S.-Mexico border. Enforcers are sent to the U.S. to hire straw purchasers who buy firearms from gun dealers and traffic them across the border (Chu and Krouse, 2009). Cartels commonly choose semiautomatic weapons in these straw purchases. For example, among 492 firearms seized in illegal trafficking from Mexico to Arizona, California, Nevada and Texas, 43\% were assault weapons and another $30 \%$ were semiautomatic guns (Violence Policy Center, 2009). ${ }^{23}$

Second, cross-border smuggling is costly in all places along the U.S.-Mexico border, and costs rise when guns have to be transported over a greater distance on the U.S. side. While time and material transport costs increase with distance for shipping all products, for illicit goods, the costs are compounded due to the risk of apprehension, and efforts to minimize this risk. For example, the preferred technology for gun smuggling across the U.S.-Mexico border is to take multiple trips transferring one to three weapons at a time (Chu and Krouse, 2009). To obscure weapons amidst other legal merchandise and high traffic flows, guns are transported via personal or commercial vehicles through major ports of entry. ${ }^{24}$ The combination of high-frequency smuggling methods and enforcement-related risks underscores why proximity to entry ports is an important determinant of the street price of guns. The costs associated with trafficking guns across the border manifest in large profit margins of $300 \%$ to $500 \%$ (Chu and Krouse, 2009; Freedman, 2011b), which vary by distance. ${ }^{25}$

Third, our empirical strategy posits that transport costs should vary not only by distance to

\footnotetext{
${ }^{23}$ In addition, the analysis found that of 226 rifles, $90 \%$ were either of the AK- 47 or AR-15 series. The Hearst survey also reported that the two most frequently trafficked guns were the AK-47 and the Bushmaster .223 AR-15, which are both semi-automatic rifles (Freedman, 2011b).

${ }^{24}$ In particular, "firearms are generally trafficked along major U.S. highways and interstates and through border crossings into Mexico (GAO, 2009, p.22)." The centrality of ports in border trafficking was recently highlighted by Richard Cortez, the mayor of the border city of McAllen, Texas, who noted: "According to the Department of Justice, 90 percent of the drugs smuggled into the U.S. enter through the land ports...There is no data on firearms, but anecdotally, the ports are where they too traverse the border." (Testimony before House Subcommittee Hearing:"Using Resources Effectively to Secure Our Border at Ports of Entry", April 5, 2011.)

${ }^{25}$ For example, the New York Times reports that a $\$ 125$ handgun in San Diego sells for three times this amount in Tijuana, which is right across the border, but sells for $\$ 500$ or more further south in Mexico (Weiner and Thompson, 2001).
} 
border, but also by distance to non-California ports after 2004. We expect this kind of variation because of state laws: the price of purchasing assault weapons should be higher in CA, where it is illegal to do so, compared to other border states. While there is no data source tracking illicit weapons purchases in America, anecdotal evidence indicates that there are substantial price differentials that vary across states based on the stringency of gun laws. For example, premia between $300 \%$ to $600 \%$ have been recorded for guns sold illegally in New York, purchased originally in Georgia and Virginia, which have laxer gun laws (Mayors Against Illegal Guns, 2008). ${ }^{26}$ Relatedly, Knight (2011) documents spillovers in gun flows from states with weaker gun laws into nearby states. Enforcement risks related to state law explain why it would be costly to source guns from other states, transport them west within American territory, and bring them across the border into Mexico via California. ${ }^{27}$ Ultimately, gun price differentials have not been arbitraged away across U.S. states, indicating that the distance within the U.S. matters, regardless of whether it is Mexican or American traffickers moving weapons.

Of course, there will be some assault weapons smuggling that occurs near California, in part due to spillovers from nearby gun shops in Arizona. However, as shown in Panel A of Figure III, this spillover is likely to be limited since gun shops are more concentrated in eastern Arizona, owing to greater population density in that part of the state. Moreover, a spillover near CA would lead our empirical strategy to underestimate the true effect of how the FAWB expiration affects violence.

Finally, geographic segmentation among Mexican drug traffickers, with particular cartels controlling key entry ports, also add turf-based costs for cartels to arbitrage arms availability across different segments of the border. This is important given the central role of cartels in gun trafficking. Panel B of Figure III shows the approximate areas of influence and headquarter locations of the Tijuana, Sinaloa, Juárez, and Gulf cartels over the 2002-2006 period. As indicated by the map, enforcers from the Tijuana cartel would have to cross into Juárez or Gulf cartel territory to obtain weapons from border ports in Arizona, New Mexico, or Texas. Entering rival cartel territory can have direct violence-related costs by initiating clashes. Moreover, Mexican cartels work with particular U.S. street gangs on the American side of the border, suggesting that it is costlier to smuggle weapons across ports that are not under a cartel's control, where such alliances are missing. ${ }^{28}$

\footnotetext{
${ }^{26}$ Virginia and Georgia both have weak gun laws, ranking 8 and 12, respectively, on the Brady Center's scale of gun control stringency. New York has strong gun laws, reflected in a ranking of 62 . While we do not have equivalent anecdotal accounts for $\mathrm{CA}$, we expect similar price differentials between $\mathrm{CA}$ and the other border states, since CA's Brady Center score is 81, while Arizona earns 0, and New Mexico and Texas earn 4 on this scale.

${ }^{27}$ For example, the Roberti-Roos Assault Weapons Control Act, enacted in California in 1989, explicitly prohibits not just the possession, but also the transport of assault weapons.

${ }^{28}$ For instance, Barrio Azteca, a major gang operating in TX, is closely aligned with the Juárez cartel, while the 18th street gang from CA is linked to the Tijuana cartel (National Drug Threat Assessment, 2010).
} 


\section{Data}

\subsection{Dependent variables}

We analyze a number of different dependent variables related to violent crime. Individual-level mortality statistics from the Instituto Nacional de Estadística y Geografía (INEGI) list the location and cause of death for the universe of officially registered deaths in Mexico. These are aggregated at the municipio level to generate annual and quarterly counts of homicides and homicides tied specifically to guns over the 2002-2006 period. ${ }^{29}$ We view both variables as key outcomes: while gun-related homicide is a more direct measure of violence arising from gun law changes, it may also under-estimate actual gun killings, since the specific cause is unknown for $15 \%$ of the homicides in our sample. We also generate counts of these two variables for sub-groups, including individuals 18 and older without a high school degree, and young males between 18 and 30 without a high school degree, for $88 \%$ of the observations which contain these demographic variables. In addition, we create counts of non-gun homicides and non-homicide deaths.

We also analyze data on crime gun seizures from the Mexican military, the Secretariat of National Defense (SEDENA), defined as the number of guns seized in the campaign against drug-traffickers and in violation of Mexico's gun laws. These data present a partial picture since the Office of the Mexican Attorney General (PGR) also seizes crime guns, but has not released the municipal level data. Since aggregate numbers by the Mexican presidency specify the total number of guns seized annually (Calderón, 2009), this allows us to establish that SEDENA accounts for approximately $30 \%$ of total gun seizures nation-wide during the sample period. State-level figures from the agencies show that SEDENA accounts for $23 \%$ of the seizures in Baja California, south of CA, and $28 \%$ of the seizures in the other Mexican border states, indicating that both agencies operate across various parts of the border and the data are not systematically missing for any particular region, such as the area near California. The SEDENA data is also disaggregated by weapons type, allowing us to analyze handguns separately from rifles, the gun category that includes assault weapons. We generate annual counts of handguns and rifles seized. Because seizures are coded at the daily level, we are also able to create annual counts of guns seized in events where more than one gun was seized in a given municipio in a given day.

To present additional results on how the original passage of the FAWB in 1994 affects violence, we also utilize a smaller set of dependent variables that are accessible for this earlier time period. In particular, we analyze the municipal level counts of total and gun-related

\footnotetext{
29 As discussed in Section 2.1, we focus on this period because this is when dynamics of the Mexican drug war remained relatively constant, after the head of the Sinaloa cartel unleashed a wave of violence in 2001, but before major military operations were launched at the end of 2006 .
} 
homicides over 1992-1996.

\subsection{Independent variables}

We construct several measures of a municipio's proximity to various parts of the U.S.-Mexico border. First, an indicator variable codes if municipios lie adjacent to California (the "CA segment"), versus Texas, Arizona and New Mexico (the "non-CA segment"). A second variable measures a municipio's proximity to ports of entry that straddle the border. Appendix Table A.I shows how we classify border crossings into 18 ports of entry. A border crossing is considered a separate port if it is at least 20 miles away from another major border crossing. ${ }^{30}$ Otherwise, they are considered part of the same port, and named after the border crossing with higher annual average truck flows. ${ }^{31}$ We refer to the ports in AZ, NM and TX as either non-CA or treatment ports. ${ }^{32}$ Panel A of Figure IV shows the location of all ports, along with the highways in Mexico. The blue-shaded areas demarcate the set of municipios at the U.S. border which also have a major highway. ${ }^{33}$

We also generate the centroid-to-centroid distance between a given municipio and the nearest of the treatment ports, and subtract this distance (in thousands of miles) from 1, to create a "Proximity NCA" measure. Analogously,"Proximity border" is based on centroid distance to the nearest of any of the 18 ports. We use centroid-based proximity in our primary specifications since it best captures the average distance from a port to a municipio. However, for robustness, we also employ edge-based proximity, which measures the distance to the closest point along a municipio's boundary.

To account for the drug trade, we obtain SEDENA data on drugs seized by the military during drug-war operations in each municipio, and county-level data on drugs seized in the U.S. from the Drug Enforcement Agency, the U.S. Customs and Border Protection and the Department of Homeland Security (DHS). For both types of seizures, we use international prices from the United Nations Office of Drugs and Crime to aggregate the value of the four major drugs traded across the two countries - marijuana, heroin, cocaine and methamphetamine. ${ }^{34}$

\footnotetext{
${ }^{30}$ Straight-line distances were calculated based on distance from the actual border crossing, rather than the center of the port city. The classification also remains the same if we use driving distances.

${ }^{31}$ The 18 ports generated by this classification are: San Diego, Tecate and El Centro in CA; Yuma, Lukeville, Sasabe, Nogales, Naco and Douglas in AZ; Columbus in NM; and El Paso, Presidio, Del Rio, Eagle Pass, Laredo, Rio Grande City, McAllen and Brownsville in TX.

${ }^{32}$ Alternative port definitions with other distance criteria or requiring a "major port" to have some minimal level of truck traffic do not affect our results (see Online Appendix Table A.VI).

${ }^{33}$ The GIS shapefile for Mexican highways in 2009 comes from http://www.mapcruzin.com/download-mexicocanada-us-transportaton-shapefile.htm.

${ }^{34} 12$ of the 18 ports are situated in different U.S. counties, and in these cases a unique county-level value of drug seizures is assigned to each port. However, San Diego and Tecate are both situated in San Diego county (CA); Lukeville and Sasabe belong to Pima County (AZ); and Naco and Douglas are part of Cochise county $(\mathrm{AZ})$.
} 
Assigning drug values to the nearest port yields a municipio-level variable representing the value of drugs seized in the nearest port. In addition, data from the Mexican authorities provides us with the hectares of marijuana and heroin poppies eradicated within each Mexican municipio. Given the prevalence of zeroes, we use the log of one plus these variables in the analysis. ${ }^{35}$

SEDENA data on the number of individuals detained by the Mexican military during drug war operations (scaled by population) provide us with an important measure of enforcement at the municipal level. On the U.S. side, the Federal Bureau of Investigation (FBI) Uniform Crime Reports provide information on the number of police officers stationed in each port (in per capita terms). ${ }^{36}$ DHS data also allows us to control for the number of undocumented immigrants apprehended in each border patrol sector. ${ }^{37}$

INEGI data also gives the number of prosecutions of narcotics-related crimes in each municipality. We generate average counts of narcotics crimes per capita for the pre-treatment sample period, (i.e., 2002 to 2004), and utilize this measure as a proxy for the density of drug trafficking activity in each municipio. In particular, we designate the municipios above the mean of this variable as the high drug trafficking sample.

We also obtain data on a number of economic variables from both sides of the border. The 2000 Mexican Census compiled by INEGI gives cross-sectional measures of log income per capita in 2000 and the school enrollment ratio in 2000, defined as the fraction of the population ages 6 to 24 attending school. INEGI data also gives population and total municipal expenditure. For the U.S., the Quarterly Census of Employment and Wages (QCEW) from the Bureau of Labor Statistics provides county-level measures of average earnings and employment, which are combined with population from the U.S. Census Bureau to generate the employment-topopulation ratio in the nearest port.

We are able to access data on a subset of these control variables for the 1992-1996 period. This includes: INEGI data on population and municipal expenditure, and eradication of marijuana and heroin poppies in Mexican municipios; as well as QCEW data for average earnings and employment in the nearest U.S. port cities.

\footnotetext{
${ }^{35}$ Resa Nestares (2004) develops a proxy measure of drug traffickers and offenders in each municipio. This is based on PGR reports of convictions of possession, sale and trafficking of drugs in the top 100 municipios involved in the drug trade, from 1998 to 2001 - which precedes the period of our study. However, analysis of this measure shows the extent to which classifying areas as cartel states on the basis of cartel leadership as in Chicoine (2011) yields a coarse grouping. For example, Baja California Sur, Nayarit and Durango are classified as non-cartel states prior to 2004 by the leadership base definition. But according to the Resa Nestares variable, these states rank 5th, 6th and 8th, respectively, of 32 states, in terms of the density of drug traffickers and offenders.

${ }^{36}$ This data is available at the city level for 11 ports, and we assign the county-level equivalent for Tecate, CA; Columbus, NM; Presidio and Rio Grande in TX; and Lukeville, Naco, and Sasabe in AZ.

${ }^{37}$ The border patrol sector is a DHS-defined geographic unit. Nine ports are uniquely assigned to one of these sectors. However, Douglas, Lukeville, Naco, Nogales, and Sasabe belong to the same sector (of Tucson). Likewise, Tecate, Columbus, and Eagle Pass are a part of the San Diego, El Paso, and Del Rio sectors, respectively. And, Rio Grande City, McAllen, and Brownsville are assigned to Rio Grande Valley's sector.
} 
In addition, for both time periods, we use electoral data compiled by The Center of Research for Development (CIDAC) to construct four measures of the effective number of political parties. ${ }^{38}$ These are computed using municipality-level party vote shares in mayoral elections. $^{39}$ Our primary measure is the canonical Laakso-Taagepera (LT) index, which is defined as $N_{L T}=\frac{1}{\sum_{i} s_{i}^{2}}$, where $s_{i}$ is party $i$ 's vote share. $N_{L T}$ takes the inverse of the HerfindahlHirschman index of concentration, and thus a higher value of the index implies a larger number of effective parties, and greater competition.

For robustness, we also consider three other measures which each deal with some potential shortcomings of the LT index. Some researchers have argued that the index overstates the effective number of parties when there is one dominant party. ${ }^{40}$ There have been numerous attempts to address this problem, beginning with Molinar (1991b), who defined an alternative index as $N_{M}=1+\frac{\left(\sum_{i} s_{i}^{2}\right)-s_{1}^{2}}{\left(\sum_{i} s_{i}^{2}\right)^{2}}$. However, the Molinar index sometimes doesn't satisfy one of the desirable properties of the original LT index, that increasing the number of smaller parties should register a greater degree of competition. The measure proposed by Dunleavy and Boucek (2003), defined as $N_{D B}=\left(\frac{1}{\sum_{i} s_{i}^{2}}+\frac{1}{s_{1}}\right) \times \frac{1}{2}$, has been found to perform better in dealing with both of these problems. Another alternative which also addresses the same issues is the Golosov index, defined as $N_{G}=\sum_{i} \frac{s_{i}}{s_{i}+s_{1}^{2}+s_{i}^{2}}$, where $s_{1}$ is the largest party vote share. ${ }^{41}$

For a given year, all four indices are computed using data on the most recent mayoral election. However, to test for differential effects of FAWB policy changes based on the degree of electoral competition, we also define mean values of these indices in the respective pre-treatment sample periods. For the 2002-2006 period, this includes the 2004 elections since these took place prior to the expiration of the FAWB in September. Analogously, for the 1992-1996 period, this includes the 1994 elections, since these took place prior to the passage of the FAWB in September of that year.

\subsection{Descriptive Statistics of Key Variables}

Since gun law changes in the U.S. are likely to affect violence differentially in regions close to the border, we also define two distance-based samples. The border sample includes 38 municipios that lie along the U.S.-Mexico border, of which 35 fall along the non-CA segment and 3 along the CA segment. The 100-mile sample includes municipios whose geographic centroids lie within

\footnotetext{
${ }^{38}$ This dataset was compiled by CIDAC using primary information provided by the local electoral institutions.

${ }^{39}$ We focus on elections for mayors since they represent the highest-ranking executives at the municipal level, and thus, were commonly the office holders involved in negotiating arrangements with cartels. In addition, we are not able to use electoral data for higher level executives such as governors since we aim to utilize municipal variation in competitiveness.

${ }^{40}$ For example, with the largest party receiving $2 / 3 \mathrm{rd}$ of votes, the lower bound of $N_{L T}$ is 1.8 , which is close the value for a 2-party system, and therefore may be problematic.

${ }^{41}$ See Golosov (2010) for a more in-depth discussion of the respective strengths and weaknesses of these indices.
} 
100 miles of the nearest of the 18 ports. There are 106 municipios in this sample, shaded in green in Panel B of Figure IV.

Table I presents the descriptive statistics of our key variables for municipios within the 100 mile sample for the 2002-2006 period. We show the key dependent variables in per capita terms since our estimation strategy essentially scales the outcome variables by population. The average total homicide per capita is 0.135 and homicide tied specifically to guns per capita is 0.095 in the 100-mile sample, demonstrating that at least $70 \%$ of total homicides on average are gun-related.

\section{Empirical Strategy}

Our empirical strategy exploits the natural experiment induced by the 2004 expiration of the U.S. Federal Assault weapons ban and proximity to the U.S.-Mexico border. Since the ban relaxed restrictions on gun sales differentially in the border states of Texas, Arizona and New Mexico relative to California, which retained a previous state-level ban, we examine whether violence increased more in Mexican municipios closer to the non-California ports, relative to the California ports, after 2004.

We focus our analysis on Mexican municipios near the border, which are most likely to be affected by an influx of weapons from the U.S. Panel A of Figure V captures the essence of our empirical strategy: it shows that the sum of total homicides and gun-related homicides stayed constant in municipios within the non-CA segment over 2002-2006, but both variables diverged sharply after 2004, rising disproportionately in the CA segment. A simple difference in the means across the two segments before and after 2004 suggests a differential rise of 160 total homicides and 123 gun-related homicides in Mexican municipios closer to TX, NM and AZ after the gun law change. However, these raw mean calculations are merely suggestive, as they do not account for municipal characteristics or other changes correlated with the FAWB expiration and violence near the border.

The empirical strategy builds on this simple comparison in a number of ways. We estimate a difference-in-differences type specification which employs municipio fixed effects to sweep out time-invariant characteristics correlated with homicide rates and proximity to various border areas, as well as year fixed effects to control for year-to-year differences in killings common across all municipios. We employ a conditional fixed effects Poisson model with population exposure, since counts of homicides are bunched around a few integers: $47 \%$ of observations have no homicide, while $81 \%$ have 5 or fewer (as shown in Panel A of the Online Appendix Figure A.II). This bunching makes count regressions a more appropriate alternative relative to OLS. Panel B of Figure A.II shows that homicides per 10,000 population also displays leftcensoring, and comparing this distribution against the normal density further demonstrates 
why OLS is inappropriate. ${ }^{42}$ Finally, we use cluster-robust standard errors as recommended by Cameron and Trivedi (2009) to control for possible violations of the assumption in Poisson estimation, that the conditional mean and variance are equal. ${ }^{43}$

We begin by presenting a simple, motivational specification which just exploits the indicator of whether the municipio lies on the non-CA segment. Here, the log of the expected counts is specified as follows:

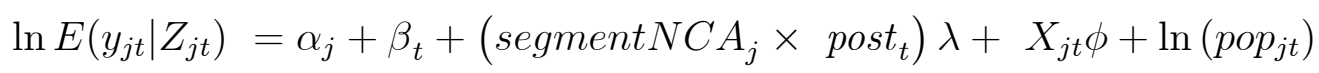

where $y_{j t}$ are homicide counts in municipio $j$ and year $t, \alpha_{j}$ are municipio fixed effects, $\beta_{t}$ are year fixed effects, $p_{0} p_{j t}$ is the municipal population in a given year, and segment $N C A_{j}$ equals 1 if the municipio lies along the non-CA segment of the U.S.-Mexico border. Post $t_{t}$ is a dummy variable that equals 1 for each year after the 2004 policy change. $\lambda$ is the coefficient of interest: it measures the differential log point increase in expected homicide counts in the non-CA versus CA segment after 2004. $X_{j t}$ is a vector of time-varying controls. $Z_{j t}$ is the full set of explanatory variables, i.e., $Z_{j t}=\left[\alpha_{j}, \beta_{t}\right.$, segment $N C A_{j} \times$ post $_{t}, \mathrm{X}_{j t}, \ln \left(\right.$ pop $\left.\left._{j t}\right)\right]$.

Since a municipio's exposure to the gun law change should vary according to its proximity to major ports in CA vs. TX, NM and AZ, our primary specification exploits the distance based-variation to non-CA ports, rather than relying solely on an indicator of proximity to the non-California portion of the border. In this case, the log of the expected counts is defined as:

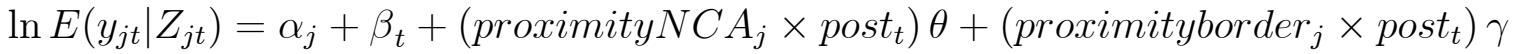

$$
\begin{aligned}
& +X_{j t} \delta+\ln \left(\text { pop }_{j t}\right)
\end{aligned}
$$

where $y_{j t}$ are counts of homicides and gun seizures in municipio $j$ and year $t$. ProximityNCA $A_{j}$ is the proximity of municipio $j$ to the nearest port in the non-CA border states - AZ, NM or TX. In this specification, a one unit change in proximity $N C A$ leads to a $\theta \log$ point increase in expected homicide counts after 2004. It is important to consider the possibility that violence may have increased in the border areas generally during our sample period. To account for such trends, we also control for proximityborder ${ }_{j} \times$ post $_{t}$ which is a municipio's proximity to any port on the U.S.-Mexico border, interacted with the post-2004 indicator.

Panel B of Figure IV shows the source of variation employed in estimating equation (2),

\footnotetext{
${ }^{42}$ The Shapiro Wilk test rejects the null hypothesis of normality at $\mathrm{p}$ values $<0.00001$ for homicides as well as homicides per 10,000 population.

${ }^{43}$ We opt to use the Poisson model with cluster-robust standard errors for two reasons. First, although the Negative Binomial allows for over-dispersion in the data while the Poisson model assumes that the conditional mean equals the variance, this weakness can be overcome by estimating robust standard errors in Poisson regressions (Cameron and Trivedi, 2009). In addition, the consistency of the coefficients in Negative Binomial estimation is more sensitive to the distributional assumption of the error term, relative to Poisson estimation.
} 
the proximity to ports in AZ, NM and TX, controlling for the overall distance to border ports. It is worth noting that this differs from the simple proximity to these three states, since there are some municipios located close to these state borders that do not have a port nearby. This distinction is important since the account we put forward relies on gun flows across the border, which take place via major highways through port cities.

\section{Main Results}

In this section, we build on the suggestive evidence shown in Panel A of Figure V, and assess the effect of the FAWB expiration on violence using Poisson estimation. Panel A of Table II presents these results for total homicides, with column (1) showing estimates of equation (1). The coefficient indicates that Mexican municipios lying along the non-California segment of the border experienced an additional $0.32 \log$ point (or 38\%) increase in homicides after 2004, compared to municipios along the California segment. The average annual homicides in the non-CA segment was 656 over 2005-2006, implying that the counterfactual deaths arising in the absence of the FAWB expiration would have been 475. Subtracting 475 from 656 suggests that the policy change resulted in an additional 181 deaths per year in the border segment near Texas, Arizona and New Mexico. This is very similar to the simple estimate of 160 differential deaths calculated on the basis of Figure V-Panel A.

Next, we address and rule out a number of potential alternative accounts with the inclusion of other control variables in column (2). First, observed homicide increases may be related to an intensification of the drug trade near the non-California ports after $2004 .{ }^{44}$ To account for time-varying determinants of the drug trade, we control for the value of major drugs seized, both in nearest U.S. port of entry and in Mexican municipios. Violence may also be connected to changes in the eradication of illicit crops, which likely reflect both drug crop cultivation as well as enforcement by the Mexican government. For example, Appendix Figure A.III shows that municipios proximate to $\mathrm{CA}$ witnessed a differential fall in the eradication of marijuana and heroin poppies after 2004. As such, we control for municipal-level eradication of these crops.

Additionally, variations in poverty rates across municipios may fuel greater homicides by lowering the opportunity cost of joining criminal organizations such as DTOs in Mexico. We thus control for the interaction of municipal income per capita and the school enrollment ratio in 2000 with post-2004 indicators, as well as log per-capita municipal expenditures, which accounts for the differential provision of basic services such as health, education and local security. Higher

\footnotetext{
${ }^{44}$ Note that municipio fixed effects control for time invariant determinants of municipal drug trade involvement, including climactic and geographic conditions that govern suitability for cultivating drug crops, and distance to coast, which may influence ease of receiving drug shipments.
} 
crime rates among U.S. cities on the non-CA part of the border may also have exerted spillovers on homicides in Mexico through cross-border links in crime syndicates. To account for this, we include controls for the employment-to-population ratio and average earnings in the county with the nearest U.S. port. Finally, violence increases may mirror immigration patterns, as drug cartels are increasingly involved with trafficking migrants across the border. We therefore control for the (log) number of unauthorized immigrants apprehended near the closest U.S. port. In addition, we verified that there were no other major changes in immigration policies at the national or state level during this period. ${ }^{45}$ The inclusion of these control variables increases the magnitude of the estimated coefficients in column (2), raising the estimate of implied annual deaths to 270 .

Panel B of Table II presents the results for gun-related homicides. The coefficient of 0.38 in column (1) suggests a $46 \%$ increase in this outcome. Given average gun murders of 420 in the post-treatment period, the counterfactual equivalent would have been 288 , implying an additional 132 gun murders in the non-California border segment due to the policy change. Again, this is quite similar to the simple calculation of 123 additional gun-related homicides per year based on Panel A of Figure V. Accounting for covariates in column (2) raises the annual estimate of such deaths to 224 .

Columns (3)-(5) present estimates of equation (2) using the sample of municipios that lie within 100 miles of ports on the U.S.-Mexico border. Here, the key treatment variable is the continuous measure of proximity to a non-California port interacted with the post-2004 indicator. Column (3) includes no controls. Column (4) controls for overall proximity to the border ports, hence accounting for other factors which may be correlated with our treatment and with violence near the border. Column (5) additionally includes the full set of income, immigration and drug controls in column (2). The coefficients remain quite similar across these alternative specifications, although the precision of the estimate improves with additional covariates.

For our preferred specification with all controls (Panel A, column (5)), the coefficient of 4.7 implies that going 100 miles toward the U.S.-Mexico border leads to a 0.47 log point (or $60 \%$ ) increase in homicides. The average municipio in our sample (which lies 57 miles from the nearest border port) is thus predicted to experience a $26 \%$ rise in homicides. ${ }^{46}$ Given the

\footnotetext{
${ }^{45}$ Over the past decade, Arizona has led the way in implementing laws geared towards curbing immigration, though both major laws were passed after our sample period. The Legal Arizona Workers Act (LAWA) was passed in 2007 and is an employer sanction regime aimed at forcing unauthorized immigrants out of the workplace. Similar laws have been implemented in other states since then. The 2010 SB1070 gives local police power to enforce non-workplace related state immigration law, and at the time of passage was considered the most severe state-level policy.

${ }^{46}$ The mean distance of 57 miles implies a proximity value of $0.43(=1.00-0.57)$. Multiplying 0.60 by 0.43 yields the predicted homicide increase of 0.258 or $26 \%$.
} 
actual average number of homicides was 1,153 in the post-2004 period, the estimate suggests an additional 238 deaths per year in the set of municipios within 100 miles of the border.

For gun-related homicides, the relevant coefficient is 6.84 (Panel B, column (5)), implying a $42 \%(0.97 \times 0.43)$ rise in gun deaths in the average municipio within the sample. Given an annual average of 738 gun-related homicides in the post-2004 period, we estimate an additional 235 such deaths due to the U.S. policy change. The similarity of the effect on total homicides (238) and gun-related homicides (235) verifies that most of the killings attributable to the FAWB expiration were gun-related. These figures serve as our preferred estimates, since we view the proximity-based approach in equation (2) with full controls as our primary specification. However, they also accord closely with estimates from the segment specification in column (2), thus bolstering the internal validity of our estimation. Overall, our preferred specification indicates that the annual additional deaths due to this policy change represent around $21 \%$ of all homicides and $30 \%$ of gun-related homicides in our post-intervention sample, which are sizable magnitudes.

Panel A of Figure VI shows the effects of the change in law by year: we interact proximityNCA with year dummies (instead of post) using 2004 as the omitted category, and plot the annual coefficients. The controls include overall proximity to border interacted with year. For total homicides there is a clear, sharp rise between 2004 and 2005 and the effect mostly persists through 2006. The results for gun-related homicides is noisier, but the same pattern is reproduced here as well.

Our main estimates use annual data since most of the control variables are only available at the yearly level. However, we also present estimates with counts at the quarterly level. Since the expiration of the FAWB took effect in September 2004, this approach allows us to re-assign the last quarter of 2004 to the post-treatment period. In addition, since major government military operations began in December 2006, we are able to eliminate the last quarter of 2006 to ensure that we isolate the effect of gun law changes rather than rising drug war violence unleashed in the aftermath of these operations. (Correspondingly, we define a symmetric pretreatment period that extends back to the fourth quarter of 2002, estimating the effects over a 16-period window). However, one limitation of this specification is that we do not have our key control variables at the quarterly level, and thus impute quarterly values for the annual controls using linear interpolation.

Table III presents the quarterly results. Column (1) includes the overall distance control, while column (2) additionally includes the imputed income, immigration and drug controls. The coefficients from column (2) are 4.5 and 5.4 for homicides and gun-related homicides, respectively. Overall homicide effects accord closely with our annual results, while the coefficient for gun-related homicides is slightly smaller; however, both are statistically significant at the $1 \%$ level. Column (3) additionally includes four leads and lags in the treatment variable (prox- 
imityNCA $\times$ post). This specification shows that the coefficient on the first lag is substantial and significant for both total and gun homicides, indicating a clear treatment effect in the quarter following the expiration of the assault weapons ban. None of the leading terms are statistically significant, which is reassuring. Panel B of Figure VI visually traces the time path of the treatment, which is obtained by successively summing the leading and lagging terms. The figure also shows the unmistakable jump in the treatment effect in the first period lag. The last coefficient (labeled "4+") represents the long term effect of the policy, and confirms that the increase in violence was persistent. The size of these last period coefficients (6.6 and 7.8 for homicides and gun-related homicides, respectively) are somewhat larger than those from the contemporaneous specifications using either quarterly or annual data. These estimates imply that the FAWB expiration led to an increase of 330 homicides and 248 gun-related homicides.

\subsection{Robustness Checks}

In Table IV, we consider a number of alternative explanations for our findings, and test the robustness of our baseline results to additional estimators, controls, and samples. Column (1) reproduces the baseline results from column (5) of Table II. Column (2) shows that the effects continue to be statistically significant with Negative Binomial estimation, although the coefficients are somewhat smaller in magnitude. As discussed in section 4 , the Poisson results are preferred as the consistency of the estimates do not rely on specific distributional assumptions (while cluster robust variance estimates deal with the potential overdispersion problem).

We next account for spatial linear trends in homicides by including an interaction of proximity NCA with time in the specification. The maximum likelihood estimates do not converge with the inclusion of these trends along with municipio and year fixed effects. However, in column (3), we show that the coefficient is similar when we replace year effects with a post-2004 indicator, and in column (4) we include the linear trend control along with this indicator. The coefficients of interest are actually larger in magnitude in column (4) than in columns (3) or (1), and remain significant for both homicides and gun homicides, indicating that underlying trends do not confound the results. ${ }^{47}$

Since most guns are trafficked along major highways even once they reach Mexico, column (5) restricts the sample to those municipios that have at least one major highway. The coefficients are almost identical as the baseline, confirming that the results are not driven by some idiosyncratic feature of the few regions lacking highway access.

If a rise in homicides is correlated with factors that also promote other types of mortality, then our estimates may be biased upward if we do not control for these omitted factors or the

\footnotetext{
${ }^{47}$ The estimates in column (4) are particularly large in comparison to those in column (3), and more similar in magnitude to those in column (1). The small size of the coefficients in (3) is likely to reflect the fact that time effects are very coarsely specified in this specification, relative to the specifications in both (1) and (4).
} 
ensuing increase in other deaths. ${ }^{48}$ In column (6), we control for other non-homicide deaths, as well as non-gun related murders, and find that the results for homicides and gun related homicides remain nearly identical.

In column (7), we address the alternative account that estimated violence increases reflect an increase in state enforcement efforts, such as government military operations, which are also potentially correlated with our treatment. We do so by controlling for the contemporaneous number of drug-related detentions per capita by the Mexican military. In addition, we account for differential enforcement levels across U.S. ports cities by controlling for the number of police officers per capita in the nearest port. Since enforcement controls are likely to respond positively to increased criminal activity induced by the policy change, including their contemporaneous values is a form of over-controlling, and represents a particularly tough hurdle. Even so, we find that the coefficients remain statistically significant at conventional levels and large in magnitude especially for gun-related killings.

Finally, we explore the impact of the FAWB expiration on non-gun homicides. This expected effect is ambiguous. Added gun supply may have led to a substitution away from the use of other weapons, lowering these other types of homicides. On the other hand, it may have increased non-gun murders by expanding the drug war more generally, which has increasingly involved killings by other means such as beheadings and mutilations. Panel $\mathrm{C}$ of Table IV shows the FAWB expiration did not affect non-gun homicides in any of the specifications, even while there is a strong impact on gun-related homicides (Panel B). This demonstrates that there was little substitution away from other types of murders and also provides additional validity to the causal channel proposed for our findings. Figure V-Panel B also demonstrates that non-gun homicides did not increase differentially in the non-CA segment after 2004.

We present additional falsifications to demonstrate that the effects were specific to a rise in murders. Panel B of Figure V shows that there was no divergence in gun-related suicides in the wake of the FAWB expiration. Appendix Table A.II confirms that our continuous treatment (proximityNCA $\times$ post) correspondingly exerts no significant effect on gun suicides, suicides conducted by other arms, and aggregate suicides, as well as deaths arising from accidents. The effects on homicides in particular, as opposed to suicides, suggest that observed violence increases are connected to organized criminal activity, and do not simply reflect increases in violent acts committed by individuals acting independently — an idea we further explore in section 6.1 below.

We include several other robustness checks in the Online Appendix. Table A.III reproduces all three Panels of Table IV with estimates of equation (1), and shows the robustness of these

\footnotetext{
${ }^{48}$ For example, political destabilization, natural disasters or an economic downturn may result in greater non-murder deaths through a rise in poverty and erosion of basic services, while increasing violence and crime by reducing the opportunity cost of participating in illicit activities.
} 
results to the simple segment specification. Figure A.IV alters the distance bands used for the continuous treatment specification, demonstrating that the results are not driven by the specific choice of the 100-mile band.

Table A.IV deals with potential spatial confounds: since variation in centroid distances may reflect size differences across municipalities, we show that the effects are robust to controlling for area and using distance to municipal edge (vs. centroid). We also find little evidence of violence spilling across municipios spatially, since there are no significant effects of lagged homicides in neighboring municipios. Table A.V shows that key results continue to hold when we drop municipios whose nearest port is closest to each of the non-California border states in the U.S. This indicates that the estimates are not driven by other violence promoting events adjacent to particular parts of the border. ${ }^{49}$ Finally, Table A.VI shows that the results are robust across various definitions of a major port of entry, including those that impose no distance restriction or a distance of at least 30 miles between border crossings; as well as those that impose restrictions based on minimum annual truck flow criteria of at least 1000 or 5000 trucks per year.

\subsection{Gun Seizures}

Next, we present supporting evidence on the proliferation of arms in Mexico following the FAWB expiration in the U.S., using data on SEDENA crime gun seizures. If the policy change is causally related to violence through assault weapons sales, we should expect to see greater increases in counts of the rifle category, but not the handgun category. We analyze two additional outcomes, "multiple rifles" and "multiple handguns", which are counts of guns on days when multiple guns of that type were seized in a given municipality. These multiple seizures are more likely to reflect gun possession by members of organized crime groups. The results in Table $\mathrm{V}$ indicate that the policy shock did increase the number of rifles seized in Mexico, but not the number of handguns. Strikingly, the effect is strongest for "multiple rifles" seizures, while the "multiple handguns" seizures has the opposite sign and is not significant.

Since the FAWB did not affect the stringency of gun laws governing handguns, these findings provide strong evidence that the policy change increased assault weapons supply south of the border. The findings on multiple rifle seizures also suggest that the killings associated with increased gun supply reflect more activity by organized crime syndicates such as DTOs, which were best positioned to take advantage of permissive U.S. gun regulations in trafficking weapons

\footnotetext{
${ }^{49}$ One other spatial-based concern is potential endogeneity in CA's decision to retain its state-level ban (and in TX, AZ and NM's decisions to remain without such bans). The most plausible account is one where restrictive state-level gun laws are passed in response to rising nearby violence. Yet, this cannot explain our findings for two reasons. First, it is unclear why there would be a differential spurt in violence right around 2004 owing to the endogeneity in state maintenance of their pre-2004 policies. Second, we observe violence increases near the non-CA states which decided not to pass a state ban, which runs contrary to the account.
} 
to Mexico.

\section{The Mediating Role of Drug-Trafficking and Electoral Competition}

This section explores potential mechanisms through which access to assault weapons affects violence, by analyzing heterogeneous effects of our treatment across demographic groups, time periods, and the institutional context, including the degree of electoral competition and extent of narcotics trafficking.

\subsection{Violence across Demographic Groups}

If homicide increases are driven by members of crime syndicates targeting one other, we posit that our estimated effects should be larger for deaths of young men from a lower socioeconomic stratum, as this is the demographic group most likely to be involved with drug cartels. ${ }^{50}$ To explore this question, we disaggregate the counts of total homicides into sub-groups based on age, gender and educational attainment, which we use as a proxy for socioeconomic status. ${ }^{51}$

Since 12 percent of the individual-level mortality observations were missing data on one of these characteristics, and we aim to compare effects on sub-groups directly to effects on overall homicides, we begin by re-generating municipio-level counts of killings for observations that are not missing any one of these characteristics. Column (1) of Table VI presents these results, which are similar in magnitude to the baseline effects in Table II. The coefficients in columns (2)-(3) show that the treatment effects are substantially larger for the sub-group of individuals above the age of 18 who have not completed high school, relative to everyone else (the complementary set). Reassuringly for our interpretation, this is particularly true for gunrelated homicides (Panel B). Columns (4)-(5) show that the difference in estimated effects for the sub-group versus its complementary set are even larger for young men (between the ages of 18 and 30) who have not completed high school. For example, for gun-related homicides, the coefficient for all non-missing killings in column (1) is 6.5. The coefficient for young men without high school in column (4) is 13.9, while the coefficient for everyone else in column (5) is 5.1. The larger effects for young men with relatively low educational attainment is consistent with the idea that the expansion of organized crime has made a larger contribution to the rise in killings.

\footnotetext{
${ }^{50}$ For example, data from the Mexican presidency indicates that between 2006 and 2010, men comprised over $92 \%$ of drug-war related killings, and the age decile which represented the largest fraction of deaths were those between the ages of 21 and 30 .

${ }^{51}$ Our approach is similar to Owens (2011) who also uses age-specific changes in homicide rates to detect organized criminal activity following criminalization in U.S. alcohol markets.
} 


\subsection{The Role of Electoral Competition}

In this subsection, we examine whether political conditions related to Mexico's democratic transition mediate the extent to which gun supply changes increase violence. In particular, we focus on the role of electoral competition in local elections.

First, we consider a period-based falsification: if the competition hypothesis holds, we should observe relatively small homicide effects associated with the passage of the FAWB in 1994, when PRI remained relatively hegemonic, as compared to 2004, when political competition was greater. Since California already had a state-level ban in place from 1989, the passage of the federal ban should have reduced the flow of weapons differentially out of the other border states. In estimating the effect of this reverse experiment on killings in Mexico, we again focus on the two year window before and after the policy change, with 1992 to 1996 serving as the relevant sample period.

It is important to establish that there were meaningful differences in the extent of electoral competition during the two time periods when the two policy changes took place. Figure I shows that there was a clear difference in the effective number of political parties contesting mayoral elections in 1994 versus 2004 within our 100-mile sample. Online Appendix Figure A.V shows that the mean of the LT index was 1.7 for the sample period prior to the 1994 treatment and 2.2 for the sample period prior to the 2004 treatment. It also shows the full distribution of these indices in the two pre-treatment sample periods. ${ }^{52}$ These figures establish that the two time spans with relatively greater access to assault weapons - prior to 1994 and subsequent to 2004 - were qualitatively different in terms of the competitiveness of the political regimes.

Table VII shows the results for the 1994 experiment, using the same specifications as in Table II. The estimates indicate that the FAWB passage exerted no significant effects on total or gun-related homicides. Columns (1), (3) and (4) exclude the additional control variables related to drugs and socioeconomic conditions. Columns (2) and (5) include the subset of these controls accessible for the earlier period - municipal expenditures and marijuana and heroin poppy eradication, as well as employment and earnings in U.S. port cities. To ensure comparability of the results over the two periods, we verify that the main 2002-2006 results (from columns (2) and (5) of Table II) continue to hold with this smaller control set. ${ }^{53}$

The null effect in Table VII is consistent with the account that increased gun availability after 1994 did not promote violence as this policy change took place during a low-competition period, when informal agreements between drug-traffickers and PRI mayors limited the extent of fighting among DTOs, and between DTOs and the state. In contrast, the 2002 policy

\footnotetext{
${ }^{52}$ The Kolmogorov-Smirnov test strongly rejects the null hypothesis that the distributions of the LT indices in Figure A.V are the same over the two periods ( $p$ value $<0.00001)$.

${ }^{53}$ These results are not presented for brevity, but are available from the authors upon request.
} 
change took place in an environment marked by greater competition: by this time, many municipios had experienced turnover in PRI mayorships, which undermined these informal sanctions. The contrasting findings in the two periods provide suggestive evidence that the political environment plays a mediating role in the gun-crime relationship.

However, one limitation of this comparison is that the effect of shutting off gun supply may be different than the effect of suddenly making guns available. ${ }^{54}$ In addition, the two periods with easier access to assault weapons, before 1994 and after 2004, differed in some other key political-economic dimensions. Most importantly, trade between the two countries was more limited in the earlier period. NAFTA was not implemented until 1994, which may have increased trade in illegal as well as legal goods (Andreas, 1996). Second, by the 2000s, the near disappearance of the major Colombian cartels led to the dominance of Mexican cartels in the drug distribution network, ${ }^{55}$ which is likely to be important in determining how gun supply changes induce violence, quite apart from the democratic transition in Mexico.

Given these potential alternative reasons for heterogenous effects across the two periods, we further examine the competition mechanism by testing whether the FAWB expiration induced differential increases in homicides among municipios that were more competitive during the 2002-2006 sample period. We utilize four different measures of the average effective number of political parties in the pre-treatment sample period-i.e., those based on elections prior to the 2004 policy change. ${ }^{56}$ The LT index is our primary measure of competition, but we also use the Molinar, Dunleavy-Boucek and Golosov indices for robustness. We introduce three-way interactions with these political competition indices and the treatment variable, proximity $N C A_{j} \times$ post $_{t}$. We estimate:

$$
\begin{array}{r}
\ln E\left(y_{j t} \mid Z_{j t}\right)=\left(\text { proximity NCA }_{j} \times \text { post }_{t}\right) \theta_{1}+\left(\text { proximity NCA }_{j} \times \text { post }_{t} \times \text { index }_{j}\right) \theta_{2} \\
+\left(\text { proximityborder }_{j} \times \text { post }_{t}\right) \gamma_{1}+\left(\text { proximityborder }_{j} \times \text { post }_{t} \times \text { index }_{j}\right) \gamma_{2} \\
+\left(\text { post }_{t} \times \text { index }_{j}\right) \gamma_{3}+X_{j t} \delta+\ln \left(\text { pop }_{j t}\right)+\alpha_{j}+\beta_{t}
\end{array}
$$

For ease of comparison between the two-way and three-way interaction specifications, we

\footnotetext{
${ }^{54}$ This has to do with the distinction between stocks and flows. Since guns are durable goods, switching off the flow of guns has only a limited effect on the stock of guns in the short run. In contrast, switching on the supply may have a quicker impact as rapid inflows build up the stock.

${ }^{55}$ In the early 1990s, the Medellin and Cali drug cartels of Colombia were the key players in the market. Only half the cocaine arriving to U.S. was transported through Mexico, with Mexican cartels operating as sub-contractors (O'Neil, 2009). In contrast, by the 2000s, the Mexican cartels dominated the drug distribution network, and over 90 percent of cocaine in the U.S. entered through Mexico.

${ }^{56}$ It is important to use the pre-treatment sample period to avoid the possibility that the FAWB expiration itself affected political competition. Depending on election years in a municipio, these measures are based on either one or two elections. However, focusing on only the last election prior to the treatment generates similar results.
} 


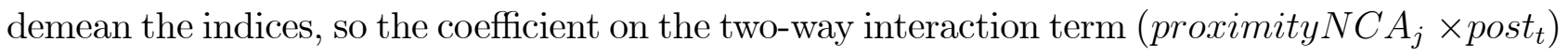
can be interpreted as the effect in a municipality with the mean effective number of parties $(\overline{\text { index }}) .{ }^{57}$

Table VIII presents these results. Column (1) shows the LT interaction in the entire 100-mile sample, controlling solely for proximity to border (which now includes the proximityborder $_{j} \times$ post $_{t}$ two-way interaction, as well as the proximityborder ${ }_{j} \times$ post $_{t} \times$ index $_{j}$ three-way interaction). The large, positive estimate of $\theta_{2}$ highlights that the FAWB treatment led to significantly larger increases in overall and gun-related homicides among municipios with a larger number of effective political parties.

If political competition played this mediating role between guns and violence because it contributed to drug cartel destabilization, then these competition-based differentials should themselves be larger in areas where drug trafficking was more prevalent. To explore this hypothesis, column (2) examines the interaction effects in the high drug trafficking sub-sample, composed of municipios with above mean narcotics crimes per capita in the pre-treatment period. Estimates of $\theta_{2}$ are shown to be even larger in this column. This evidence is consistent with the idea that competition matters owing to its interlocking relationship with drug trafficking related instability.

Columns (3)-(4) reproduce the same results with the LT index including our full set of income, immigration and drug-related controls, and confirm that the implied differential effects are substantial. In column (3), the marginal effect of the policy is 2.4 at a municipio with average competition (as given by the mean of the LT index). However, the size of the effect is nearly four times as large in a municipio with competition that is one standard deviation above the mean. ${ }^{58}$

Columns (5)-(10) show that the same pattern of results - differential effects based on competition which are larger in high drug trafficking areas - also hold with the other three measures of the effective number of political parties. In contrast to these clear effects for the 2002-2006 period, additional results show that there were no heterogeneous effects of the 1994 FAWB passage based on the degree of political competition across municipios in the early 1990s ${ }^{59}$ Overall, the null effects of the 1994 policy change, along with varying effects of the 2004 expiration based on competitiveness, indicate that the political environment conditions the extent to which greater access to assault weapons translate into rising violence.

\footnotetext{
${ }^{57}$ Using a demeaned index simply means that the coefficient associated with (proximity $N C A_{j} \times$ post $_{t}$ ) is equal to $\theta_{1}+\theta_{2} \times \overline{i n d e x}$ as defined in equation 3 .

${ }^{58}$ The standard deviation of the LT index is 0.41 . Thus the associated coefficient for the marginal effect is $9.0(=0.41 \times 16.2+2.4)$.

${ }^{59}$ These results are not reported in the table but are available from the authors upon request.
} 


\section{Conclusion}

We find that the reach of U.S. gun laws extends beyond its borders. Our analysis shows that the expiration of the U.S. FAWB led to immediate violence increases within areas of Mexico located close to American states where sales of assault weapons became legal. The estimated effects are sizable, and unrelated to the idiosyncratic influence of specific border states, trends in socioeconomic conditions, legal enforcement patterns and drug-trafficking along the border.

The baseline estimates suggest that municipios neighboring entry ports into Texas, Arizona and New Mexico saw total homicides rise by $60 \%$ as compared to municipios 100 miles away. This implies an additional 238 homicides in the area within 100 miles of the border, in each of the two years after the 2004 policy change. To put the size of the effect into perspective, the additional homicides stemming from the FAWB expiration represent $21 \%$ of all homicides in these municipios during 2005 and 2006. Similarly, the additional gun related homicides represent $30 \%$ of all such deaths over this period.

Our findings also demonstrate that political competition plays an important role in determining the impact of gun access on violence: estimated homicide increases were greater in municipios with a larger number of effective political parties contesting elections, and these differentials were more pronounced in high drug trafficking areas. These results are consistent with the notion that increased competition associated with Mexico's democratic transition disrupted implicit agreements between DTOs and the long-ruling PRI, which had previously enabled drug cartels to operate with relative impunity in particular municipalities. They also suggest that political institutions help forge relationships between the state and non-state actors such as drug cartels, which ultimately shape the industrial organization of crime.

Our analysis of the 2002-2006 period holds the policy implication that stricter control of guns in the U.S. could help curb rising violence in Mexico, particularly over the long run. However, reinstallation of the FAWB may not exert immediate effects on crime since Mexico now has a stockpile of weapons, which will only diminish gradually with depreciation and gun seizures. This suggests that shutting off American weapons supply may need to be combined with increased enforcement measures to deliver more rapid reductions in homicide rates over the short run. These implications tie directly into the current contentious debate on weapons trafficking along the U.S.-Mexico border. Within this discussion, the Mexican government has repeatedly asked for assistance from the United States in reducing weapons flows. In May 2010, Mexican President Felipe Calderón urged the U.S. Congress to reinstate a ban on assault weapons. He stated, "I will ask Congress to help us...and to understand how important it is for us that you enforce current laws to stem the supply of these weapons to criminals and consider reinstating the assault weapons ban (Los Angeles Times, May 20, 2010)." In July 2011, President Obama approved a new regulation that requires firearms dealers in California, 
Arizona, New Mexico, and Texas to inform the BATF about multiple sales of certain types of semiautomatic rifles. However, this law has been described as "insufficient" by Mexican congressmen (El Universal, July 12, 2011) and been strongly contested by U.S. gun-rights advocates such as the National Rifle Association. Frustration over the U.S. response has most recently led the Mexican government to explore suing American manufacturers and distributors of weapons flowing into Mexico (CBS News, April 21, 2011).

The potential cross-border benefits arising from U.S. gun control policy also apply more generally, beyond Mexico. The combination of its size and the fact that it has one of most permissive regulatory regimes in the world implies that U.S. gun laws can have large regional or even global consequences. For example, most crime guns seized in Jamaica over this past decade have also been traced back to the U.S., specifically to the state of Florida (Leslie, 2010). Up to $80 \%$ of the guns in Central America may also originate from the U.S. (El Universal, November 15, 2011): some were transferred during past civil wars, while others have arrived more recently in conjunction with the drug trade (World Bank, 2010). The diffusion of these arms appear to be exacerbating gang-related violence in the previously conflict-affected nations of Guatemala, El Salvador and Nicaragua (Seelke, 2011), while spreading to the previously peaceful nations of Costa Rica and Panama (Godnick et al., 2002).

By documenting the adverse consequences of cross-border arms flows, we provide evidence of a positive relationship between gun supply and violence. In demonstrating that this effect varies by institutional context, our analysis suggests that political economy factors should be directly integrated into future studies of crime.

\section{References}

[1] Andreas, Peter. 1996. "U.S.-Mexico: Open Markets, Closed Border." Foreign Policy (Summer) 103: 51-69.

[2] Arias, Enrique D. and Daniel Goldstein. 2010. Violent Democracies in Latin America. Durham and London: Duke University Press.

[3] Astorga, Luis. 1999. "Drug Trafficking in Mexico: A First General Assessment." UNESCO, Management of Social Transformations, Discussion Paper 36.

[4] Astorga, Luis. 2005. El siglo de las drogas. Mexico City: Plaza y Janés.

[5] Astorga, Luis and David A. Shirk. 2010. "Drug Trafficking Organizations and CounterDrug Strategies in the U.S.-Mexican Context". Working Paper, Center for U.S.-Mexican Studies, UC San Diego. 
[6] Ayres, Ian and John Donohue. 1999. "Non-discretionary Concealed Weapons Law: A Case Study of Statistics, Standards of Proof, and Public Policy," American Law and Economics Review 1: 436-470.

[7] Ayres, Ian and John Donohue. 2003. "Shooting Down the 'More Guns, Less Crime' Hypothesis" Stanford Law Review 51: 1193-1312.

[8] Bartra, Roger. 2012. "La Hidra Mexicana: El Retorno del PRI". Letras Libres, January.

[9] Bergman, Marcelo and Laurence Whitehead. 2009. Criminality, Public Security and the Challenge to Democracy in Latin America. Notre Dame, Indiana: University of Notre Dame Press.

[10] Black, Dan and Daniel Nagin. 1998. "Do Right-to-Carry Laws Deter Violent Crime?" Journal of Legal Studies 27: 209-219.

[11] Blattman, Chris and Edward Miguel. 2010. "Civil War." The Journal of Economic Literature 48(1): 3-57.

[12] Bureau of Alcohol, Tobacco, Firearms and Explosives. 2010. Lists of Federal Firearms Licensees. Available at: http://www.atf.gov/about/foia/ffl-list-2010.html, last accessed March 3, 2012.

[13] Calderón, Felipe. 2009. Tercer informe de gobierno. (Third Government Report of the Mexican Presidency).

[14] Cameron, A. C. and P.K. Trivedi. 2009. Microeconometrics Using Stata. College Station, TX: Stata Press.

[15] CBS News. 2011. "Mexico wants to Sue U.S. Gunmakers", April 21. Online article http://www.cbsnews.com/8301-31727_162-20056210-10391695.html, last accessed April $27,2011$.

[16] Centro de Investigaci - ón para el Desarrollo, A. C. (CIDAC). 2011. Base de datos electoral CIDAC. Available at: http://www.cidac.org/esp/Datos_Electorales.php

[17] Chicoine, Luke. 2011. "Exporting the Second Amendment: U.S. Assault Weapons and the Homicide Rate in Mexico." Working Paper, University of Notre Dame.

[18] Chu, Vivian S. and William J. Krouse. 2009. "Gun Trafficking and the Southwest Border." Congressional Research Service Report R40733.

[19] Collier, Paul. 2007. The Bottom Billion. Oxford: Oxford University Press. 
[20] Collier, Paul, and Anke Hoeffler. 1998. "On Economic Causes of Civil War." Oxford Economic Papers 50: 563-573.

[21] Collier, Paul, and Anke Hoeffler. 2004. "Greed and Grievance in Civil War." Oxford Economic Papers 56: 563-595.

[22] Collier, Paul, et al. 2003. Breaking the Conflict Trap: Civil War and Development Policy. Oxford and Washington DC: Oxford University Press and World Bank.

[23] Congressional Research Service (CRS). 2007. Mexico's Drug Cartels. Report for Congress. October 16.

[24] Dell, Melissa. 2011. "The Economic and Spillover Effects of Organized Crime: Evidence from the Mexican Drug War." Working paper, MIT.

[25] DellaVigna, Stefano and Eliana La Ferrara. 2010. "Detecting Illegal Arms Trade." American Economic Journal: Economic Policy 2(4): 26-57.

[26] Díaz-Cayeros, Alberto, Beatriz Magaloni, Aila Matanock, and Vidal Romero. 2011. "Living in Fear: Mapping the Social Embeddedness of Drug Gangs and Violence in Mexico." Working Paper, UCSD.

[27] Donohue, John and Steven D. Levitt. 1998. "Guns, Violence, and the Efficiency of Illegal Markets." American Economic Review: Papers and Proceedings 88(2): 463-467.

[28] Duggan, M. 2003. "More guns, more crime." Journal of Political Economy 109(5): 10861114.

[29] Duggan, M., Randi Hjalmarsson, Brian A. Jacob. (forthcoming). "The Short-Term and Localized Effect of Gun Shows: Evidence from California and Texas" Review of Economics and Statistics.

[30] Dunleavy, Patrick and Françoise Boucek. 2003. "Constructing the Number of Parties." Party Politics 9: 291-315.

[31] El Universal. 2011. "Ven insuficiente plan de EU para control de armas", July 12. http://www.eluniversal.mx/notas/778906.html

[32] El Universal. 2011. "Centroamérica, paraíso de las armas", November 15. http://www.eluniversal.com.mx/internacional/75188.html

[33] Escalante, Fernando. 2011. "Homicidios 2008-2009: La muerte tiene permiso." Nexos, January 03 . 
[34] Fearon, James D., and David Laitin. 2003. "Ethnicity, Insurgency, and Civil War." American Political Science Review 97: 75-90.

[35] Freedman, Dan. 2011a. "California gun-control laws cut flow to Mexico" SF Gate, May 29. Online article. Retrieved from: http://www.sfgate.com/cgibin/article.cgi?f=/c/a/2011/05/28/MN6U1JM5GF.DTL, last accessed February 29, 2012.

[36] Freedman, Dan. 2011b. "Study finds Mexican gangs prefer high-powered assault rifles." The Houston Chronicle. May 29. online article http://www.chron.com/news/nationworld/article/Study-finds-Mexican-gangs-prefer-high-powered-1683978.php, last accessed February 29, 2012.

[37] Frías, C. and J. Valdez. 2002. "Buscará la DEA extradición de Arellano Félix", La Jornada, March 10. http://www.jornada.unam.mx/2002/03/10/004n1pol.php?origen=politica.html

[38] Friman, H. R. and P. Andreas. 1999. The Illicit Global Economy and State Power. Lanham, MD: Rowman \& Littlefield Publishers.

[39] Gleditsch, Kristian Skrede. 2002. All Politics Is Local: The Diffusion of Conflict, Integration, and Democratization. Ann Arbor, MI: Univer sity of Michigan Press.

[40] Gleditsch, Kristian Skrede. 2007. "Transnational Dimensions of Civil War" Journal of Peace Research 44: 293-309.

[41] Gleditsch, Kristian Skrede and Kyle C. Beardsley. 2004. "Nosy Neighbors: Third Party Actors in Central American Conflicts." Journal of Conflict Resolution 46: 379-402.

[42] Gleditsch, Kristian Skrede and Idean Salehyan. 2007. "Civil War and Interstate Disputes", in Kaare Strom \& Magnus Oberg (eds.) Resources, Governance and Civil Conflict. London: Routledge.

[43] Gleditsch, Kristian Skrede, Idean Salehyan and Kenneth Schultz. 2008. "Fighting at Home, Fighting Abroad: How Civil Wars Lead to International Disputes." Journal of Conflict Resolution 52: 479-506.

[44] Godnick, William, Robert Muggah and Camilla Wasznik. 2002. "Stray Bullets: the Impact of Small Arms Misuse in Central America." Small Arms Survey, occasional paper, Geneva.

[45] Golosov, Grigorii. 2010. "The Effective Number of Parties: A New Approach." Party Politics 16: 171-192. 
[46] Hiskey, Jonathan T. and Shaun Bowler. 2005. "Local Context and Democratization in Mexico" American Journal of Political Science 49: 57-71.

[47] Instituto Nacional de Estadística y Geografía (INEGI). 2011. Estadísticas de mortalidad.

[48] Killebrew, Bob and Jennifer Bernal. 2010. Crime Wars: Gangs, Cartels and U.S. National Security. Center for a New American Security.

[49] Knight, Brian. 2011. "State Gun Policy and Cross-State Externalities: Evidence from Crime Gun Tracing." NBER Working Paper 17469.

[50] Koper, Christopher S., and Jeffrey A. Roth. 2001. "The Impact of the 1994 Federal Assault Weapons Ban on Gun Markets: An Assessment of Short-Term Primary and Secondary Market Effects." Journal of Quantitative Criminology 18(2): 239-266.

[51] Laakso Markku and Rein Taagepera. 1979. "The 'Effective' Number of Parties: A Measure with Application to West Europe" Comparative Political Studies 12: 3-27

[52] Leslie, Glaister. 2010. "Confronting the Don: the Political Economy of Gang Violence in Jamaica." Small Arms Survey, occasional paper, Geneva.

[53] Lott, John. 1998. More Guns, Less Crime: Analyzing Crime and Gun Control Laws. University of Chicago Press: Chicago, Illinois. (2nd and 3rd editions in 2001 and 2010.)

[54] Lott, John R. and David B. Mustard. 1997. "Crime, Deterrence, and Right-to-Carry Concealed Handguns." Journal of Legal Studies 26(1): 1-68.

[55] Ludwig, Jens. 1998. "Concealed-Gun-Carrying Laws and Violent Crime: Evidence from State Panel Data." International Review of Law and Economics 18: 239-254.

[56] Ludwig, Jens and Philip J. Cook. 2000. "Homicide and Suicide Rates Associated with Implementation of the Brady Handgun Violence Prevention Act." Journal of the American Medical Association 284(5): 585- 591.

[57] Luhnow, David and Jose de Cordoba. 2009. "The Drug Lord Who Got Away", The Wall Street Journal, June.

[58] Mayors Against Illegal Guns. 2008. "Inside Straw Purchasing."

[59] Merino, Mauricio. 2003. La transición votada. Crítica ala interpretación del cambio político en México. Mexico City: Fondo de Cultura Económica.

[60] McDonald, James H. 2005. "The Narcoeconomy and Small-town, Rural Mexico." Human Organization 64: 115-125. 
[61] Miguel, Edward, Shanker Satyanath, and Ernest Sergenti. 2004. "Economic Shocks and Civil Conflict: An Instrumental Variables Approach." Journal of Political Economy 112(4): 725-753.

[62] Molinar, Juan. 1991a. El tiempo de la legitimidad: Elecciones, Autoritarismo y Democracia en México. Mexico City: Cal y Arena.

[63] Molinar, Juan. 1991b. "Counting the Number of Parties: An Alternative Index." American Political Science Review 85: 1383-1391.

[64] Moody, Carlisle. 2001. "Testing for the Effects of Concealed Weapons Laws: Specification Errors and Robustness." Journal of Law and Economics 44: 2, Part 2, 799-813.

[65] Naím, Moisés. 2006. Illicit: How Smugglers, Traffickers, and Copycats are Hijacking the Global Economy. New York: Anchor Books.

[66] Nájar, Alberto. 2005. "La nueva geografía del narco", La Jornada, July 24. http://www.jornada.unam.mx/2005/07/24/mas-najar.html

[67] National Drug Intelligence Center. 2010. National Drug Threat Assessment.

[68] O'Neil, Shannon. 2009. "The Real War in Mexico: How Democracy Can Defeat the Drug Cartels." Foreign Affairs, July/August.

[69] Osorio, Javier. 2012. "Democratization and Drug violence in Mexico." Working paper, University of Notre Dame.

[70] Owens, Emily G. 2011. "The Birth of the Organized Crime? The American Temperance Movement and Market-Based Violence". Working Paper, Cornell.

[71] Procuraduría General de la República (PGR). 2008. "Tráfico de armas México-USA". November 27.

[72] Resa Nestares, Carlos. 2004. "El mapa de las drogas en Mexico." El Comercio de Drogas Ilegales en Mexico-Notas de Investigacion.

[73] Ríos, Viridiana and David A. Shirk. 2011. "Drug Violence in Mexico: Data and Analysis Through 2010". Trans-Border Institute, University of San Diego.

[74] Salehyan, Idean. 2008. "The Externalities of Civil Strife: Refugees as a Source of International Conflict." American Journal of Political Science 52: 787-801.

[75] Salehyan, Idean. 2009. Rebels Without Borders: Transnational Insurgencies in World Politics. Ithaca and London: Cornell University Press. 
[76] Salehyan, Idean and Kristian Skrede Gleditsch. 2006. "Refugee Flows and the Spread of Civil War" International Organization 60: 335-366.

[77] Sartori, Giovanni. 1976. Parties and Party Systems: A Framework for Analysis. New York: Cambridge University Press.

[78] Seelke, Clare Ribando. 2011. "Gangs in Central America." Congressional Research Service Report RL34112.

[79] Snyder, Richard and Angelica Duran-Martinez. 2009. "Does illegality breed violence? Drug trafficking and state-sponsored protection rackets." Crime, Law, and Social Change 52: 253-273.

[80] Toro, María Celia. 1995. Mexico's War on Drugs. Causes and Consequences. Boulder: Lynne Rienner.

[81] United Nations Office of Drugs and Crime (UNODC). 2010. The Globalization of Crime.

[82] U.S. Government Accountability Office (GAO). 2009. "Firearms Trafficking: U.S. Efforts to Combat Arms Trafficking to Mexico Face Planning and Coordination Challenges." Report to Congressional Requesters.

[83] Villarreal, Andrés. 2002. "Political Competition and Violence in Mexico: Hierarchical Social Control in Local Patronage Structures." American Sociological Review 67: 477-498.

[84] Violence Policy Center Report. 2009. "Indicted: Types of Firearms and Methods of Gun Trafficking from the United States to Mexico as Revealed in U.S. Court Documents."

[85] Weiner, Tim and Ginger Thompson. 2001. "U.S. Guns Smuggled into Mexico Aid Drug War." The New York Times, May 19.

[86] World Bank. 2010. "Crime and Violence in Central America Volume II." Report No. 56781LAC. 
Table I

Descriptive Statistics

\begin{tabular}{|c|c|c|c|}
\hline & Obs. & Mean & Std. dev. \\
\hline \multicolumn{4}{|l|}{ Panel-level Variables 2002-2006: } \\
\hline Population & 530 & 76272 & 216489 \\
\hline Homicides per 1000 pop. & 530 & 0.135 & 0.312 \\
\hline Gun-related homicides per 1000 pop. & 530 & 0.095 & 0.267 \\
\hline Non-homicide deaths per 1000 pop. & 530 & 4.218 & 1.881 \\
\hline Non-gun homicides per 1000 pop. & 530 & 0.032 & 0.082 \\
\hline Rifles seized per 1000 pop. & 530 & 0.088 & 0.37 \\
\hline Multiple rifles seized per 1000 pop. & 530 & 0.019 & 0.106 \\
\hline Handguns seized per 1000 pop. & 530 & 0.073 & 0.344 \\
\hline Multiple handguns seized per 1000 pop. & 530 & 0.015 & 0.117 \\
\hline Log municipal expenditure per capita & 521 & -5.878 & 0.619 \\
\hline Log drug value seized in municipio & 530 & 6.403 & 7.905 \\
\hline Log marijuana eradication & 530 & 0.195 & 0.699 \\
\hline Log poppy eradication & 530 & 0.098 & 0.436 \\
\hline Log drug value seized in nearest port & 530 & 18.569 & 1.198 \\
\hline Log unauthorized immigrants in nearest port & 530 & 11.736 & 0.933 \\
\hline Log earnings per capita in nearest port & 530 & 10.164 & 0.211 \\
\hline Employment ratio in nearest port & 530 & 0.29 & 0.064 \\
\hline \multicolumn{4}{|l|}{ Panel-level Variables 1992-1996: } \\
\hline Population & 400 & 74740 & 179035 \\
\hline Homicides per 1000 pop. & 400 & 0.098 & 0.137 \\
\hline Gun-related homicides per 1000 pop. & 400 & 0.062 & 0.106 \\
\hline Log municipal expenditure per capita & 398 & -7.895 & 0.611 \\
\hline Log marijuana eradication & 400 & 0.220 & 0.603 \\
\hline Log poppy eradication & 400 & 0.010 & 0.104 \\
\hline Log earnings per capita in nearest port & 400 & 9.790 & 0.176 \\
\hline Employment ratio in nearest port & 400 & 0.258 & 0.072 \\
\hline \multicolumn{4}{|l|}{ Cross-sectional variables: } \\
\hline Segment NCA & 37 & 0.921 & 0.274 \\
\hline Distance border (thousands) & 106 & 0.057 & 0.027 \\
\hline Distance NCA (thousands) & 106 & 0.06 & 0.028 \\
\hline Proximity border (thousands) & 106 & 0.943 & 0.027 \\
\hline Proximity NCA (thousands) & 106 & 0.94 & 0.028 \\
\hline Highway & 106 & 0.774 & 0.421 \\
\hline Log municipal income per capita in 2000 & 104 & 8.983 & 0.294 \\
\hline Municipal school enrollment in 2000 (percent) & 106 & 57.775 & 5.222 \\
\hline Laakso and Taagepera Index & 106 & 2.232 & 0.408 \\
\hline Molinar Index & 106 & 1.829 & 0.322 \\
\hline Dunleavy and Boucek Index & 106 & 2.06 & 0.334 \\
\hline Golosov Index & 106 & 1.976 & 0.352 \\
\hline High Drug Trafficking & 106 & 0.330 & 0.473 \\
\hline
\end{tabular}

Notes. This table shows descriptive statistics of key variables for the set of municipios that lie within 100 miles of the nearest border port, which constitutes the 100-mile sample. Distance border is a municipio's distance to the nearest of any port on the U.S.-Mexico border, in thousands of miles. Proximity border is a municipio's proximity to the nearest of any border port, defined as 1 - Distance border. Distance NCA is defined as a municipio's distance to the nearest of any non-California port, in Texas, Arizona or New Mexico, in thousands of miles. Proximity NCA is the municipio's proximity to the nearest nonCalifornia port, defined as 1 - Distance NCA. Segment NCA is an indicator of whether the municipio lies on the nonCalifornia segment of the U.S.-Mexico border, adjacent to either Texas, Arizona, or new Mexico. Highway is an indicator for whether a municipio has a highway. Log municipal income per capita is the natural log of 2000 municipal GDP per capita measured in U.S. Dollars. Municipal school enrollment is the fraction of the population aged 6-24 attending school in 2000. Log poppy and marijuana eradication are the natural log of hectares of each drug crop eradicated plus 1 . Log drug value seized in each municipio is the natural $\log$ of the value of heroin, cocaine, marijuana and methamphetamines plus 1 seized in each municipio. The Laakso and Taagepera, Molinar, Dunleavy and Boucek, and Golosov are indices of the effective number of parties contesting mayoral elections at the municipio level. High Drug Trafficking is an indicator which equals one if the municipio has an above-mean narcotics crime per capita rate over 2002-2004. 
Table II

The FAWB Expiration and Violence in Mexican Municipios

\begin{tabular}{|c|c|c|c|c|c|}
\hline & (1) & (2) & (3) & (4) & (5) \\
\hline & \multicolumn{5}{|c|}{ Panel A: Homicides } \\
\hline Segment NCA $x$ post & $\begin{array}{l}0.322 * \\
(0.173)\end{array}$ & $\begin{array}{c}0.532 * * \\
(0.231)\end{array}$ & - & - & - \\
\hline Proximity NCA $x$ post & - & - & $\begin{array}{l}4.319 * \\
(2.333)\end{array}$ & $\begin{array}{c}4.081 * * \\
(1.944)\end{array}$ & $\begin{array}{c}4.688 * * * \\
(1.810)\end{array}$ \\
\hline \multirow[t]{2}{*}{ Observations } & 185 & 180 & 420 & 420 & 409 \\
\hline & \multicolumn{5}{|c|}{ Panel B: Gun-related Homicides } \\
\hline Segment NCA $x$ post & $\begin{array}{l}0.383 * \\
(0.227)\end{array}$ & $\begin{array}{c}0.760 * * \\
(0.326)\end{array}$ & - & - & - \\
\hline Proximity NCA $x$ post & - & - & $\begin{array}{l}4.995 * \\
(3.015)\end{array}$ & $\begin{array}{l}4.654 * \\
(2.421)\end{array}$ & $\begin{array}{c}6.835 * * * \\
(2.399)\end{array}$ \\
\hline Observations & 185 & 177 & 395 & 395 & 384 \\
\hline Proximity border $\mathrm{x}$ post control? & - & - & - & Y & $\mathrm{Y}$ \\
\hline Income, immigration and drug controls? & - & $\mathrm{Y}$ & - & - & $\mathrm{Y}$ \\
\hline Sample & Border & Border & 100-mile & 100-mile & 100-mile \\
\hline $\begin{array}{l}\text { Notes. All estimates are based on Poisson regressi } \\
\text { effects. Robust standard errors clustered at the mu } \\
\text { whether the municipio lies on the non-California s } \\
\text { interacts the proximity of a municipio to the neares } \\
\text { post interacts the proximity to the nearest of all port } \\
\text { (5) include: log municipal per capita income in } 200 \\
\text { expenditures per capita; log value of municipal } \\
\text { municipio plus } 1 \text {; as well as the employment ratio, } \\
\text { nearest U.S. port. The border sample includes the } \\
\text { includes the set of municipios that lie within } 100 \\
\text { level; and } * \text { is significant at the } 10 \% \text { level. }\end{array}$ & $\begin{array}{l}\text { using popu } \\
\text { pio level a } \\
\text { lent of the } \\
\text { rt in Arizon } \\
\text { ith a post-2 } \\
\text { nd the scho } \\
\text { seizures pl } \\
\text { average eal } \\
\text { f municipi } \\
\text { s of the ne }\end{array}$ & $\begin{array}{l}\text { on exposure } \\
\text { lown in par } \\
\text {--Mexico bo } \\
\text { Jew Mexico } \\
\text { indicator. In } \\
\text { g ratio in } 20 \\
\text {; log hectar } \\
\text { gs, log unau } \\
\text { lat are locat }\end{array}$ & $\begin{array}{l}\text { iables not sh } \\
\text { ses. Segmen } \\
\text { with a post- } \\
\text { exas with a p } \\
\text {, immigratio } \\
\text { nteracted wit } \\
\text { f marijuana } \\
\text { zed immigrar } \\
\text { ong the U.S. }\end{array}$ & $\begin{array}{l}\text { include muni } \\
\text { A x post inte } \\
\text { indicator. Pr } \\
004 \text { indicator } \\
\text { drug control } \\
\text { ost-2004 ind } \\
\text { eroin poppie } \\
\text { d log value o } \\
\text { cio border. } \\
\text { level; } * * \text { is }\end{array}$ & $\begin{array}{l}\text { and year fixec } \\
\text { an indicator o } \\
\text { ity NCA x pos } \\
\text { ximity border } \\
\text { columns (2) an } \\
\text {; log municipa } \\
\text { dicated in eacl } \\
\text { gs seized in th } \\
00 \text {-mile sampl } \\
\text { icant at the 5\% }\end{array}$ \\
\hline
\end{tabular}




\begin{tabular}{|c|c|c|c|}
\hline & (1) & (2) & (3) \\
\hline & \multicolumn{3}{|c|}{ Panel A: Homicides } \\
\hline Lead1 Proximity NCA $x$ post & - & - & $\begin{array}{l}-2.773 \\
(1.882)\end{array}$ \\
\hline Lead2 Proximity NCA $x$ post & - & - & $\begin{array}{c}1.279 \\
(1.628)\end{array}$ \\
\hline Lead3 Proximity NCA $x$ post & - & - & $\begin{array}{c}3.382 \\
(2.381)\end{array}$ \\
\hline Lead4 Proximity NCA $x$ post & - & - & $\begin{array}{l}-1.999 \\
(1.444)\end{array}$ \\
\hline Proximity NCA $x$ post & $\begin{array}{c}3.484 * * \\
(1.714)\end{array}$ & $\begin{array}{c}4.485^{* * * *} \\
(1.395)\end{array}$ & $\begin{array}{l}-2.420 \\
(2.458)\end{array}$ \\
\hline Lag1 Proximity NCA $x$ post & - & - & $\begin{array}{c}10.983 * * * \\
(4.049)\end{array}$ \\
\hline Lag2 Proximity NCA $x$ post & - & - & $\begin{array}{l}-2.377 \\
(3.263)\end{array}$ \\
\hline Lag3 Proximity NCA $x$ post & - & - & $\begin{array}{c}0.388 \\
(2.380)\end{array}$ \\
\hline Lag4 Proximity NCA $x$ post & - & - & $\begin{array}{c}0.093 \\
(1.344)\end{array}$ \\
\hline \multirow[t]{2}{*}{ Observations } & 1,311 & 1,091 & 1,009 \\
\hline & \multicolumn{3}{|c|}{ Panel B: Gun-related Homicides } \\
\hline Lead1 Proximity NCA $x$ post & - & - & $\begin{array}{l}-3.258 \\
(2.403)\end{array}$ \\
\hline Lead2 Proximity NCA $x$ post & - & - & $\begin{array}{c}1.085 \\
(2.518)\end{array}$ \\
\hline Lead3 Proximity NCA $x$ post & - & - & $\begin{array}{c}0.866 \\
(2.509)\end{array}$ \\
\hline Lead4 Proximity NCA $x$ post & - & - & $\begin{array}{l}-1.674 \\
(2.421)\end{array}$ \\
\hline Proximity NCA $x$ post & $\begin{array}{l}4.020^{*} \\
(2.281)\end{array}$ & $\begin{array}{c}5.351 * * * \\
(1.905)\end{array}$ & $\begin{array}{l}-0.061 \\
(3.116)\end{array}$ \\
\hline Lag1 Proximity NCA $x$ post & - & - & $\begin{array}{l}9.336^{* * *} \\
(3.819)\end{array}$ \\
\hline Lag2 Proximity NCA $x$ post & - & - & $\begin{array}{l}-1.915 \\
(3.195)\end{array}$ \\
\hline Lag3 Proximity NCA $x$ post & - & - & $\begin{array}{c}1.232 \\
(3.592)\end{array}$ \\
\hline Lag4 Proximity NCA $x$ post & - & - & $\begin{array}{c}2.170 \\
(1.812)\end{array}$ \\
\hline Observations & 1,184 & 952 & 878 \\
\hline Proximity border $\mathrm{x}$ post control? & $\mathrm{Y}$ & Y & Y \\
\hline Income, immigration and drug controls? & - & $\mathrm{Y}$ & $\mathrm{Y}$ \\
\hline Sample & 100-mile & 100-mile & 100-mile \\
\hline $\begin{array}{l}\text { Notes. All estimates are based on Poisson regre } \\
\text { municipio and quarter fixed effects. Robust standar } \\
\text { Proximity NCA x post interacts the proximity of a } \\
\text { a post- } 4 \text { th quarter of } 2004 \text { indicator. Proximity bo } \\
\text { post-4th quarter of } 2004 \text { indicator. Income, immigr } \\
\text { and (5) of Table II. The } 100 \text {-mile sample includes } \\
\text { Column (3) includes } 4 \text { leads and } 4 \text { lags of the Prox } \\
\text { significant at the } 5 \% \text { level; and * is significant at the }\end{array}$ & $\begin{array}{l}\text { population } \\
\text { tered at the } m \\
\text { the nearest por } \\
\text { nteracts the pr } \\
\text { g controls in } \\
\text { unicipios that } \\
\text { post variable }\end{array}$ & $\begin{array}{l}\text { ire. Variables } \\
\text { io level are s } \\
\text { rizona, New } 1 \\
\text { y to the neare } \\
\text { ( }(2) \text { are those } \\
\text { thin } 100 \text { mile } \\
\text { is significant }\end{array}$ & $\begin{array}{l}\text { shown includ } \\
\text { n in parentheses } \\
\text { co or Texas witl } \\
\text { f all ports with } \\
\text { d in columns ( } 2 \\
\text { the nearest port } \\
1 \% \text { level; } * * \text { i }\end{array}$ \\
\hline
\end{tabular}




\section{Table IV}

The FAWB Expiration and Violence - Robustness Checks

\begin{tabular}{|c|c|c|c|c|c|c|c|}
\hline & (1) & $(2)$ & (3) & (4) & (5) & (6) & (7) \\
\hline & \multicolumn{7}{|c|}{ Panel A: Homicides } \\
\hline Proximity NCA $x$ post & $\begin{array}{c}4.688^{* * * *} \\
(1.810)\end{array}$ & $\begin{array}{c}2.512 * * \\
(1.171)\end{array}$ & $\begin{array}{l}2.936^{*} \\
(1.562)\end{array}$ & $\begin{array}{c}6.220 * * * \\
(2.308)\end{array}$ & $\begin{array}{c}4.833 * * * \\
(1.870)\end{array}$ & $\begin{array}{l}4.219 * * \\
(1.782)\end{array}$ & $\begin{array}{l}3.447 * \\
(1.866)\end{array}$ \\
\hline Proximity border $\mathrm{x}$ post & $\begin{array}{c}0.844 \\
(1.648)\end{array}$ & $\begin{array}{l}-0.190 \\
(1.827)\end{array}$ & $\begin{array}{c}0.090 \\
(1.645)\end{array}$ & $\begin{array}{l}-0.105 \\
(2.151)\end{array}$ & $\begin{array}{c}1.816 \\
(1.702)\end{array}$ & $\begin{array}{c}1.566 \\
(1.846)\end{array}$ & $\begin{array}{c}1.119 \\
(1.667)\end{array}$ \\
\hline Non-gun homicides & - & - & - & - & - & $\begin{array}{c}0.007 * * * \\
(0.002)\end{array}$ & - \\
\hline Non-homicide deaths & - & - & - & - & - & $\begin{array}{c}0.000 \\
(0.000)\end{array}$ & - \\
\hline \multirow[t]{2}{*}{ Observations } & 409 & 409 & 409 & 409 & 350 & 409 & 409 \\
\hline & \multicolumn{7}{|c|}{ Panel B: Gun-related Homicides } \\
\hline Proximity NCA $x$ post & $\begin{array}{c}6.835 * * * \\
(2.399)\end{array}$ & $\begin{array}{c}3.476^{* *} \\
(1.513)\end{array}$ & $\begin{array}{l}4.285^{* *} \\
(2.124)\end{array}$ & $\begin{array}{l}7.590^{* *} \\
(3.022)\end{array}$ & $\begin{array}{c}6.999 * * * \\
(2.543)\end{array}$ & $\begin{array}{c}6.964 * * * \\
(2.332)\end{array}$ & $\begin{array}{l}4.573 * \\
(2.473)\end{array}$ \\
\hline Proximity border $\mathrm{x}$ post & $\begin{array}{l}-0.135 \\
(2.872)\end{array}$ & $\begin{array}{l}-2.172 \\
(2.630)\end{array}$ & $\begin{array}{l}-1.592 \\
(2.849)\end{array}$ & $\begin{array}{l}-0.466 \\
(3.044)\end{array}$ & $\begin{array}{c}1.527 \\
(3.088)\end{array}$ & $\begin{array}{l}-0.818 \\
(3.053)\end{array}$ & $\begin{array}{c}0.304 \\
(2.704)\end{array}$ \\
\hline Non-gun homicides & - & - & - & - & - & $\begin{array}{l}-0.001 \\
(0.002)\end{array}$ & - \\
\hline Non-homicide deaths & - & - & - & - & - & $\begin{array}{c}0.000 \\
(0.000)\end{array}$ & - \\
\hline \multirow[t]{2}{*}{ Observations } & 384 & 384 & 384 & 384 & 335 & 384 & 384 \\
\hline & \multicolumn{7}{|c|}{ Panel C: Non-gun Homicides } \\
\hline Proximity NCA $x$ post & $\begin{array}{l}-0.601 \\
(1.631)\end{array}$ & $\begin{array}{l}-0.601 \\
(1.918)\end{array}$ & $\begin{array}{l}-0.587 \\
(1.285)\end{array}$ & $\begin{array}{c}1.691 \\
(2.067)\end{array}$ & $\begin{array}{l}-0.687 \\
(1.697)\end{array}$ & - & $\begin{array}{l}-0.519 \\
(1.787)\end{array}$ \\
\hline Proximity $\mathrm{x}$ post & $\begin{array}{c}2.014 \\
(2.308)\end{array}$ & $\begin{array}{l}2.014 \\
(2.714)\end{array}$ & $\begin{array}{l}2.109 \\
(2.354)\end{array}$ & $\begin{array}{l}-0.531 \\
(2.925)\end{array}$ & $\begin{array}{c}1.664 \\
(2.513)\end{array}$ & - & $\begin{array}{c}1.952 \\
(2.275)\end{array}$ \\
\hline Observations & 312 & 312 & 312 & 312 & 287 & - & 312 \\
\hline Year fixed effects? & $\mathrm{Y}$ & $\mathrm{Y}$ & - & - & $\mathrm{Y}$ & $\mathrm{Y}$ & $\mathrm{Y}$ \\
\hline Post-2004 indicator? & - & - & $\mathrm{Y}$ & $\mathrm{Y}$ & - & - & - \\
\hline Linear time trends? & - & - & - & Y & - & - & - \\
\hline Income, immigration and drug controls? & Y & Y & $\mathrm{Y}$ & Y & $\mathrm{Y}$ & Y & Y \\
\hline Current enforcement controls? & - & - & - & - & - & - & $\mathrm{Y}$ \\
\hline Sample & 100-mile & 100-mile & 100-mile & 100-mile & $\begin{array}{l}\text { 100-mile } \\
\& \text { highway }\end{array}$ & 100-mile & 100-mile \\
\hline Estimator & Poisson & $\begin{array}{l}\text { Negative } \\
\text { Binomial }\end{array}$ & Poisson & Poisson & Poisson & Poisson & Poisson \\
\hline
\end{tabular}


Table V

The FAWB Expiration and Gun Seizures

\begin{tabular}{|c|c|c|c|c|}
\hline & (1) & (2) & (3) & (4) \\
\hline & Rifles & $\begin{array}{c}\text { Multiple } \\
\text { Rifles }\end{array}$ & Handguns & $\begin{array}{l}\text { Multiple } \\
\text { Handguns }\end{array}$ \\
\hline Proximity NCA $x$ post & $\begin{array}{c}10.265^{*} \\
(5.733)\end{array}$ & $\begin{array}{c}22.909 * * * \\
(8.817)\end{array}$ & $\begin{array}{c}3.551 \\
(5.206)\end{array}$ & $\begin{array}{c}-7.191 \\
(13.359)\end{array}$ \\
\hline Observations & 244 & 159 & 242 & 129 \\
\hline Proximity border x post control? & $\mathrm{Y}$ & Y & $\mathrm{Y}$ & Y \\
\hline Income, immigration and drug controls? & $\mathrm{Y}$ & Y & $\mathrm{Y}$ & Y \\
\hline Sample & 100-mile & 100-mile & 100-mile & 100-mile \\
\hline
\end{tabular}


Table VI

The FAWB Expiration and Violence across Demographic Groups

(1)

(2)

(3)

(4)

(5)

Panel A: Homicides

Proximity NCA $x$ post

\begin{tabular}{ccccc}
\hline $3.991 * * *$ & $4.935 * * *$ & $3.833 * *$ & $7.720 * * *$ & $3.341 * *$ \\
$(1.478)$ & $(1.713)$ & $(1.870)$ & $(2.331)$ & $(1.522)$
\end{tabular}

Observations

409

381

364

259

399

Panel B: Gun-related Homicides

Proximity NCA $x$ post

\begin{tabular}{ccccc}
\hline $6.477 * * *$ & $10.940^{* * *}$ & 3.799 & $13.894 * * *$ & $5.108^{* *}$ \\
$(2.168)$ & $(2.657)$ & $(2.360)$ & $(3.187)$ & $(2.279)$
\end{tabular}

Observations

384

312

334

200

374

Proximity border $\mathrm{x}$ post control?

$\mathrm{Y} \quad \mathrm{Y}$

$\mathrm{Y}$
$\mathrm{Y}$

Y

$\mathrm{Y}$

$\mathrm{Y}$

$\mathrm{Y}$

$\mathrm{Y}$

Income, immigration and drug controls?

All

Aged 18+

All but 18+

Males 18-30

All but males w/o HS

w/o HS

w/o HS

18-30 w/o HS

Notes. All estimates are based on Poisson regressions using population exposure. Variables not shown include municipio and year fixed effects. Robust standard errors clustered at the municipio level are shown in parentheses. Proximity NCA $x$ post interacts the proximity of a municipio to the nearest port in Arizona, New Mexico and Texas with a post-2004 indicator. Proximity border X post interacts the proximity to the nearest of all ports with a post-2004 indicator. Income, immigration and drug controls are those used in columns (2) and (5) of Table II. The "All" sample includes all homicide or gun-related homicide observations not missing information about age, gender and education. For the other samples, "18+" denotes those 18 years or older, 18-30 indicates those between the ages of 18 and 30, and "w/o HS" indicates those without a High School degree. $* * *$ is significant at the $1 \%$ level; $* *$ is significant at the $5 \%$ level; and $*$ is significant at the $10 \%$ level. 


\section{Table VII}

Early Period Falsification: The 1994 FAWB Passage and Violence in Mexican Municipios

(1)

(2)

(3)

(4)

(5)
Segment NCA $x$ post

Proximity NCA $x$ post

Observations

Segment NCA $x$ post

Proximity NCA $x$ post

Observations

Proximity border $\mathrm{x}$ post control?

Income and drug controls?

$\begin{array}{cc}0.110 & 0.265 \\ (0.240) & (0.295)\end{array}$

Panel A: Homicides

$\begin{array}{ll}-0.421 & 0.107\end{array}$

(2.453) (2.317)

1.492

(2.786)

$\begin{array}{llll}155 & 155 & 310 & 310\end{array}$

Panel B: Gun-related Homicides

\begin{tabular}{ccccc}
\hline-0.059 & 0.171 & - & - & - \\
$(0.239)$ & $(0.283)$ & & & \\
- & - & -2.429 & -1.948 & 0.469 \\
& & $(2.490)$ & $(2.275)$ & $(2.609)$
\end{tabular}

155

155

270

270

268

$\begin{array}{ll}- & - \\ - & \mathrm{Y}\end{array}$

Border

Border

100-mile

100-mile

100-mile

Notes. All estimates are based on Poisson regressions using population exposure. Variables not shown include municipio and year fixed effects. Robust standard errors clustered at the municipio level are shown in parentheses. Segment NCA x post interacts an indicator of whether the municipio lies on the non-California segment of the U.S.-Mexico border with a post-1994 indicator. Proximity NCA $x$ post interacts the proximity of a municipio to the nearest port in Arizona, New Mexico or Texas with a post-1994 indicator. Proximity border $x$ post interacts the proximity to the nearest of all ports with a post-1994 indicator. Income and drug controls in columns (2) and (5) include: $\log$ municipal expenditures per capita; log hectares of marijuana and heroin poppies eradicated in each municipio plus 1 ; as well as the employment ratio, and log average earnings in the nearest U.S. port. The border sample includes the set of municipios that are located along the U.S.- Mexico border. The 100-mile sample includes the set of municipios that lie within 100 miles of the nearest port. *** is significant at the $1 \%$ level; $* *$ is significant at the $5 \%$ level; and $*$ is significant at the $10 \%$ level. 
Table VIII

The FAWB Expiration and Violence - Heterogeneous Effects by Electoral Competition and Drug Trafficking

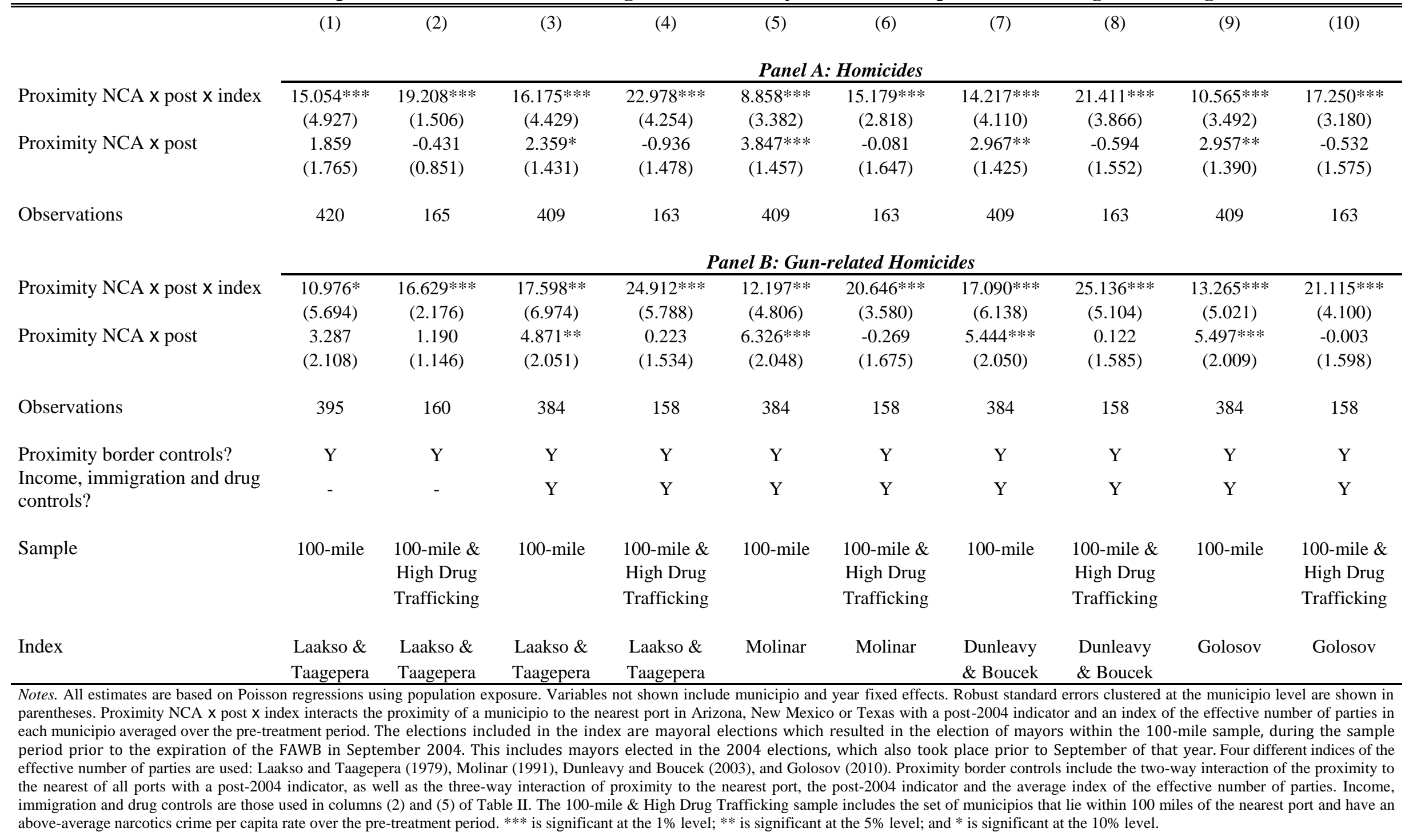




\section{Figure I}

\section{Political Competition over Time}

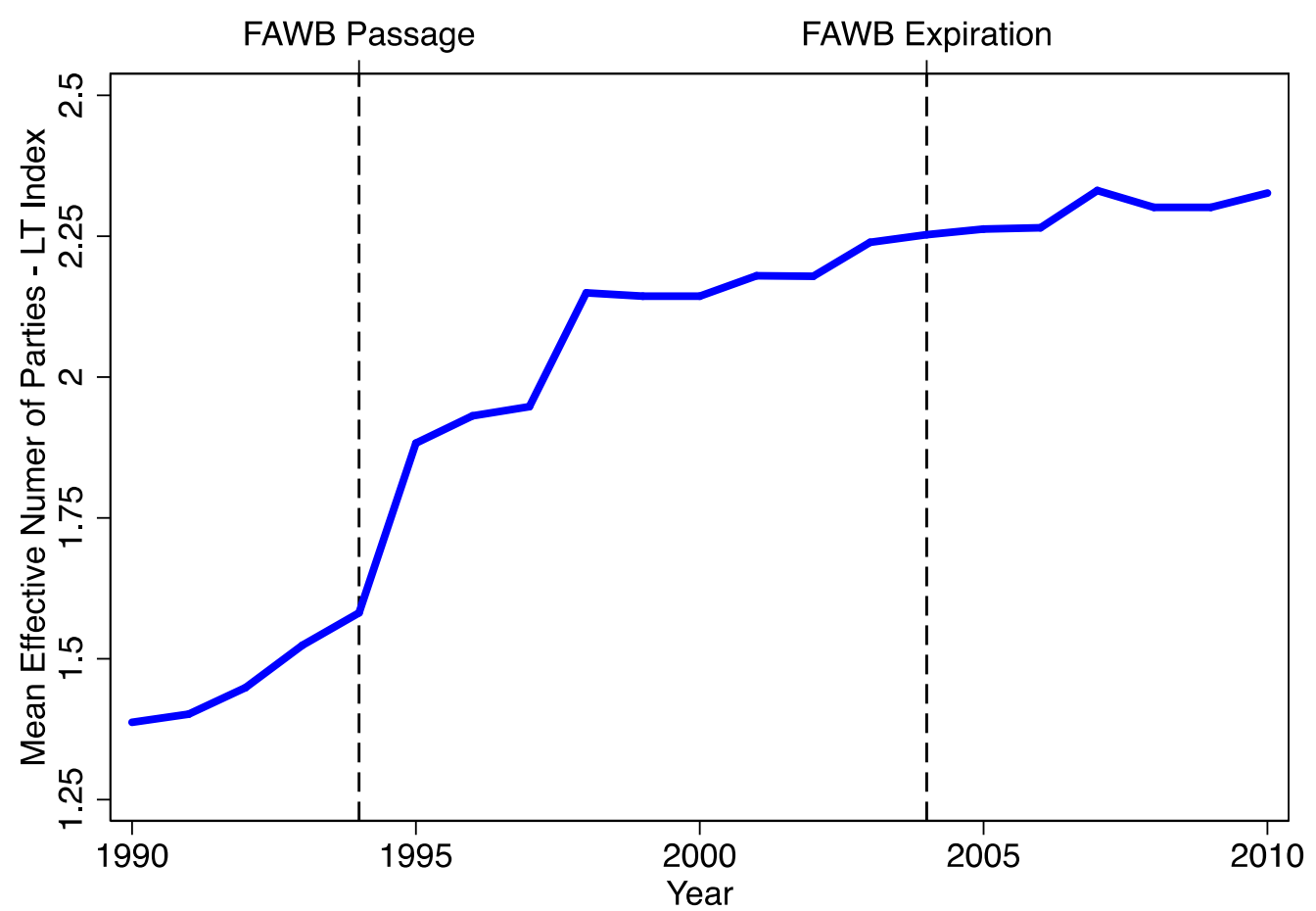

Notes. This figure shows the mean Laakso-Taagepera (LT) index of the effective number of political parties represented among mayoral elections (which take place at the municipal level). For a given year, the LT index is computed using data on the most recent mayoral election. The line labeled "FAWB Passage" denotes 1994, the year in which the U.S. Federal Assault Weapons Ban was passed. The line labeled "FAWB Expiration" denotes 2004, the year in which this legislation expired. 
Figure II

Gun Sales and Production - California versus Other Border States

\section{Panel A: $\quad$ Estimated Annual Total Gun Sales}

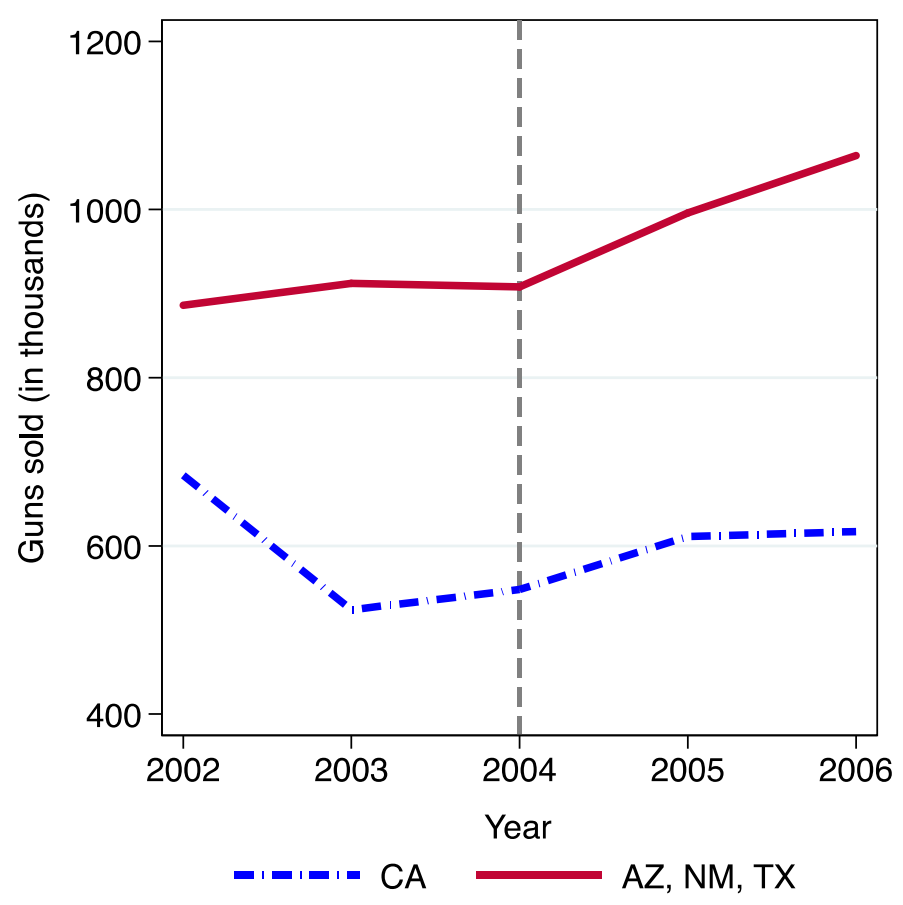

Panel B: $\quad$ Annual Total Production of Rifles

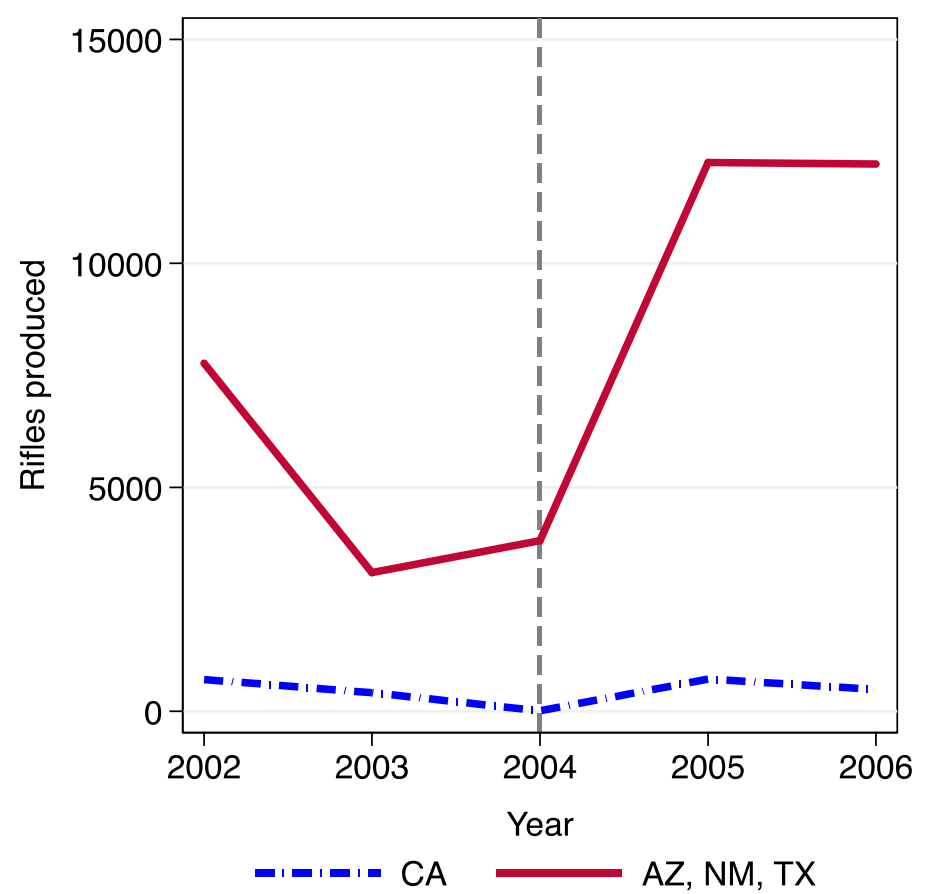

Notes. In Panel A, the total number of gun sales (in thousands) is approximated by the number of FBI NICS firearm background checks originating in the relevant state. The NICS data is available at: http://www.fbi.gov/about-us/cjis/nics/reports/state totals 2011. In Panel B, data on the annual production of rifles comes from the BATF's Annual Firearms Manufacturing and Exportation Reports (AFMER). The dashed vertical line marks 2004, the year in which the federal assault weapons ban expire 
Figure III

Firearms Dealers and Cartel Presence along the U.S. Mexico Border

\section{Panel A: $\quad$ Licensed Firearms Dealers in the Border States}

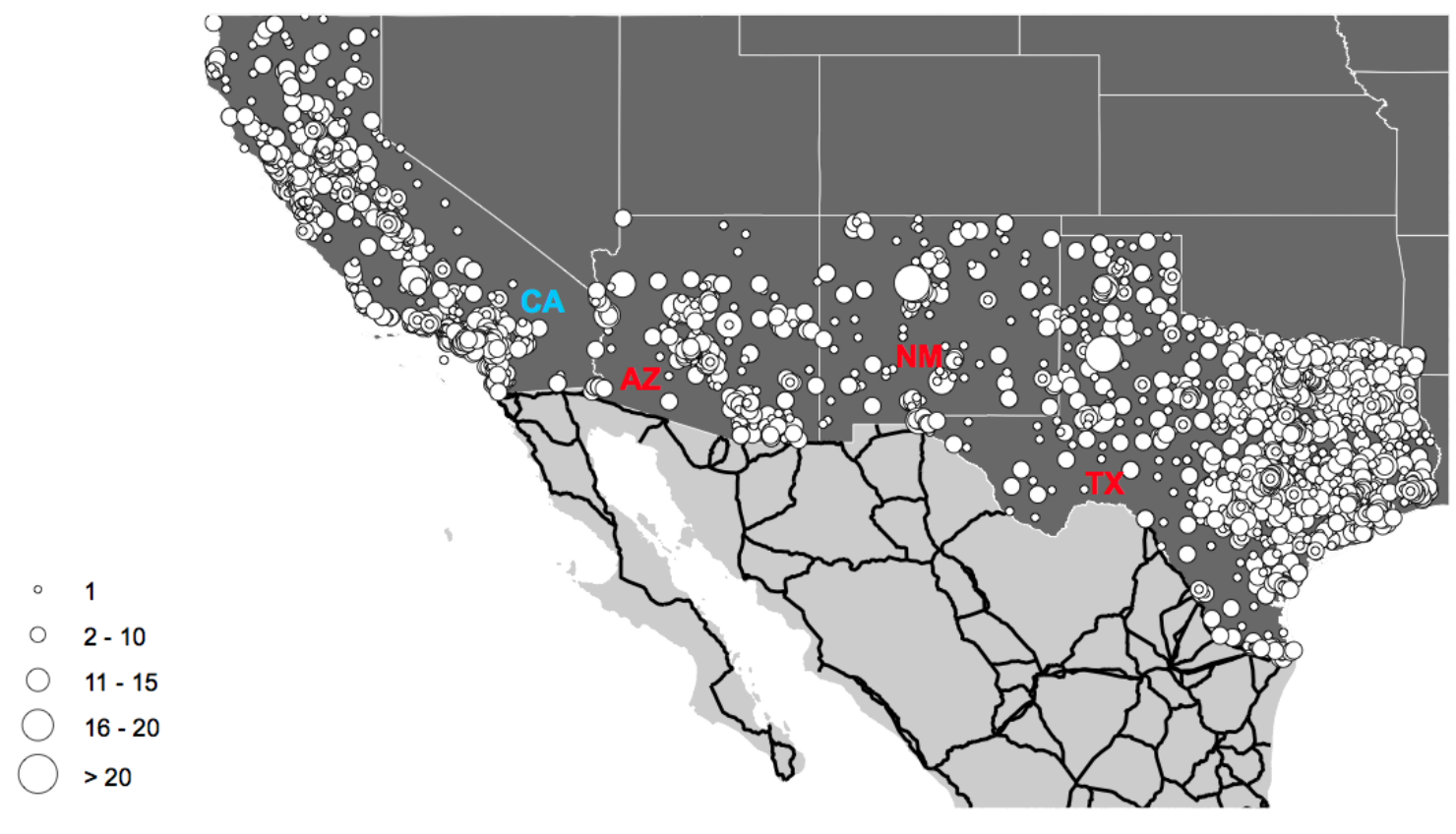

Panel B: $\quad$ Cartel Presence along the U.S.-Mexico Border (2002-2006)

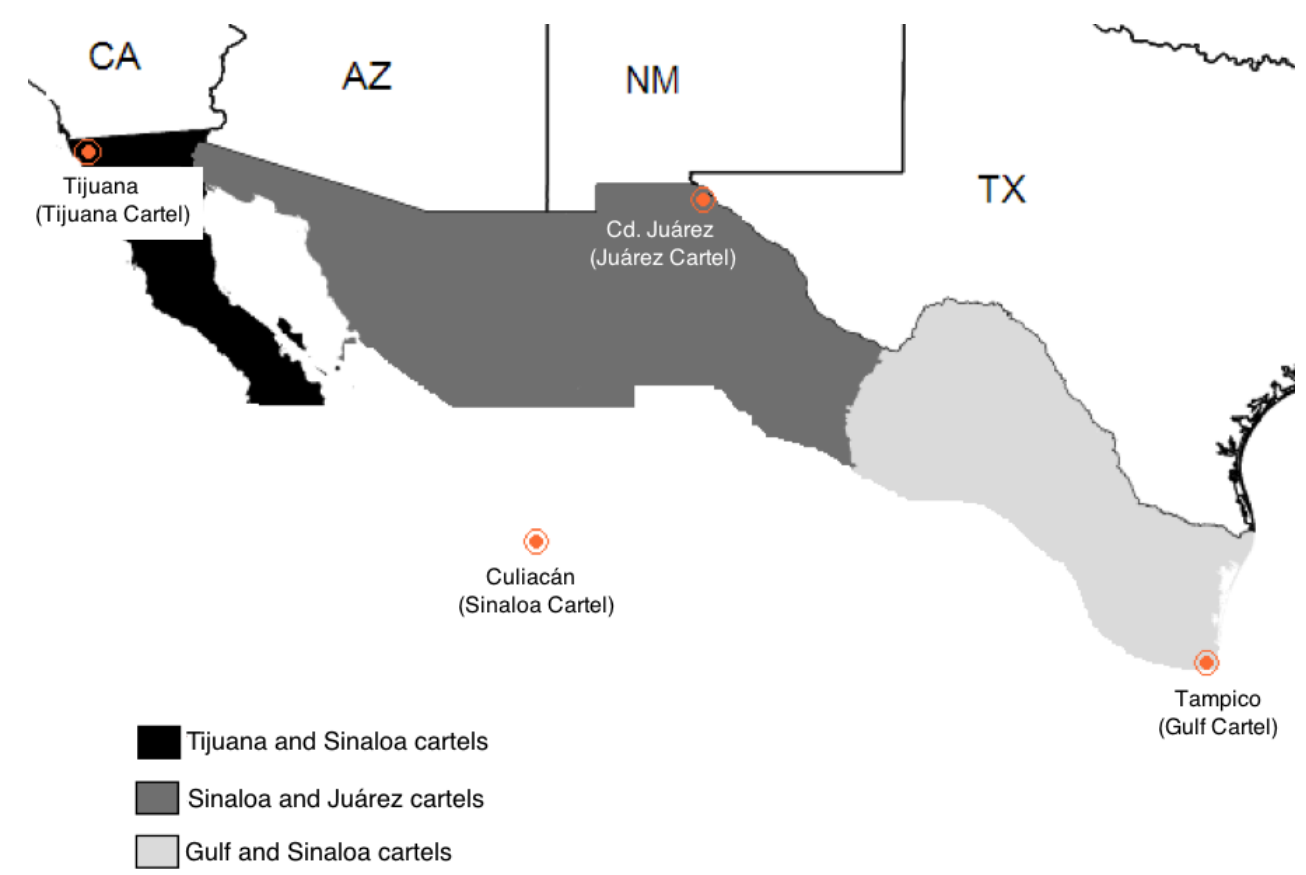

Notes. The map in Panel A uses data from the BATF to map graduated circles representing the number of licensed firearms dealers by ZIP code in California (CA), Arizona (AZ), New Mexico (NM) and Texas (TX) as of January 2010, the earliest date for which this information is publicly available. This data can be accessed from: http://www.atf.gov/about/foia/ffl-list.html/. The black lines represent highways in Mexico. Panel B shows the approximate geographic location of Mexican Cartels in border states over 2002-2006, based on information from Frías and Valdez (2002), Nájar (2005), CRS (2007), and STRATFOR Global Intelligence (2008). The shaded areas denote the areas in which various cartels operate. Circles with a dot inside represent the headquarter cities of each cartel, with the relevant cartel written in parentheses. The U.S. border states include California (CA), Arizona (AZ), New Mexico (NM) and Texas (TX). 
Figure IV

Ports of Entry, Proximity, and Homicides

Panel A: $\quad$ Ports of Entry, and Highways on the U.S.-Mexico Border

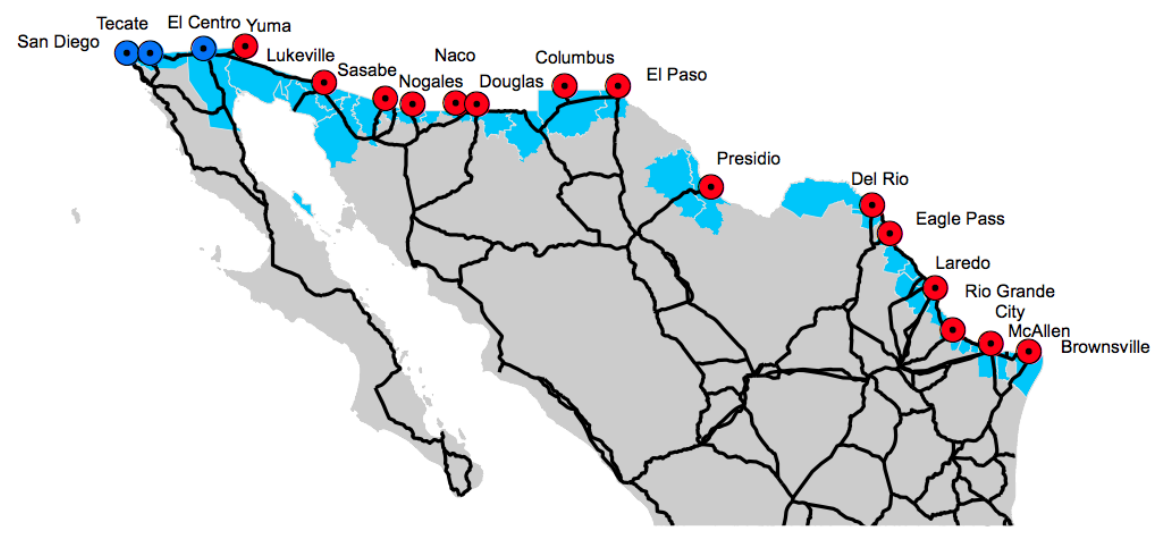

Panel B: $\quad$ Continuous measure of Proximity of Municipios to non-CA Ports of Entry

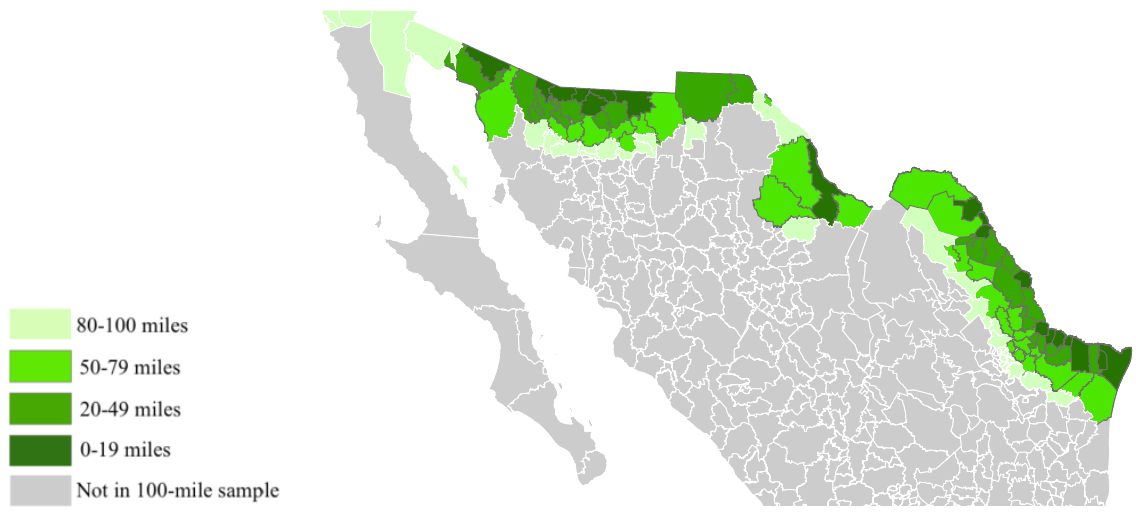

Notes. In Panel A, the black lines represent highways. Municipios in blue constitute the sample of municipios on the border with highways. Port cities in California (San Diego, Tecate, and El Centro) are marked in blue. Port cities in other states are marked in red: Yuma (AZ), Lukeville (AZ), Sasabe (AZ), Nogales (AZ), Naco (AZ), Douglas (AZ), Columbus (NM), El Paso (TX), Presidio (TX), Del Rio (TX), Eagle Pass (TX), Laredo (TX), Rio Grande (TX), McAllen (TX), and Brownsville (TX). Panel B shows the "residual proximity" of each muncipio. This is constructed by first regressing "proximity" (i.e., 100 miles - distance) to the nearest non-California port on proximity to the nearest of any border ports for the municipios in the 100-mile sample, and then generating residuals from this regression, which represent the identifying variation in our research design. The magnitudes of these residuals are represented by the four shades of green so that darker shades signify proximity to a non-CA port, holding overall proximity constant. 


\section{Figure V \\ Total Homicides in Municipios Bordering California versus Other Border States}

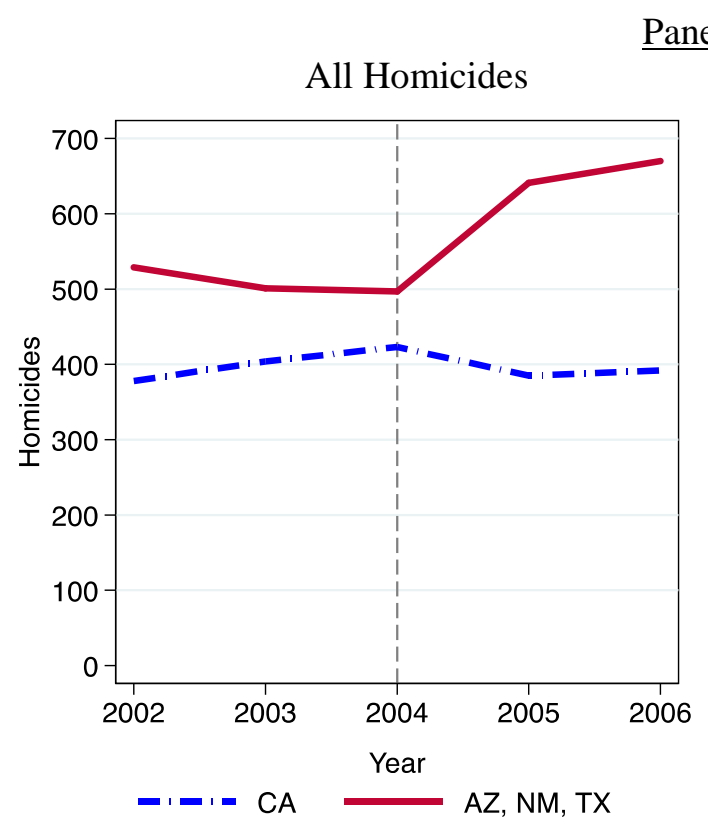

$\underline{\text { Panel A }}$

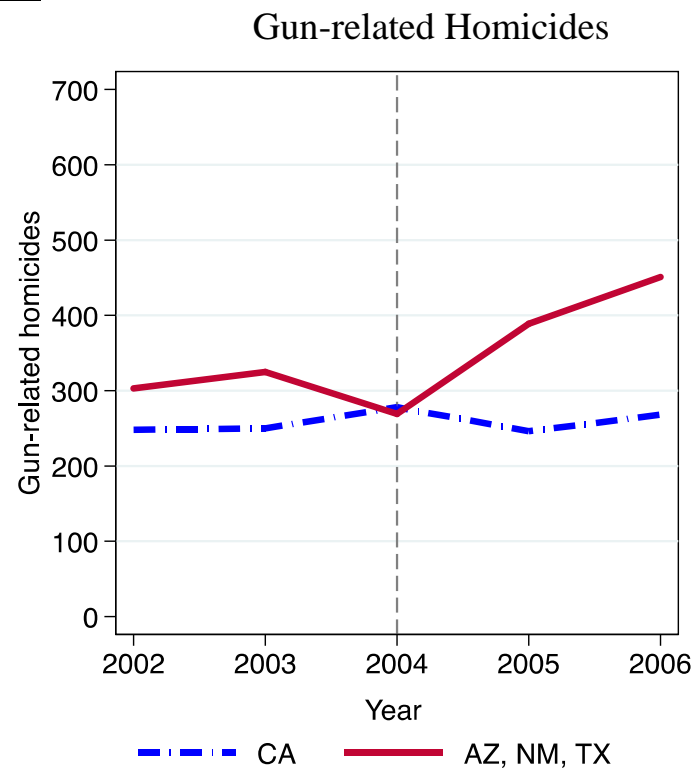

$\underline{\text { Panel B }}$

Non-gun Homicides

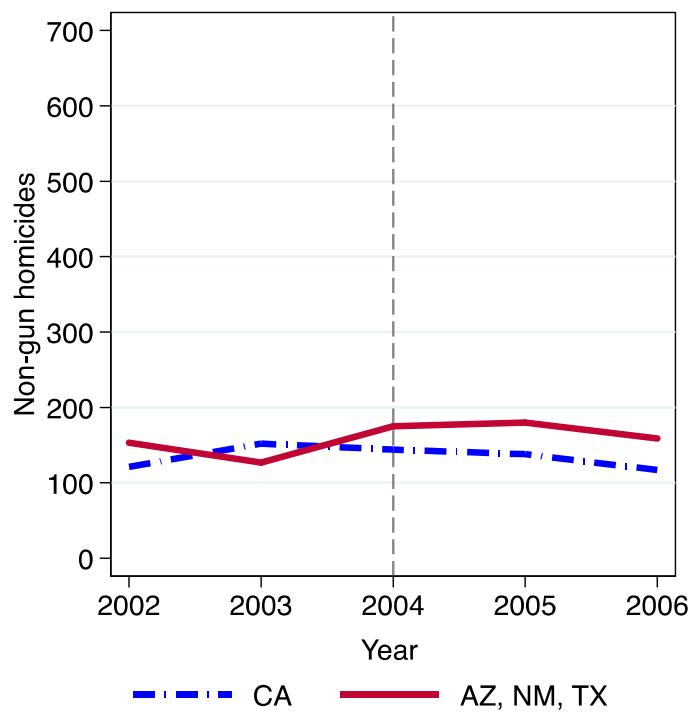

Gun-related Suicides

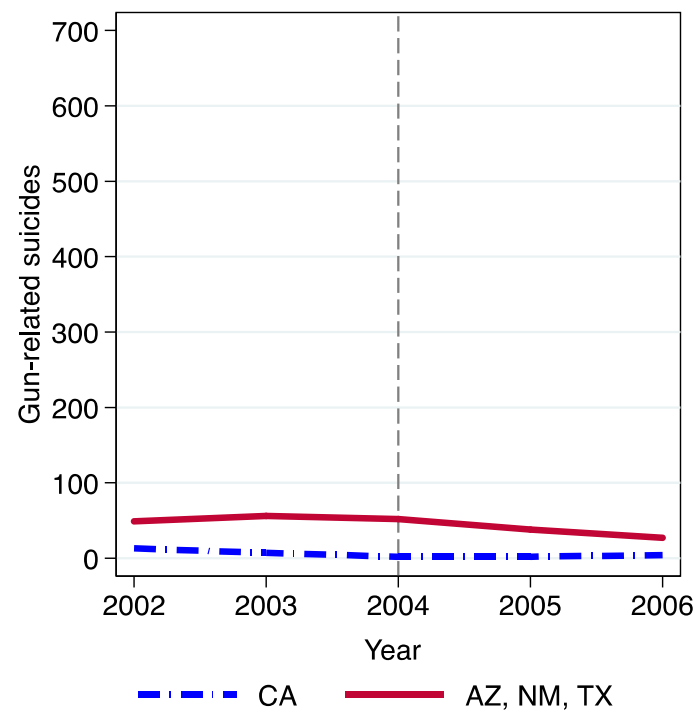

Notes. Panel A plots the total number of homicides (left) and homicides specifically tied to guns (right) in the border municipios adjacent to California (the CA segment), versus the border municipios adjacent to Arizona, New Mexico and Texas (the non-CA segment). Panel B plots the equivalent numbers of non-gun homicides (left) and gun-related homicides (right). The dashed line denotes 2004 , the year in which the federal assault weapons ban expired. 
Figure VI

Time Paths of Violence Using Annual and Quarterly Data

\author{
Panel A: Effect by Year
}

\section{All Homicides}

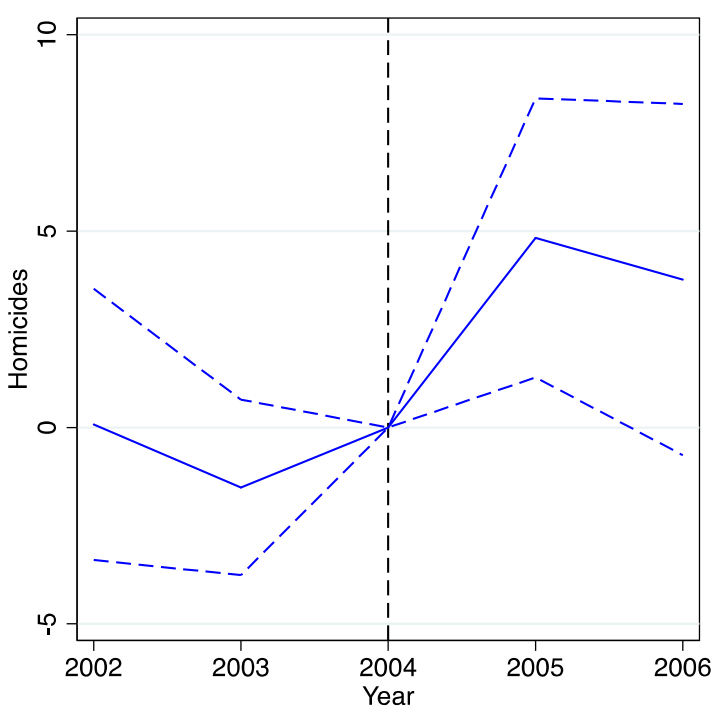

Gun-related Homicides

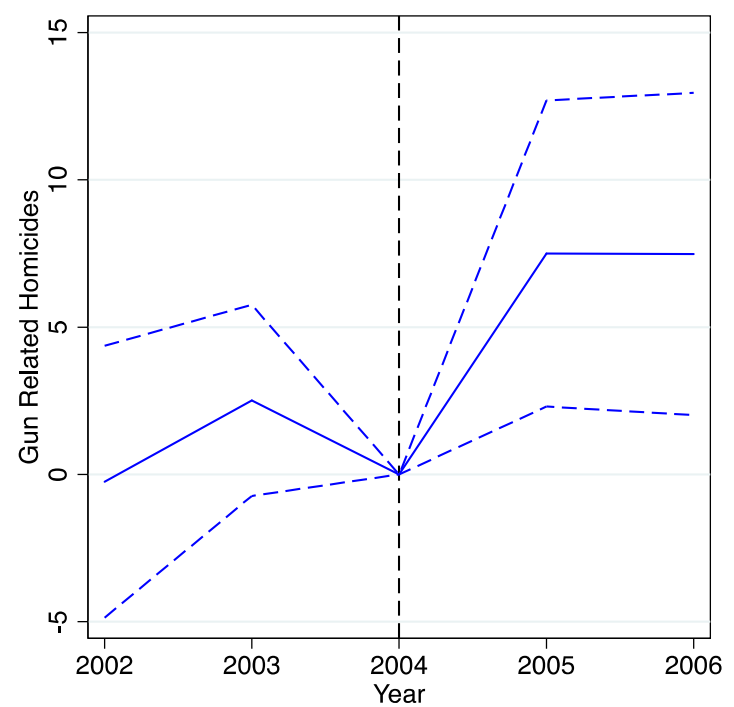

Panel B: Dynamic Response Using Quarterly Data
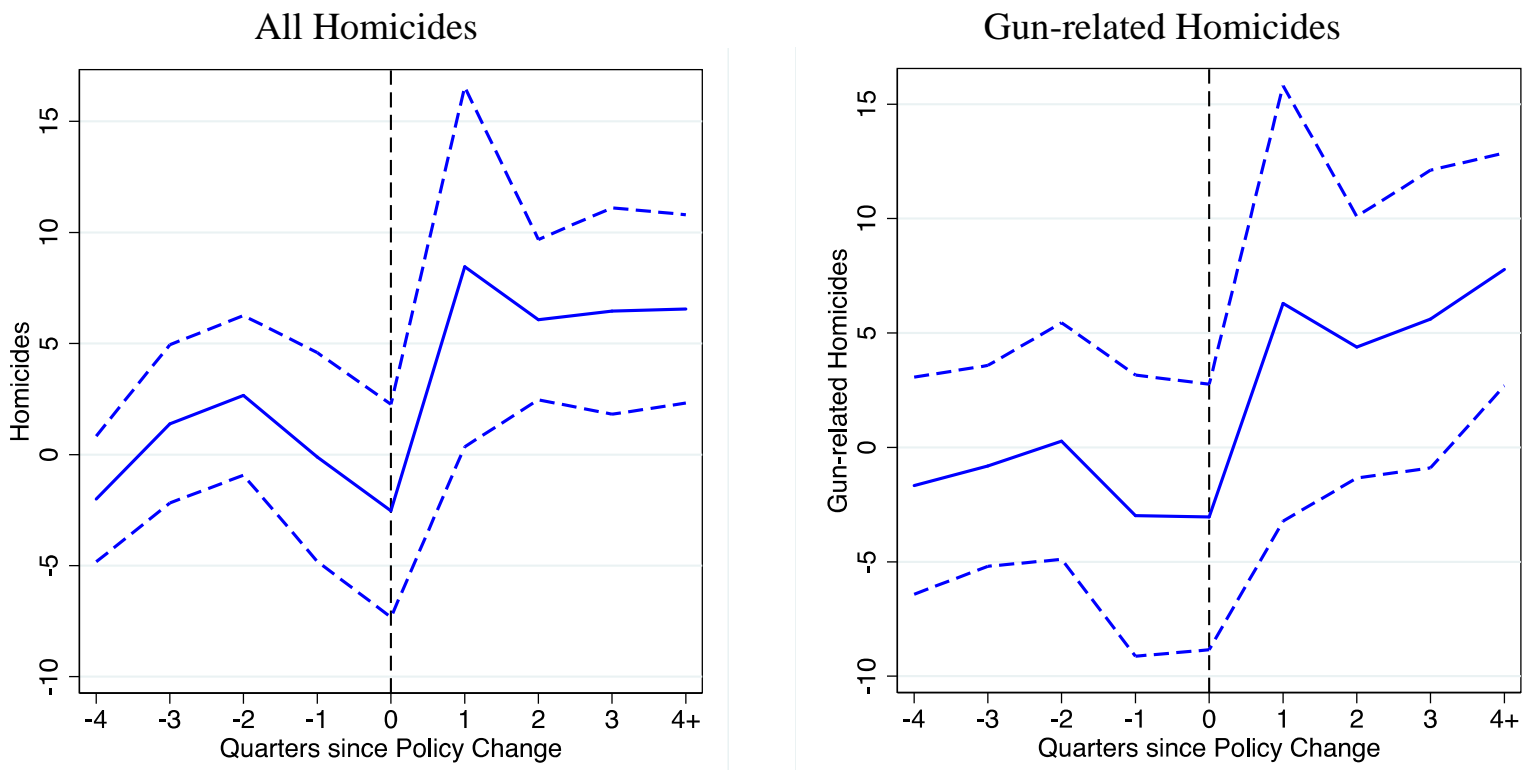

Notes. In Panel A, the solid blue line plots the Poisson regression coefficients for Proximity NCA interacted with each year regressed on the outcome variables. 2004 is the omitted category. All regressions include municipio and year fixed effects; Proximity border $x$ post; as well as the other annual control variables from Table II, column (5). In Panel B, the solid blue line plots the running sum of four quarterly lags and leads of Poisson regression coefficients for Proximity NCA x Post regressed on the outcome variables. The treatment date is the $4^{\text {th }}$ quarter of 2004. All regressions include municipio and year fixed effects; Proximity Border x Post; and quarterly interpolated values of the annual controls in Table II, column (5). For both panels, population is used as exposure in the regressions, while municipio-cluster-robust standard errors are used to calculate the $95 \%$ confidence intervals indicated by the blue dashed lines. 


\title{
Online Appendix to "Cross-Border Spillover: U.S. Gun Laws and Violence in Mexico"
}

\author{
December 5, 2012
}

In this Online Appendix, we present additional results, as well as background information on California's gun laws. While all the appendix figures and tables are referenced in the main paper, the appendix provides a more detailed discussion of Tables A.I (definition of ports), A.II (additional falsifications), A.III (robustness checks using the border segment specification), A.IV (spatial confounds), A.V (robustness to specific U.S. border states), and A.VI (robustness to the definition of ports). We also discuss Figure A.IV (effects by distance bands).

\section{A Additional Results}

\section{A.1 Port Definition}

First, Table A.I details our classification criteria for entry ports. We code a border crossing as a separate of port of entry if it is at least 20 miles apart from the nearest other border crossing. This yields 18 ports used in the study.

\section{A.2 Falsification}

Next, we present evidence on a few additional falsifications. If rising gun supply from the FAWB expiration led to an increase in violence associated with organized crime, then we should observe significant increases in homicides, but not suicides. Columns (1)-(3) of Table A.II show that our treatment interaction does not exert significant effects on suicides of any type, including those committed by guns. Column (4) also shows that there are no effects on accidents, which provides an additional check that proximity $N C A \times$ post is not spuriously correlated with other factors associated with rising deaths. These results support the idea that the rise in gun supply associated with this policy change led to a rise in murders, specifically, rather than other types of violent deaths. 


\section{A.3 Robustness checks with the Segment Specification}

In this subsection, we check the robustness of our results to the segment-based specification. This is given by equation (1) in the main paper, and relies solely on an indicator of whether the municipio lies adjacent to the non-California segment of the border. We consider equation (2), which utilizes continuous distance-based variation to non-CA ports, to be our primary specification. Nonetheless, Table A.III presents the full gamut of additional results using equation (1), including each regression in Table IV.

Panels A and B of Table A.III show that the results are robust to negative binomial estimation; the inclusion of linear time trends by proximity NCA; and controls for non-gun homicides as well as non-homicide deaths. The coefficients fall with the inclusion of enforcement related variables (in column (7)), which, as discussed in section 5.1, are potential over-controls. The effect for gun-related homicides becomes marginally insignificant in this specification (with a p-value of .11), but the effect for overall homicides remains statistically significant even with the inclusion of these controls. Panel $\mathrm{C}$ also confirms that there are no significant effects on non gun-related homicides with the segment-based specification.

\section{A.4 Choice of Distance Cutoff}

In choosing our municipal sample, we utilize a 100-mile cutoff, and exclude more distant municipios. Our identification strategy relies on distinguishing between overall proximity to the border and proximity to a non-California port of entry. These two variables - proximity border and proximity $\mathrm{NCA}$ - become highly correlated as we move further away from the border. For example, the correlation between the two variables is .11 in the 25-50 mile distance band, .89 in the 50-75 miles distance band, and 1 in the 75-100 mile distance band. In particular, the values of proximity border and proximity $N C A$ are identical for all municipios that are more than 65 miles away from the border. This is a reason to not include more distant municipios in our sample, as they do not provide identifying variation except through assumptions about functional form. However, there is nothing unique about the 100 mile mark, and the effect, if robust, should continue to hold in samples with other distance cutoffs.

To demonstrate the insensitivity of our findings to alternative cutoffs, we re-estimate equation (2) starting with a 25 mile sample, and then expand the sample by increments of 25 miles, until we reach 500 miles. We plot the coefficients and $95 \%$ confidence intervals associated with each sample in Figure A.IV. Here, the horizontal axis represents the distance cutoff, so a value of 200 denotes estimates in the sample of municipios within 200 miles of the U.S.-Mexico border. The results indicate that for all cutoffs between 50 and 500 miles, the point estimates are sizable and statistically significant, indicating that our results are not sensitive to the use of the 100-mile cutoff. The exception to this is the 25-mile band, which is such a small cutoff 
that the sample includes only 17 municipios, and fails to include even 23 of the 38 municipios at the border. For all cutoffs between 50 and 500 miles, the coefficients also fall in magnitude as we expand the distances. This reduction could reflect a tapering off in the marginal effects farther away from the border. However, it could also reflect greater collinearity between overall proximity and proximity to non-California ports in the samples with more distant municipios, which tends to reduce the estimated effects.

\section{A.5 Controlling for Spatial Confounds}

In this subsection, we consider and rule out potential spatial confounds to our estimated effects. We measure distance to the centroid of the municipio since our dependent variables are the average number of killings throughout the municipio, and the centroid is the most appropriate marker for capturing the average distance from a port city to the municipio. However, under this approach, larger municipios will have greater measured distance, relative to the approach where distance is measured to the edge of the municipio. This raises the potential concern that size differences may influence estimated effects, if for example, crime rates rose disproportionately in larger municipios in the post-2004 period. We address this issue in two ways. First, we control for the interaction of area (in square kilometers) with the post indicator. These results, shown in column (1) of Table A.IV, indicate that the coefficients are larger with the area control. In column (2), we take the alternate approach of measuring distance to the municipal edge. In column (3), we combine the two approaches, employing edge distance while controlling for area $\times$ post. All of these specifications use our original 100 mile sample, which avoids any differences in estimates arising due to sample changes. Overall, the robustness of the effects on total and gun-related homicides to these alternate approaches demonstrate that size and measurement issues do not confound our estimates.

Next, we consider potential spatial spillovers in violence, which may serve as an alternative mechanism through which gun supply affects homicides. For example, if violence tends to diffuse outward, then the initial entry of assaults weapons may cause an increase in violence at border municipios, but subsequent violence increases may reflect the diffusion of initial violence, rather than the diffusion of the guns themselves. ${ }^{1}$ To examine this account, for each municipio $i$, we create measures of the average homicides and gun-related homicides in the set of municipios spatially contiguous to $i$, and refer to these variables as neighbor homicides and neighbor gunrelated homicides, respectively. Since such violence propagation takes place over time, to reduce the possibility of correlated errors, column (4) of Table A.IV presents estimates with the one period lag of the neighbor variables. In general, consistency of the estimates from this spatial model requires the assumption that error terms are not spatially correlated across periods,

\footnotetext{
${ }^{1}$ We thank a referee for making this point.
} 
i.e., $E\left(e_{i t}, e_{j t^{\prime}}\right)=0$ for all $i \neq j, t \neq t^{\prime}$. To the extent that these disturbances are positively spatially correlated, this will tend to upwardly bias the estimates of spatial spillovers. This is because the presence of the correlated $e_{i t}$ terms induce a correlation between neighbor and own homicides even though there is no causal relationship between the two variables. However, as shown in column (4), the coefficients for lag neighbor homicides and lag neighbor gun-related homicides are close to zero in magnitude and statistically insignificant, indicating that there is little evidence of such spillovers. As an auxiliary check, we also include the contemporaneous as well as lagged variables in column (5), and find the results unchanged. Overall, there is little indication of either spatial spillovers or spatially correlated disturbances for killings in our sample.

\section{A.6 Robustness to Specific U.S. Border States}

Next, we address the concern that other violence-promoting shocks to particular border municipios near TX, AZ and NM may confound our estimated effects. It is possible to find specific events that occurred in these areas around the time of the FAWB expiration. For instance, the killing of the brother of the Sinaloa cartel's leader led to an increase in violence in Nuevo Laredo (on the Texas border) in 2004. ${ }^{2}$ To assess the sensitivity of our findings to such shocks, Table A.V reports the estimates when we drop all the municipios from the sample that are closest to a TX port (columns 1 and 2), to a AZ port (columns 3 and 4), and to a NM port (columns 5 and 6 ). We show the results both with and without our full set of controls.

We find that our key results continue to hold even when we drop all municipios whose nearest port is along specific border states. Dropping the AZ and NM do not affect any of the results. Dropping the TX segment is a particularly tough test, since this eliminates $60 \%$ of our sample. Even so, the effect on gun-related homicide continues to be quantitatively large and statistically significant, although the total homicide results are just shy of statistical significance at conventional levels $(p$ value $=0.101$ ). Overall, this sensitivity analysis indicates that localized events do not drive our finding that the expiration of the FAWB led to an increase in killings.

\section{A.7 Robustness to the Definition of Entry Ports}

Our proximity measure is based on defining major ports of entry on the U.S.-Mexico border. The primary definition employed in this paper consolidates border crossings within 20 miles of

\footnotetext{
${ }^{2}$ There are also specific violent events that took place on the Mexican side of the California border. For example, the Gulf and Tijuana cartels ended their year-long alliance in January 2005, and the head of the Gulf cartel dispatched their deadly enforcers, "Los Zetas," to seize smuggling routes in Baja California from the Tijuana cartel (STRATFOR, 2005). But such violence promoting events would bias the estimated effects downward.
} 
each other into single ports, but does not impose any traffic-related restrictions.

In Table A.VI we show that our findings are not driven by the choice of port definitions. We consider alternative distance cutoff rules for assigning border crossings to the same port, and also impose two truck traffic criteria, of at least 1000 or 5000 trucks per year. These are meaningful restrictions since substantial traffic flows imply that these locations are major transportation hubs. We find quantitatively similar and statistically significant effects of the expiration of the FAWB on violence in all nine cases, demonstrating the robustness of our results to these alternative port definitions.

\section{B Background Information on California's Assault Weapons Ban and Gun Control Regime}

In California, the control of assault weapons began with the passage of the Roberti-Roos Assault Weapons Control Act of 1989. The Act defined assault weapons in a manner similar to the federal ban. In particular, all weapons listed in section 12276 of California's Penal Code were (and continue to be) designated an assault weapon. ${ }^{3}$ Such firearms were designated controlled and as such could not be legally purchased, kept for sale, offered for sale, exposed for sale, given, lent, manufactured, distributed or imported as of 1991. Moreover, all pre-existing weapons were required to be registered as assault weapons with the Department of Justice. Banned weapons in California also include the AK and AR-15 weapons series.

California's weapons ban was subsequently strengthened between 1989 and 2002. The Roberti-Roos Act was challenged on constitutional grounds, but upheld by the State Supreme Court. The ruling found that effective August 16, 2000, firearm models that are variations of the AK or AR-15 with only minor differences from those two models are also considered assault weapons and are controlled. Weapons that were not registered before January 23, 2001 also had to be surrendered to law enforcement. In addition, CA Senate Bill 23, passed in 1999, and implemented in 2000 and 2002, broadened the reach of the ban. This bill introduced specific characteristics (such as flash suppressors, forward pistol grip, and the capacity to accept more than 10 rounds) that designate a gun an assault weapon. Since 2002, CA's gun law regime has remained relatively uniform.

Our empirical strategy posits that the lifting of the FAWB made gun laws more permissive in TX, AZ and NM. However, the ban would only represent a differential change in stringency compared to CA if CA's legislation was sufficiently strong to control assault weapons sales, and this control was retained in the post-2004 period. One piece of evidence indicating the relative

${ }^{3}$ Details about the California assault weapons ban can be found at:
http://ag.ca.gov/firearms/forms/pdf/awguide.pdf


ease of obtaining assault weapons in New Mexico, Texas and Arizona versus California comes from the advocacy group The Brady Center to Prevent Gun Violence, which ranks states on the restrictiveness of their gun control laws on a 100 point scale. California has consistently ranked number 1 on this list, most recently with 81 points. Specifically with reference to assault weapons, California gets a 10 out of 10 in this category. In contrast, Arizona, New Mexico and Texas scored less than 10 points in total, earning zero each in the assault weapons category. ${ }^{4}$ Another piece of suggestive evidence comes from BATF Firearms Trace data from 2006, the earliest year available, which indicates that the flow of seized guns from California to Arizona, New Mexico and Texas (358) was less than half of the reverse flow (943). ${ }^{5}$

\section{References}

[1] STRATFOR Global Intelligence. 2005. "Mexico: the New Kingpin's Rise." February 22.

${ }^{4}$ http://www.bradycampaign.org/stategunlaws/, accessed on March 8, 2012.

${ }^{5}$ http://www.atf.gov/statistics/trace-data/ 
Table A.I

Definition of Ports Based on Truck Traffic \& Distance between Border Crossings

\begin{tabular}{|c|c|c|c|c|c|}
\hline State & County & Border crossing & $\begin{array}{l}\text { Mean truck traffic } \\
(2002-2006)\end{array}$ & $\begin{array}{c}\text { Distance to other } \\
\text { nearest border crossing }\end{array}$ & Port \\
\hline $\mathrm{CA}$ & San Diego & San Diego & 726,866 & 20 miles to Tecate & San Diego \\
\hline $\mathrm{CA}$ & San Diego & Tecate & 65,943 & 20 miles to San Diego & Tecate \\
\hline $\mathrm{CA}$ & Imperial & El Centro & 295,452 & 44 miles to Yuma & El Centro \\
\hline $\mathrm{CA}$ & Imperial & Andrade & 2,207 & 17 miles to Yuma & Yuma \\
\hline $\mathrm{AZ}$ & Yuma & Yuma & 41,716 & 17 miles to Andrade & Yuma \\
\hline $\mathrm{AZ}$ & Pima & Lukeville & 921 & 80 miles to Sasabe & Lukeville \\
\hline $\mathrm{AZ}$ & Pima & Sasabe & 954 & 37 miles to Nogales & Sasabe \\
\hline $\mathrm{AZ}$ & Santa Cruz & Nogales & 257,796 & 37 miles to Sasabe & Nogales \\
\hline $\mathrm{AZ}$ & Cochise & Naco & 4,271 & 24 miles to Douglas & Naco \\
\hline $\mathrm{AZ}$ & Cochise & Douglas & 27,000 & 24 miles to Naco & Douglas \\
\hline NM & Luna & Columbus & 4,737 & 59 miles to Santa Teresa & Columbus \\
\hline NM & Dona Ana & Santa Teresa & 31,358 & 11 miles to El Paso & El Paso \\
\hline $\mathrm{TX}$ & El Paso & El Paso & 713,993 & 11 miles to Santa Teresa & El Paso \\
\hline $\mathrm{TX}$ & Presidio & Presidio & 6,365 & 197 miles to El Paso & Presidio \\
\hline $\mathrm{TX}$ & Val Verde & Del Rio & 66,254 & 52 miles to Eagle Pass & Del Rio \\
\hline $\mathrm{TX}$ & Maverick & Eagle Pass & 94,705 & 52 miles to Del Rio & Eagle Pass \\
\hline $\mathrm{TX}$ & Webb & Laredo & $1,432,466$ & 89 miles to Rio Grande City & Laredo \\
\hline $\mathrm{TX}$ & Starr & Roma & 8,589 & 11 miles to Rio Grande City & Rio Grande City \\
\hline $\mathrm{TX}$ & Starr & Rio Grande City & 38,435 & 11 miles to Roma & Rio Grande City \\
\hline $\mathrm{TX}$ & Hidalgo & McAllen & 439,920 & 19 miles to Progreso & McAllen \\
\hline $\mathrm{TX}$ & Hidalgo & Progreso & 24,372 & 19 miles to McAllen & McAllen \\
\hline TX & Cameron & Brownsville & 236,461 & 50 miles to McAllen & Brownsville \\
\hline
\end{tabular}

Notes. Mean truck traffic is the annual average number of trucks that crossed the border during 2002-2006, based on data from the Bureau of Transportation Statistics (BTS). The distance to the other nearest border crossing is computed from the actual border crossing point versus the city center. A border crossing is considered a separate port if it is at least 20 miles away from another border crossing. If two border crossings are less than 20 miles apart, they are considered part of the same port, named after the border crossing with higher truck traffic. For instance, Andrade is less than 20 miles from Yuma and is considered to be part of the Yuma port. Following the same criteria, Santa Teresa, Roma, and Progreso are considered parts of the El Paso, Rio Grande, and McAllen ports, respectively. 
Table A.II

Falsifications: The Effect of the FAWB Expiration on Suicides and Accidents

(1)

\begin{tabular}{c} 
Suicides \\
\hline 0.788 \\
$(1.331)$
\end{tabular}

431

$\mathrm{Y}$

$\mathrm{Y}$

Income, immigration and drug controls?
(2)

(3)

(4)
Proximity NCA $x$ post

Observations

Sample

100-mile

Gun Suicides

Non-gun Suicides

Accidents

$-0.096$

0.426

1.021

(5.058)

(0.554)

312

297

511

Notes. Variables not shown include municipio and year fixed effects. Robust standard errors clustered at the municipio level are shown in parentheses. Proximity border $x$ post interacts the proximity to the nearest of all ports with a post-2004 indicator. Income, immigration and drug controls include: log municipal per capita income in 2000 and the schooling ratio in 2000 interacted with a post2004 indicator; log municipal expenditures per capita; log value of municipal drug seizures plus 1; $\log$ hectares of marijuana and heroin poppies eradicated in each municipio plus 1; as well as the employment ratio, log average earnings, log unauthorized immigrants and $\log$ value of drugs seized in the nearest U.S. port of entry. $* * *$ is significant at the $1 \%$ level; ** is significant at the $5 \%$ level; and * is significant at the $10 \%$ level. 
Table A.III

The FAWB Expiration and Violence: Robustness Checks using the Segment Specification

\begin{tabular}{|c|c|c|c|c|c|c|c|}
\hline & (1) & (2) & (3) & (4) & (5) & (6) & (7) \\
\hline & \multicolumn{7}{|c|}{ Panel A: Homicides } \\
\hline \multirow{2}{*}{ Segement NCA $x$ post } & $0.532 * *$ & $0.344 * *$ & $0.361^{*}$ & $0.687 * *$ & $0.551^{* * *}$ & $0.518 * *$ & $0.401 *$ \\
\hline & $(0.231)$ & $(0.140)$ & $(0.210)$ & $(0.312)$ & $(0.240)$ & $(0.218)$ & $(0.226)$ \\
\hline \multirow[t]{2}{*}{ Non-gun homicides } & - & - & - & - & - & $0.008 * * *$ & - \\
\hline & & & & & & $(0.002)$ & \\
\hline \multirow[t]{2}{*}{ Non-homicide deaths } & - & - & - & - & - & 0.000 & - \\
\hline & & & & & & $(0.000)$ & \\
\hline \multirow[t]{2}{*}{ Observations } & 180 & 180 & 180 & 180 & 162 & 180 & 180 \\
\hline & \multicolumn{7}{|c|}{ Panel B: Gun-related Homicides } \\
\hline \multirow[t]{2}{*}{ Segment NCA $x$ post } & $0.760^{* *}$ & $0.403 * *$ & $0.533^{*}$ & $1.006^{* * *}$ & $0.805^{* *}$ & $0.758^{* *}$ & 0.555 \\
\hline & $(0.326)$ & $(0.192)$ & $(0.284)$ & $(0.388)$ & $(0.337)$ & $(0.306)$ & $(0.349)$ \\
\hline \multirow[t]{2}{*}{ Non-gun homicides } & - & - & - & - & - & 0.003 & - \\
\hline & & & & & & $(0.003)$ & \\
\hline \multirow[t]{2}{*}{ Non-homicide deaths } & - & - & - & - & - & 0.000 & - \\
\hline & & & & & & $(0.000)$ & \\
\hline \multirow[t]{2}{*}{ Observations } & 177 & 177 & 177 & 177 & 162 & 177 & 177 \\
\hline & \multicolumn{7}{|c|}{ Panel C: Non-gun Homicides } \\
\hline \multirow[t]{2}{*}{ Segment NCA $x$ post } & -0.073 & 0.181 & -0.097 & -0.182 & -0.122 & - & -0.082 \\
\hline & $(0.200)$ & $(0.211)$ & $(0.186)$ & $(0.300)$ & $(0.196)$ & & $(0.209)$ \\
\hline Observations & 156 & 156 & 156 & 156 & 143 & - & 156 \\
\hline Year fixed effects? & $\mathrm{Y}$ & Y & - & - & Y & Y & Y \\
\hline Post-2004 indicator? & - & - & Y & Y & - & - & - \\
\hline Linear time trends? & - & - & - & Y & - & - & - \\
\hline Income, immigration and drug controls? & Y & Y & $\mathrm{Y}$ & Y & $\mathrm{Y}$ & Y & Y \\
\hline Current enforcement controls? & - & - & - & - & - & - & Y \\
\hline Sample & 100-mile & 100-mile & 100-mile & 100-mile & $\begin{array}{l}\text { 100-mile } \\
\& \text { highway }\end{array}$ & 100-mile & 100-mile \\
\hline Estimator & Poisson & $\begin{array}{l}\text { Negative } \\
\text { Binomial }\end{array}$ & Poisson & Poisson & Poisson & Poisson & Poisson \\
\hline
\end{tabular}

Notes. Estimates in columns (1) and (3)-(7) are based on Poisson regressions using population exposure. Estimates in column (2) are based on negative binomial regressions. Variables not shown include municipio fixed effects. Robust standard errors clustered at the municipio level are shown in parentheses. Segment NCA $x$ post interacts an indicator of whether the municipio lies on the non-California segment of the U.S.-Mexico border with a post-1994 indicator. Income, immigration and drug controls include: $\log$ municipal per capita income in 2000 and the schooling ratio in 2000 interacted with a post-2004 indicator; log municipal expenditures per capita; log value of municipal drug seizures plus $1 ; \log$ hectares of marijuana and heroin poppies eradicated in each municipio plus 1 ; as well as the employment ratio, log average earnings, log unauthorized immigrants and log value of drugs seized in the nearest U.S. port of entry. All specifications include year effects except columns (3)-(4), which include a post-2004 indicator. Column (4) also includes linear time trends at the municipio level. Column (5) restricts the sample to municipios that have a highway. Current enforcement controls in Column (7) include military drug-war detentions per capita in Mexican municipios, as well as police officers per capita in the nearest U.S. port. $* * *$ is significant at the $1 \%$ level; ** is significant at the $5 \%$ level; and * is significant at the $10 \%$ level. 
Table A.IV

The FAWB Expiration and Violence: Robustness to Spatial Confounds

\begin{tabular}{|c|c|c|c|c|c|}
\hline & (1) & (2) & (3) & (4) & (5) \\
\hline & \multicolumn{5}{|c|}{ Panel A: Homicides } \\
\hline Proximity NCA $x$ post & $\begin{array}{c}5.247 * * * \\
(1.848)\end{array}$ & $\begin{array}{l}3.284 * * \\
(1.461)\end{array}$ & $\begin{array}{c}5.254 * * * \\
(1.772)\end{array}$ & $\begin{array}{c}4.743 * * * \\
(1.913)\end{array}$ & $\begin{array}{l}4.799 * * \\
(1.920)\end{array}$ \\
\hline Lag neighbor homicides & - & - & - & $\begin{array}{c}0.002 \\
(0.005)\end{array}$ & $\begin{array}{c}0.002 \\
(0.005)\end{array}$ \\
\hline Neighbor homicides & - & - & - & - & $\begin{array}{c}0.002 \\
(0.005)\end{array}$ \\
\hline \multirow[t]{2}{*}{ Observations } & 409 & 409 & 409 & 409 & 409 \\
\hline & \multicolumn{5}{|c|}{ Panel B: Gun-related Homicides } \\
\hline Proximity NCA $x$ post & $\begin{array}{c}8.261 * * * \\
(2.495)\end{array}$ & $\begin{array}{c}4.820 * * \\
(1.894)\end{array}$ & $\begin{array}{c}7.877 * * * \\
(2.273)\end{array}$ & $\begin{array}{c}7.408 * * * \\
(2.548)\end{array}$ & $\begin{array}{c}7.441 * * * \\
(2.458)\end{array}$ \\
\hline Lag neighbor gun-related homicides & - & - & - & $\begin{array}{c}0.014 \\
(0.013)\end{array}$ & $\begin{array}{c}0.015 \\
(0.011)\end{array}$ \\
\hline Neighbor gun-related homicides & - & - & - & - & $\begin{array}{c}0.017 \\
(0.016)\end{array}$ \\
\hline Observations & 384 & 384 & 384 & 384 & 384 \\
\hline Proximity border $\mathrm{x}$ post control? & Y & $\mathrm{Y}$ & $\mathrm{Y}$ & $\mathrm{Y}$ & $\mathrm{Y}$ \\
\hline Income, immigration and drug controls? & Y & Y & Y & Y & Y \\
\hline Area control? & $\mathrm{Y}$ & - & $\mathrm{Y}$ & - & - \\
\hline $\begin{array}{l}\text { Sample } \\
\text { Distance measure }\end{array}$ & $\begin{array}{l}\text { 100-mile } \\
\text { centroid }\end{array}$ & $\begin{array}{c}\text { 100-mile } \\
\text { edge }\end{array}$ & $\begin{array}{c}\text { 100-mile } \\
\text { edge }\end{array}$ & $\begin{array}{l}\text { 100-mile } \\
\text { centroid }\end{array}$ & $\begin{array}{r}100 \text {-mile } \\
\text { centroid }\end{array}$ \\
\hline $\begin{array}{l}\text { Notes. All estimates are based on Poisson regressio } \\
\text { Robust standard errors clustered at the municipio le } \\
\text { the nearest port in Arizona, New Mexico and Texa } \\
\text { all ports with a post-2004 indicator. Income, imm } \\
\text { ratio in } 2000 \text { interacted with a post- } 2004 \text { indicato } \\
\text { hectares of marijuana and heroin poppies eradica } \\
\text { unauthorized immigrants and log value of drugs sei }\end{array}$ & $\begin{array}{l}\text { Ising populatic } \\
\text { are shown in } p \\
\text { th a post-2004 } \\
\text { ion and drug c } \\
\text { g municipal } \\
\text { in each muni } \\
\text { in the nearest }\end{array}$ & $\begin{array}{l}\text { exposure. Va } \\
\text { entheses. Prox } \\
\text { dicator. Prox } \\
\text { trols include: } \\
\text { enditures pe } \\
\text { io plus 1; as } \\
\text { S. port of ent }\end{array}$ & $\begin{array}{l}\text { les not shown } \\
\text { ity NCA x po } \\
\text { ty border } x \text { po } \\
\text { municipal pe } \\
\text { pita; log valu } \\
\text { ell as the emp } \\
\text { *** is sionific }\end{array}$ & $\begin{array}{l}\text { municipio } \\
\text { acts the proxi } \\
\text { racts the prox } \\
\text { a income in } 2 \\
\text { nunicipal dru } \\
\text { nt ratio, log } \\
\text { the } 1 \% \text { level; }\end{array}$ & $\begin{array}{l}\text { ar fixed effects } \\
\text { f a municipio to } \\
\text { to the nearest o } \\
\text { d the schoolin } \\
\text { ares plus } 1 ; \text { lo } \\
\text { e earnings, lo } \\
\text { ignificant at th }\end{array}$ \\
\hline
\end{tabular}


Table A.V

The FAWB Expiration and Violence: Robustness to Specific U.S. Border States

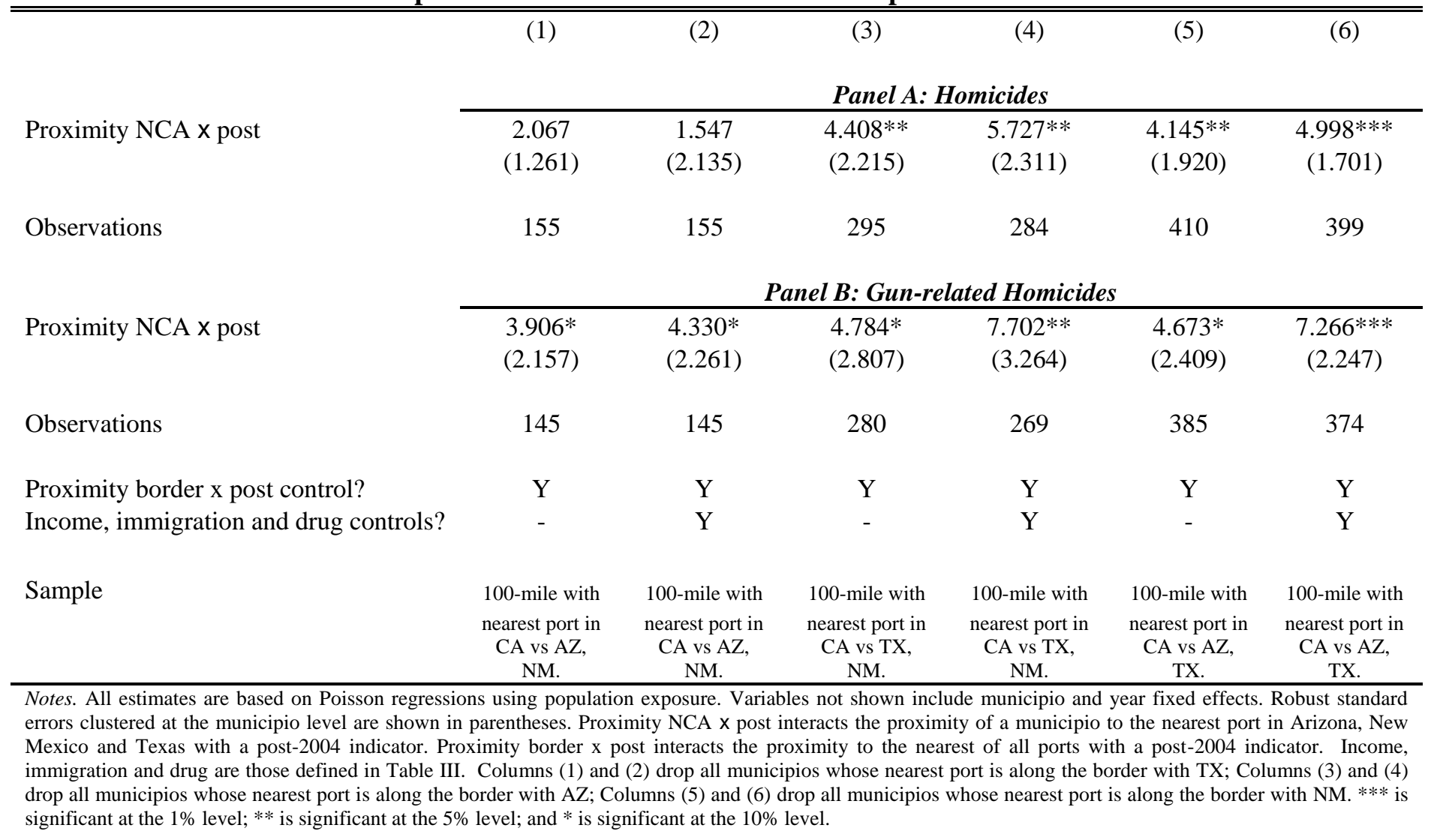


Table A.VI

The FAWB Expiration and Violence: Robustness to Different Definitions of Entry Ports
(1)
(2)
(3)
(4)
(5)
(6)
(7)

(8)

(9)

Panel A: Homicides

$\begin{array}{lccccccccc}\text { Proximity NCA x post } & 3.776^{* * *} & 4.688^{* * *} & 4.390^{* *} & 4.102 * * * & 4.782^{* * *} & 4.323 * * & 4.395 * * * & 5.226 * * * & 4.611^{* * *} \\ & (1.261) & (1.810) & (1.795) & (1.263) & (1.795) & (1.811) & (1.273) & (1.569) & (1.633) \\ \text { Observations } & 454 & 409 & 409 & 439 & 394 & 394 & 434 & 389 & 389\end{array}$

Panel B: Gun-related Homicides

\begin{tabular}{|c|c|c|c|c|c|c|c|c|c|}
\hline Proximity NCA $x$ post & $\begin{array}{l}3.926 * * \\
(1.778)\end{array}$ & $\begin{array}{c}6.835^{* * *} \\
(2.399)\end{array}$ & $\begin{array}{c}6.639 * * * \\
(2.415)\end{array}$ & $\begin{array}{l}3.855^{* *} \\
(1.783)\end{array}$ & $\begin{array}{c}6.747 * * * \\
(2.378)\end{array}$ & $\begin{array}{c}6.313 * * * \\
(2.436)\end{array}$ & $\begin{array}{l}4.133^{* *} \\
(1.925)\end{array}$ & $\begin{array}{c}7.085^{* * * *} \\
(2.100)\end{array}$ & $\begin{array}{c}6.664 * * * \\
(2.239)\end{array}$ \\
\hline Observations & 419 & 384 & 384 & 404 & 369 & 369 & 399 & 364 & 364 \\
\hline \multirow{2}{*}{$\begin{array}{l}\text { Proximity border } x \text { post control? } \\
\text { Income, immigration and drug } \\
\text { controls? }\end{array}$} & $\mathrm{Y}$ & $\mathrm{Y}$ & $\mathrm{Y}$ & $\mathrm{Y}$ & $\mathrm{Y}$ & $\mathrm{Y}$ & $\mathrm{Y}$ & $\mathrm{Y}$ & $\mathrm{Y}$ \\
\hline & $\mathrm{Y}$ & $\mathrm{Y}$ & $\mathrm{Y}$ & $\mathrm{Y}$ & $\mathrm{Y}$ & $\mathrm{Y}$ & $\mathrm{Y}$ & $\mathrm{Y}$ & $\mathrm{Y}$ \\
\hline \multirow{2}{*}{$\begin{array}{l}\text { Truck traffic criteria? } \\
\text { Distance to other crossing } \\
\text { criteria? }\end{array}$} & None & None & None & 1000 & 1000 & 1000 & 5000 & 5000 & 5000 \\
\hline & None & 20 miles & 30 miles & None & 20 miles & 30 miles & None & 20 miles & 30 miles \\
\hline Number of ports & 22 & 18 & 16 & 20 & 16 & 14 & 17 & 14 & 13 \\
\hline
\end{tabular}

Sample

100-mile 100-mile 100-mile 100-mile 100-mile 100-mile 100-mile 100-mile 100-mile

Notes. All estimates are based on Poisson regressions using population exposure. Variables not shown include municipio and year fixed effects. Robust standard errors clustered at the municipio level are shown in parentheses. Proximity NCA x post interacts the proximity of a municipio to the nearest port in Arizona, New Mexico or Texas with a post2004 indicator. Proximity border x post interacts the proximity to the nearest of all ports with a post-2004 indicator. Income, immigration and drug controls include: log municipal per capita income in 2000 and the schooling ratio in 2000 interacted with a post-2004 indicator; $\log$ municipal expenditures per capita; log value of municipal drug seizures plus 1; log hectares of marijuana and heroin poppies eradicated in each municipio plus 1 ; as well as the employment ratio, log average earnings, log unauthorized immigrants and log value of drugs seized in the nearest U.S. port of entry. Columns (1)-(3) define ports of entry without any restrictions on truck flows; columns (4)-(6) require border crossings to have a truck flow of at least 1000 per year to be classified as ports of entry. Columns (7)-(9) require ports to have truck flows of at least 5000 per year. Columns (1), (4) and (7) do not place any restrictions on how far one bordering crossing is from another border crossing to be considered a separate port. Columns (2), (5) and (8) require two border crossings to be at least 20 miles apart to be classified as separate ports. Columns (3), (6) and (9) require border crossings to be at least 30 miles apart to be classified as separate ports. *** is significant at the $1 \%$ level; ** is significant at the $5 \%$ level; and * is significant at the $10 \%$ level. 
Figure A.I

Mexican Crime Guns Traced to the United States

Panel A: $\quad$ Overall Fraction Traced to U.S. Over Time

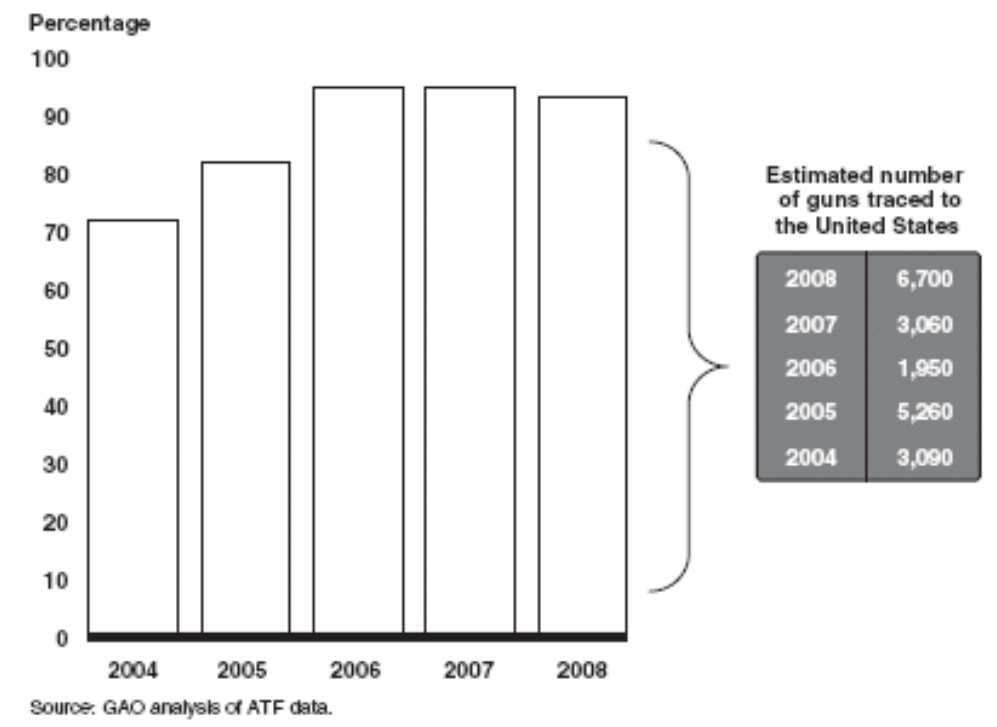

Panel B: $\quad$ Source of Traced Guns - 2004-2008

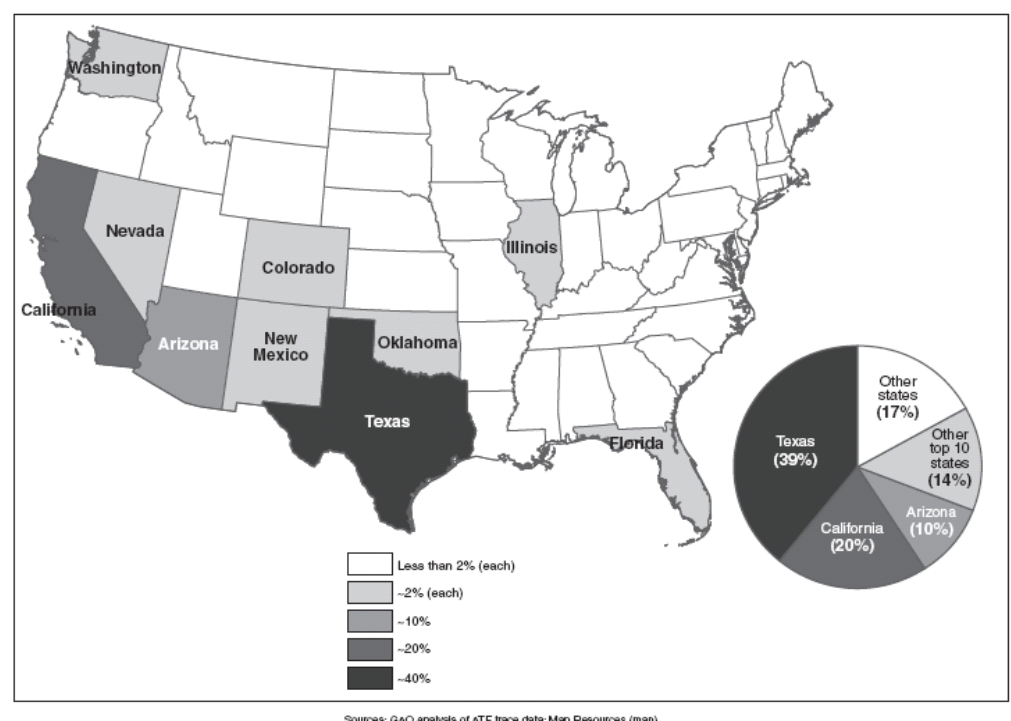

Notes. Both figures are from the GAO (2009) Report and based on BATF data. Mexican authorities send a quarter of seized firearms to BATF for tracing the location of the last legal transaction. The underlying data has not been made available to the public or researchers by BATF. 
Figure A.II

Distribution of Homicide Counts and Homicides per 10,000 Population

Panel A: $\quad$ Homicide Counts

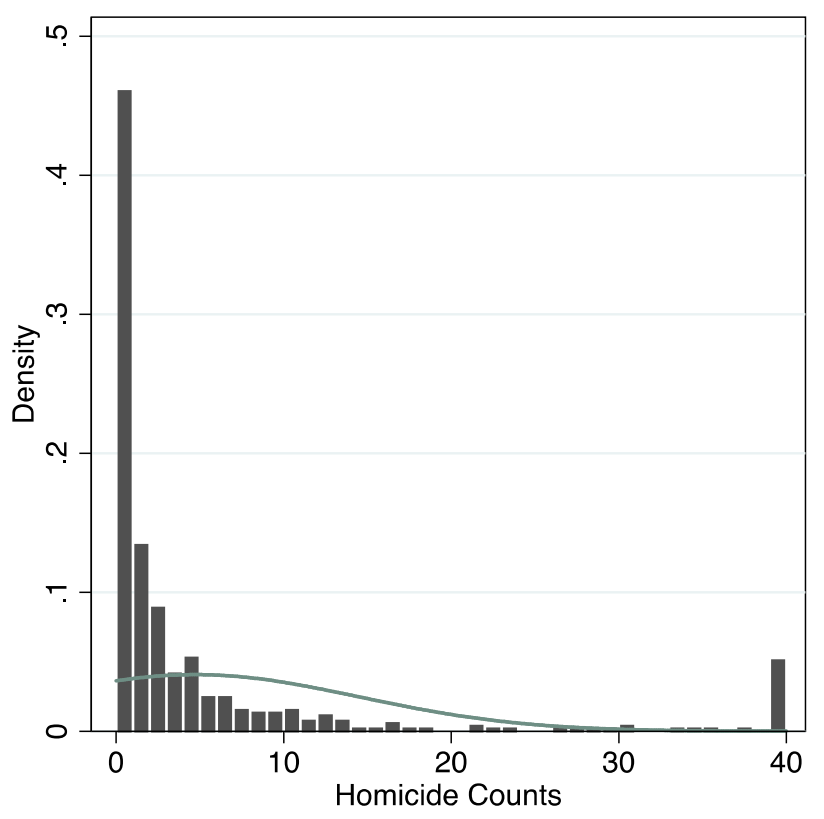

Panel B: $\quad$ Homicides per 10,000 Population

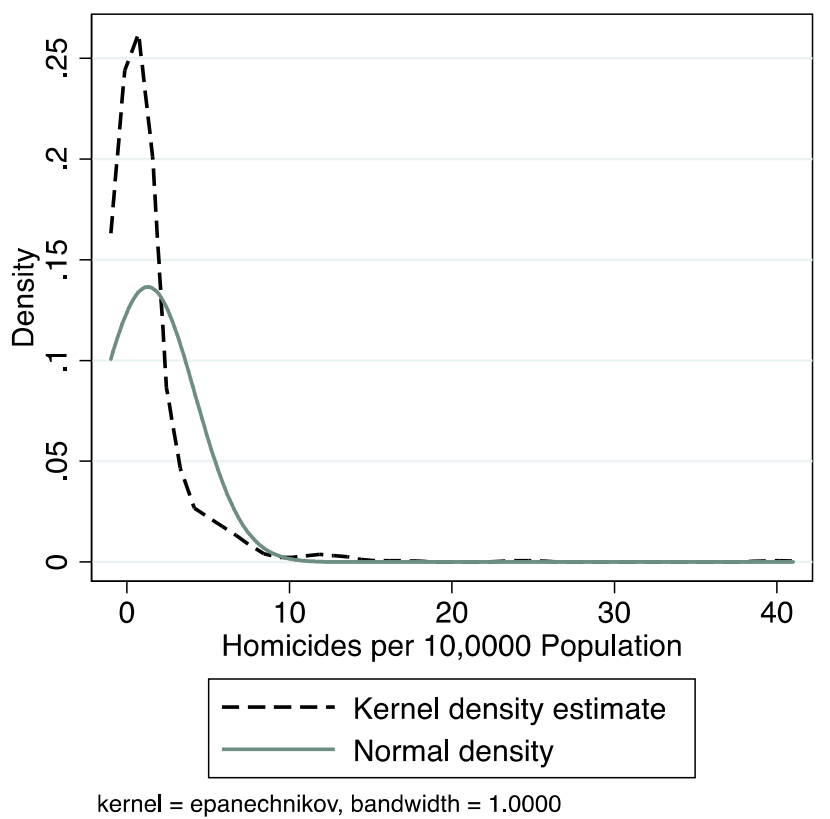

Notes. Panel A reports the histogram of homicide counts in the sample, along with a fitted Normal density, for the sample of municipios within 100 miles of a border port, over 2002-2006. Counts of 40 or more homicides are aggregated into the category " 40 ". Panel B reports the kernel density estimate of homicides per 10,000 population in each municipio over the same time period, along with a fitted normal density estimate. 


\section{Figure A.III \\ Changes in Drug Eradication in Mexican Municipios}

Panel A: $\quad$ Change in Hectares of Marijuana Eradicated - 2005-2006 versus 2002-2004

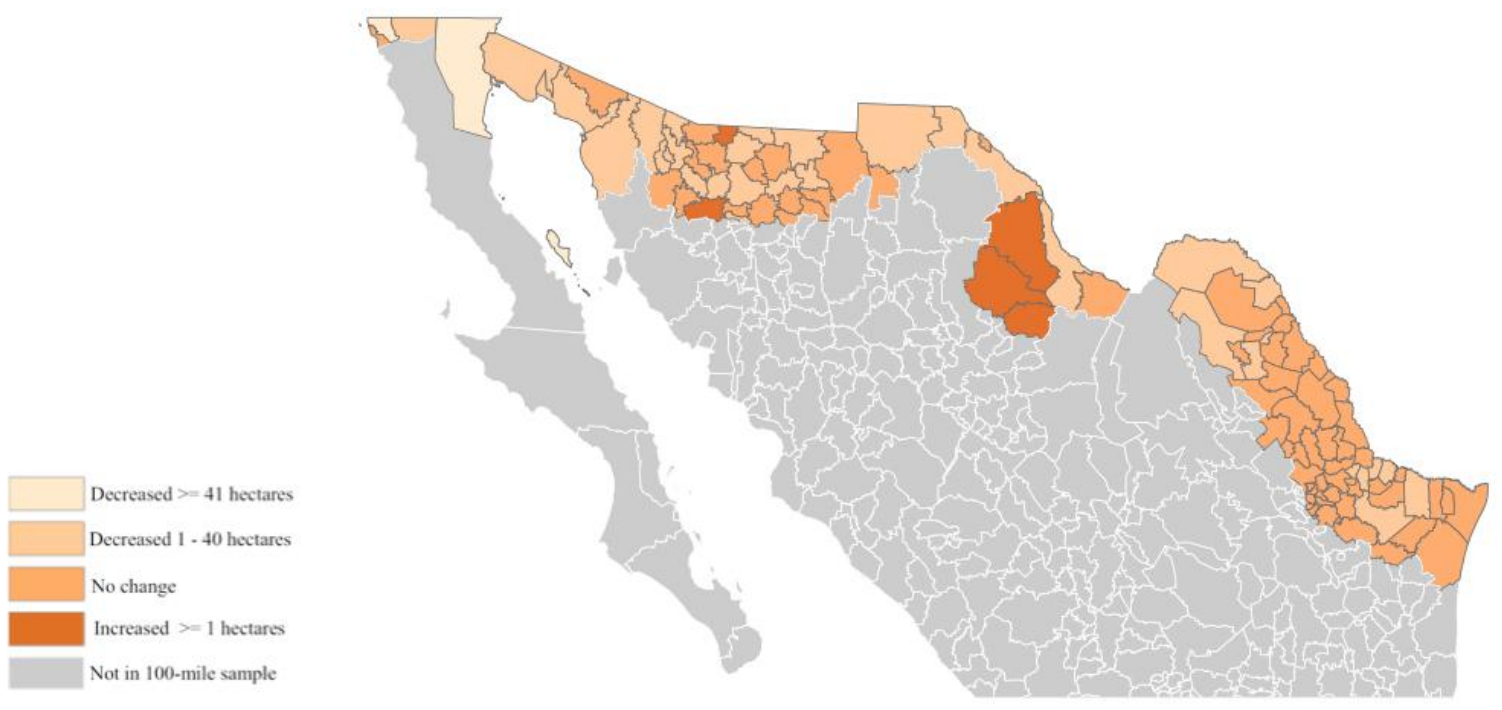

Panel B: $\quad$ Change in Hectares of Poppy Eradicated - 2005-2006 versus 2002-2004
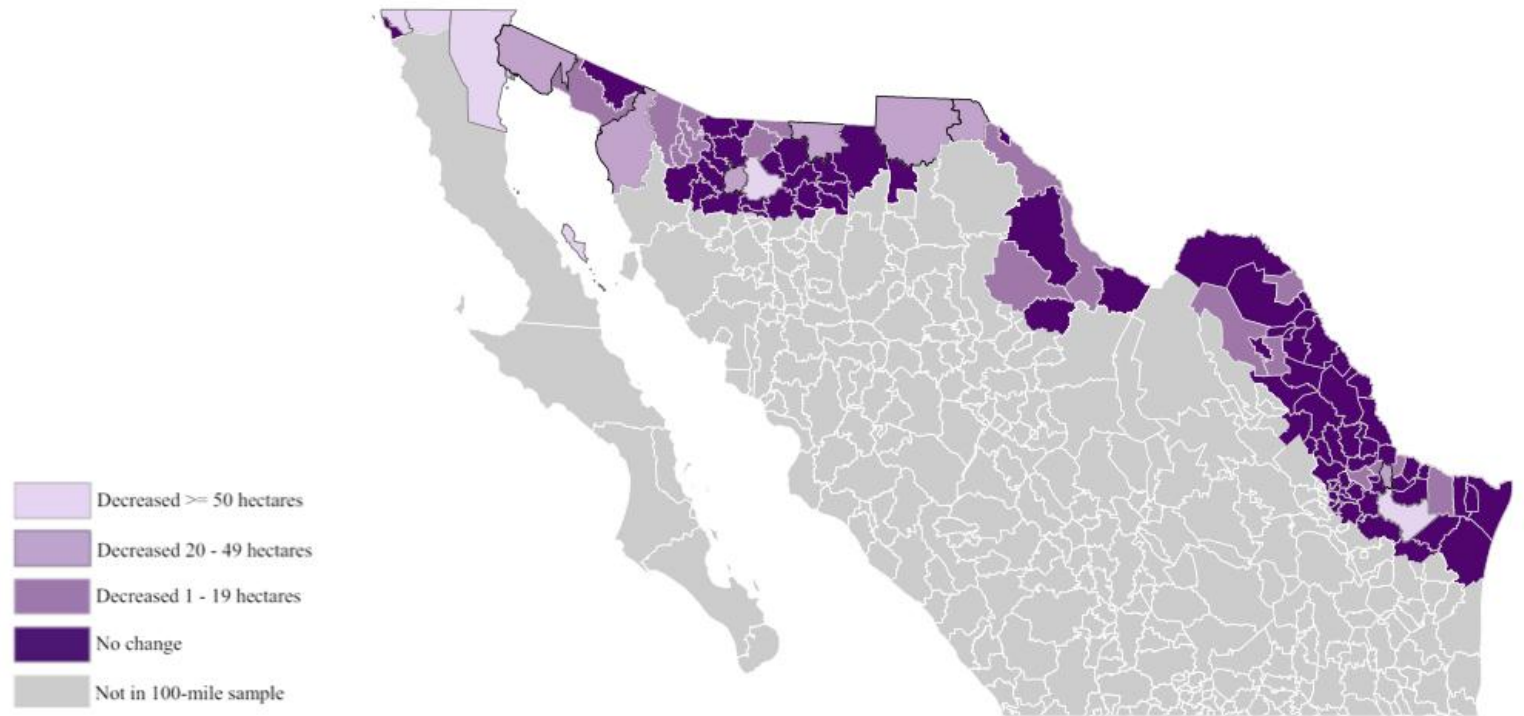

Notes. This figure shows the change in hectares of marijuana and poppy eradicated in each municipio between the pre-treatment period (2002-2004) and post-treatment period (2005-2006) for the set of municipios within 100 miles of an entry port, the 100-mile sample. Lighter colors indicate larger decreases in eradication over this period. 
Figure A.IV

Effects on Violence by Distance Bands
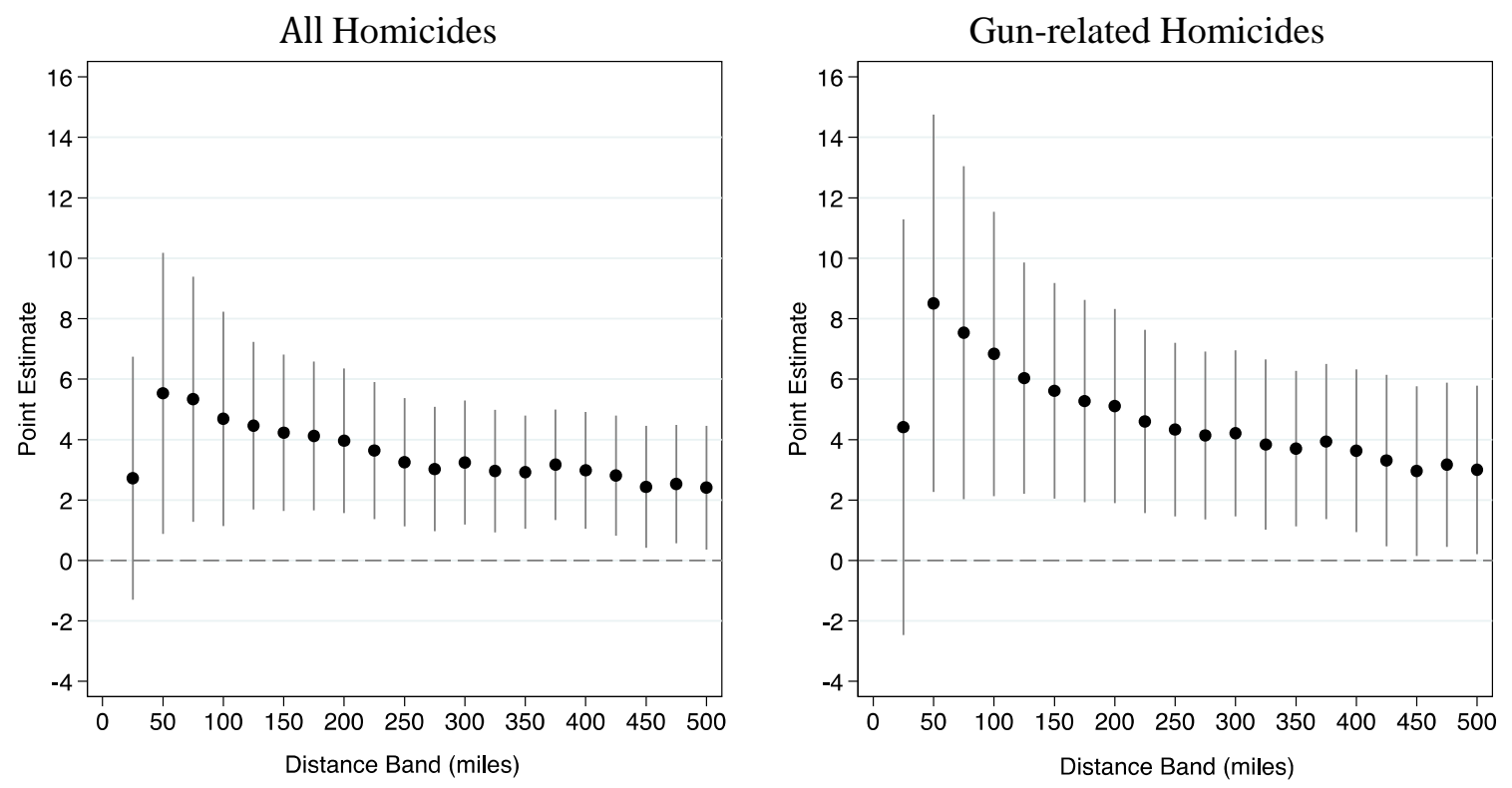

Notes. Black dots plot the Poisson regression coefficients for Proximity NCA $\times$ Post regressed on the outcome (annual counts of homicides in the left panel, and counts of gun-related homicides in the right panel), restricting the sample to the set of municipios that lie within the designated distance bands. Controls include municipio and year fixed effects; Proximity Border x post; log municipal per capita income in 2000 and the schooling ratio in 2000 interacted with a post-2004 indicator; $\log$ municipal expenditures per capita; $\log$ value of municipal drug seizures plus 1 ; $\log$ hectares of marijuana and heroin poppies eradicated in each municipio plus 1 ; as well as the employment ratio, log average earnings, log unauthorized immigrants and log value of drugs seized in the nearest U.S. port of entry. Population is used as exposure. Municipio-cluster-robust standard errors are used to calculate the 95\% confidence intervals indicated by vertical bars. 
Figure A.V

Political Competition Prior to 1994 and 2004 Treatments
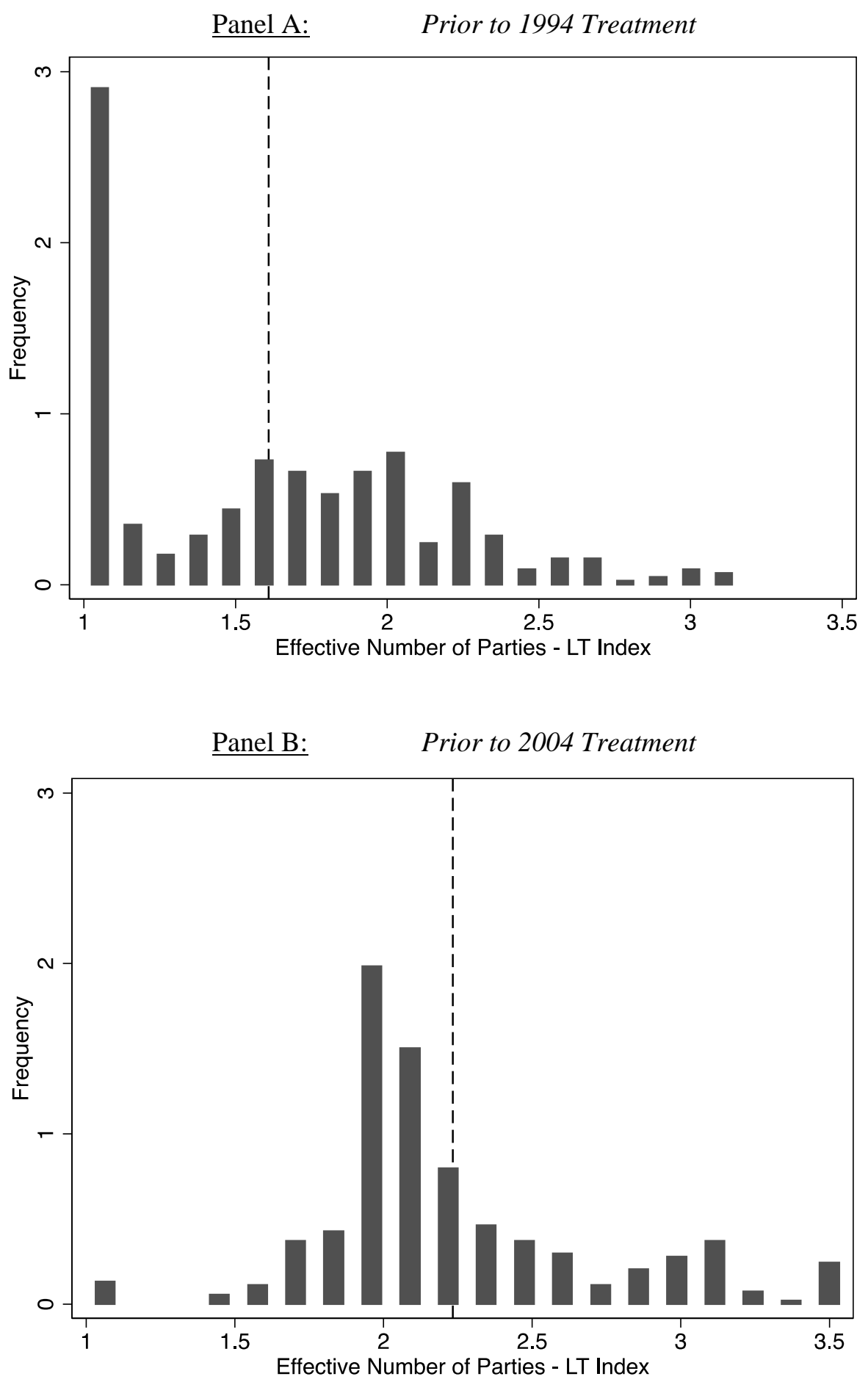

Notes. Panel A shows the distribution of the Laakso-Taagpera index of the effective number of political parties represented among mayoral elections, which resulted in the election of mayors within the 100-mile sample, during the sample period prior to the passage of the FAWB in September 1994 . This includes mayors elected in the 1994 elections, which took place prior to September. Panel B shows the distribution of the same index among mayoral elections which resulted in the election of mayors within the 100-mile sample, during the sample period prior to the expiration of the FAWB in September 2004. This includes mayors elected in the 2004 elections, which also took place prior to September of that year. The dashed lines show the means of these indeces within these sub-samples. 